University of Louisville

ThinkIR: The University of Louisville's Institutional Repository

Electronic Theses and Dissertations

$12-2019$

\title{
Middle school outreach efforts to involve immigrant parents: what are the perceptions of school personnel and immigrant parents?
}

Marcella Denise Franklin-Williams

University of Louisville

Follow this and additional works at: https://ir.library.louisville.edu/etd

Part of the Educational Leadership Commons

\section{Recommended Citation}

Franklin-Williams, Marcella Denise, "Middle school outreach efforts to involve immigrant parents: what are the perceptions of school personnel and immigrant parents?" (2019). Electronic Theses and Dissertations. Paper 3320.

https://doi.org/10.18297/etd/3320

This Doctoral Dissertation is brought to you for free and open access by ThinkIR: The University of Louisville's Institutional Repository. It has been accepted for inclusion in Electronic Theses and Dissertations by an authorized administrator of ThinkIR: The University of Louisville's Institutional Repository. This title appears here courtesy of the author, who has retained all other copyrights. For more information, please contact thinkir@louisville.edu. 


\title{
MIDDLE SCHOOL OUTREACH EFFORTS TO INVOLVE IMMIGRANT PARENTS: WHAT ARE THE PERCEPTIONS OF SCHOOL PERSONNEL AND IMMIGRANT PARENTS?
}

\author{
By \\ Marcella Denise Franklin-Williams \\ B.A. Biology, University of Louisville, 1988 \\ M.A.T., University of Louisville, 1997 \\ A Dissertation \\ Submitted to the Faculty of the \\ College of Education and Human Development of the University of Louisville \\ In Partial Fulfillment of the Requirements \\ for the Degree of \\ Doctor of Education in Educational Leadership and Organizational Development \\ Department of Educational Leadership, Evaluation, and Organizational Department \\ University of Louisville \\ Louisville, KY
}

December 2019 
Copyright 2019 by M. Denise Franklin-Williams

All rights reserved 



\title{
MIDDLE SCHOOL OUTREACH EFFORTS TO INVOLVE IMMIGRANT PARENTS: WHAT ARE THE PERCEPTIONS OF SCHOOL PERSONNEL AND IMMIGRANT PARENTS?
}

\author{
By
}

Marcella Denise Franklin-Williams

B.A., University of Louisville, 1988

M.A.T., University of Louisville, 1997

\section{A Dissertation Approved on}

November 12, 2019

by the following Dissertation Committee:

Kyle Ingle

Dissertation Chairperson

Detra D. Johnson

Dissertation Chairperson

Meera Alagaraja

Committee Member

April Brooks

Outside Committee Member 


\section{DEDICATION}

This dissertation is dedicated to my husband, children, parents, and family

Tracy L. Williams, Sr.

Trey L. Williams

Taylor Denise Williams

Jordan Franklin Williams

Connie Franklin, my amazing mother

Haywood Franklin Sr., my awesome father

and

The entire Carrithers Middle School Faculty and Staff,

From whom I have had the best support and encouragement. I have become stronger because of you. I love you all! 


\section{ACKNOWLEDGEMENTS}

THE AMERICAN DREAM IS A POWERFUL CONCEPT! This was stated in the book, "The American Dream and the Public Schools" by Jennifer Hochschild and Nathan Scovronick. During my doctoral journey, I had the privilege and opportunity to read and discuss this book. I also had the privilege and opportunity to learn from and work with some of the best professors in the business.

Thank you, Dr. Brian Shumate and Dr. Marty Pollio, for reminding me of why I first went into the education business. You two, being JCPS family, inspired me to fight for my students, become an effective principal, and work towards my doctoral degree. The stories shared by both of you were captivating yet authentic. I could listen to both of you for hours. You both are great role models for teachers and administrators.

To my dissertation committee, Thank you for reading my work, challenging me to make it better, encouraging me to never give up, and supporting me the entire way! This was not an easy job, and your guidance will never be forgotten. A special shout out goes to Dr. Kyle Ingle, Dr. Detra Johnson, Dr. Meera Alagaraja, and Dr. April Brooks. Much respect and love to you all!

Lastly and most especially, to my doctoral partner, Dr. Kathy Stovall, without you I would have quit a long time ago, but I think we pushed and encouraged each other to keep going, to take baby steps, to keep pushing, but never quit! And throughout this journey, we created a great friendship! May God continue to bless you! We did it!!!!! 


\title{
ABSTRACT \\ MIDDLE SCHOOL OUTREACH EFFORTS TO INVOLVE IMMIGRANT PARENTS: WHAT ARE THE PERCEPTIONS OF SCHOOL PERSONNEL AND IMMIGRANT PARENTS?
}

\author{
Marcella Denise Franklin-Williams
}

December 13, 2019

Throughout the years, a concern plaguing the education world is parent involvement. Ongoing research indicates students whose parents and family members are involved tend to experience greater academic achievement and decreased behavior issues (McNeal, 2015). With regard to parent involvement, immigrant parent involvement takes this concern to a new level with regard to the growing racial and ethnic diversity in education (Outley \& Skuza, 2019). Guided by Epstein's six types of involvement and Yosso's community cultural wealth, this study explores one urban middle school's outreach efforts to involve immigrant parents.

In this qualitative case study, one middle schools' stakeholders-the principal, the Youth Services Center Coordinator, three teachers, and selected immigrant parentsparticipated by sharing personal perceptions of their schools' outreach efforts to involve immigrant parents. Semi-structured interviews were utilized to collect data from the participants. Findings suggest interactions between the home and school, student sense of belonging, school personnel motivation, and parent efficacy are important factors to increasing immigrant parent involvement. 


\section{TABLE OF CONTENTS}

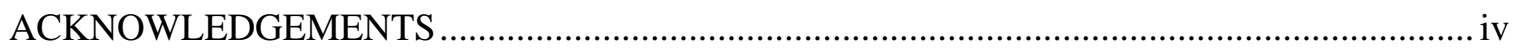

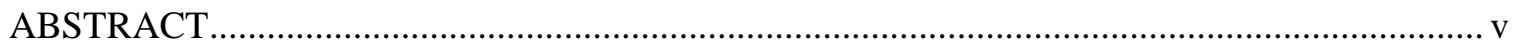

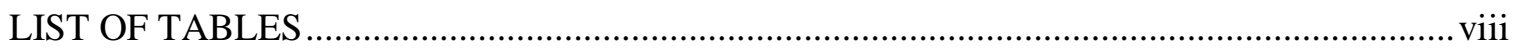

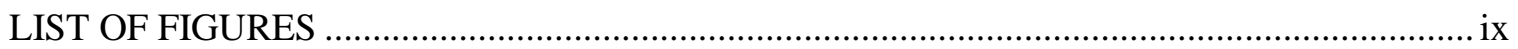

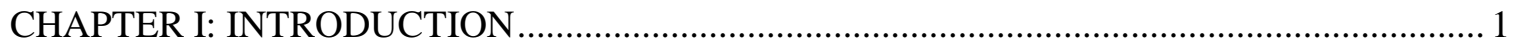

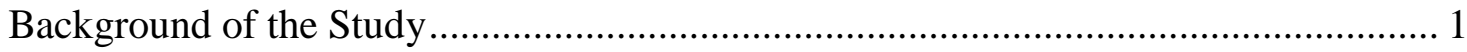

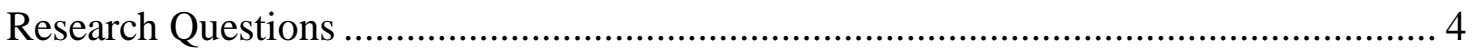

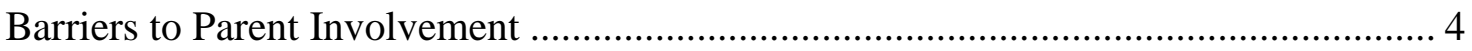

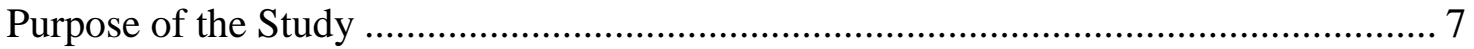

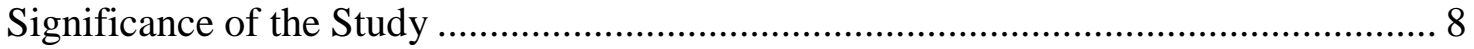

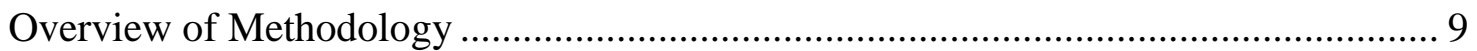

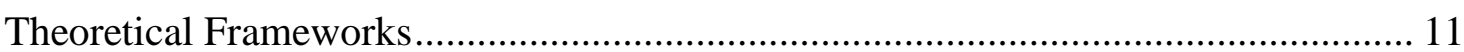

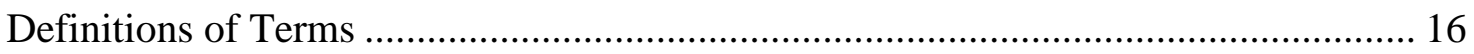

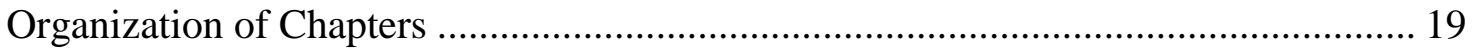

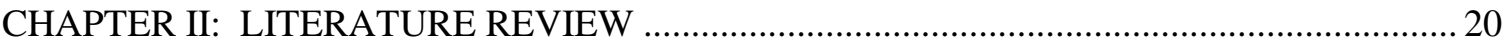

Introduction to Parent Involvement........................................................................... 20

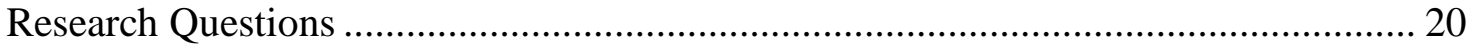

Parent Involvement: What It Is and Why It Matters .......................................... 21

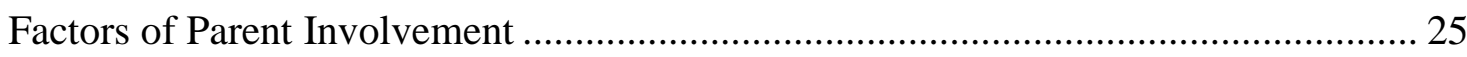

Racial and Ethnic Differences in Parent Involvement ............................................ 29

Engaging Parents-District and School Level Efforts ............................................. 40

Middle School Programs and Immigrant Parent Involvement ................................... 50

Summary of Findings, Data Trends and Direction for Future Research...................... 59

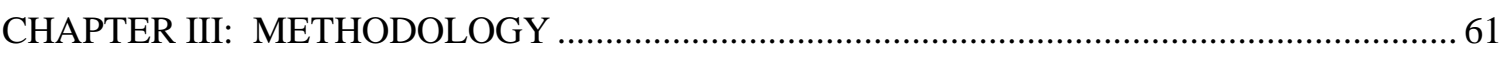

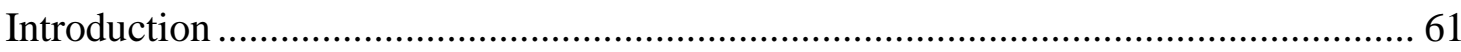

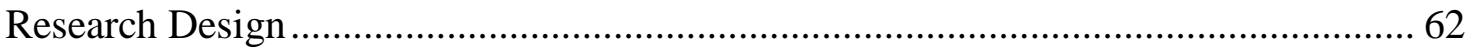

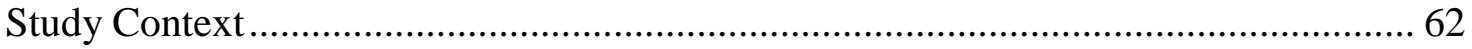




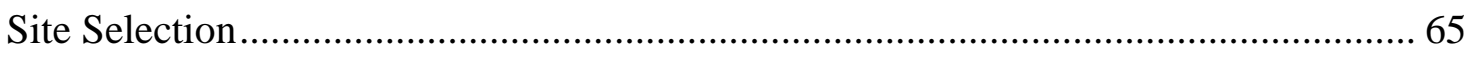

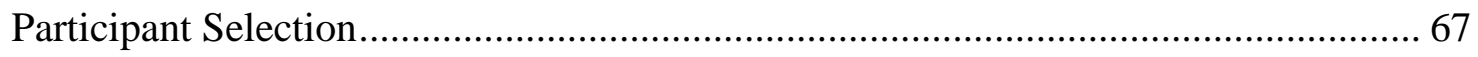

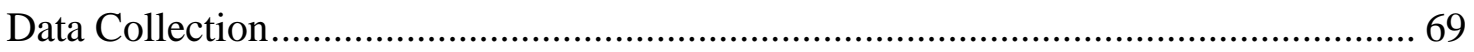

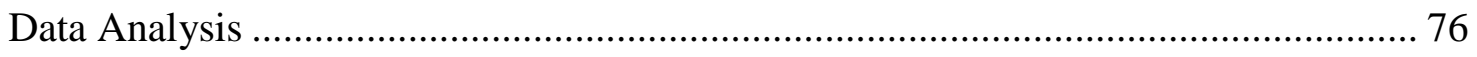

Ensuring Credibility, Confirmability, and Dependability ........................................ 81

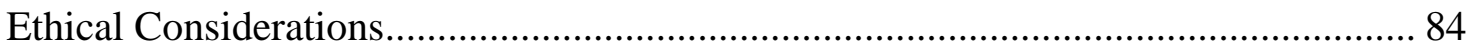

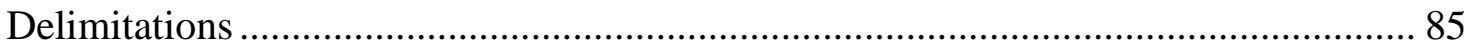

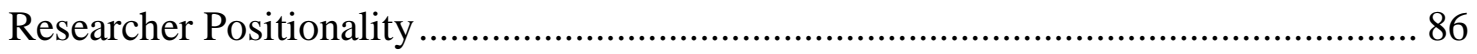

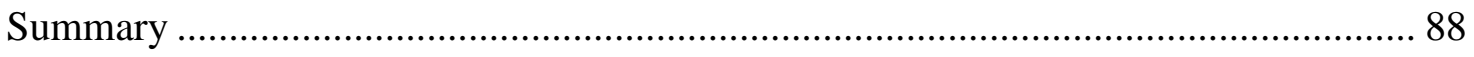

CHAPTER IV: ANALYSIS AND FINDINGS ………………………………………....... 90

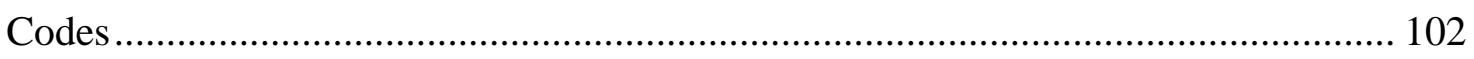

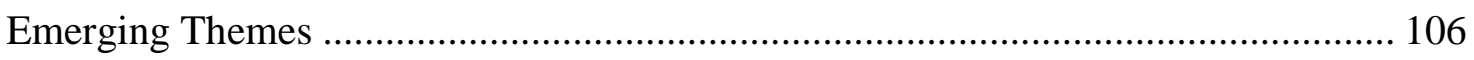

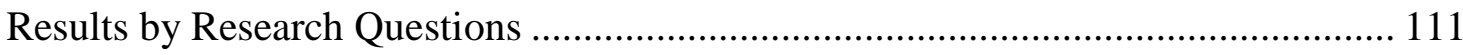

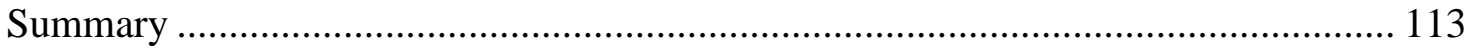

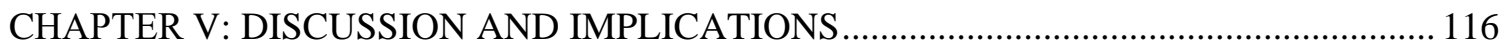

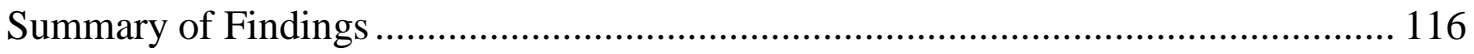

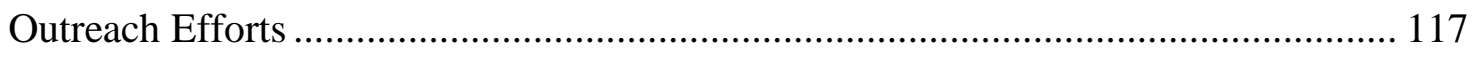

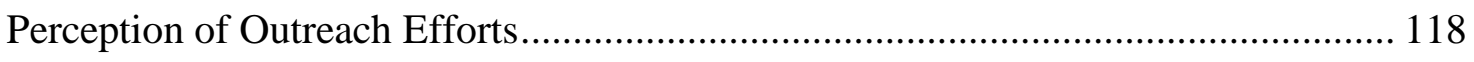

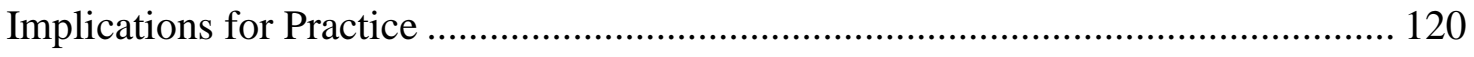

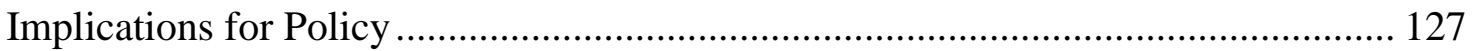

Implications for Future Research ................................................................... 130

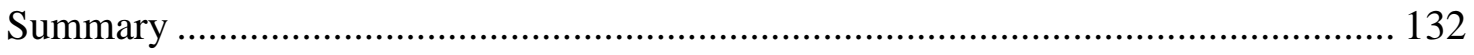

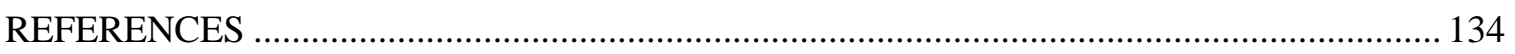

APPENDIX A: INFORMED CONSENT DOCUMENT ………………………………….... 142

APPENDIX B: RECRUITMENT CORRESPONDENCE ………………………………….... 147

APPENDIX C: RECRUITMENT CORRESPONDENCE ........................................................ 148

APPENDIX D: SCHOOL PERSONNEL INTERVIEW PROTOCOL .......................................... 149

APPENDIX E: IMMIGRANT PARENT INTERVIEW PROTOCOL ………………………..... 151

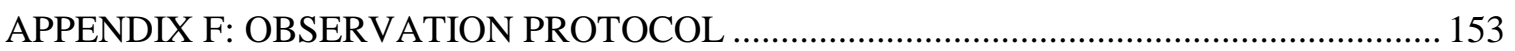

APPENDIX G: RESEARCH INFORMATIONAL LETTER ……………………………........ 154

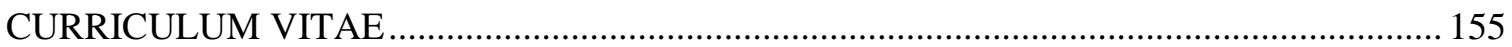




\section{LIST OF TABLES}

Table 1: Middle School LEP Enrollment Data 2018-2019..........................78

Table 2: Demographic Information of Participants............................. 82

Table 3: List of Inductive Codes........................................... 111

Table 4: List of Deductive Codes..............................................112

Table 5: Most Frequently Referenced Codes..................................116 


\section{LIST OF FIGURES}

Figure 1: Epstein and Yosso Application on Immigrant Parent Involvement.........93

Figure 2: Data Triangulation............................................. 99

Figure 3: Visual Frequency of Coding......................................116 


\section{CHAPTER I: INTRODUCTION}

"We are shaped by every language and culture, drawn from every end of this earth. We know that our patchwork heritage is a strength, not a weakness." (B. Obama, 2009).

\section{Background of the Study}

Parents and family members share an important role in a student's educational journey. Similarly, teachers and other school personnel such as family resource coordinators, guidance counselors, and assistant principals play very important roles in the lives of students. For instance, parents are responsible for making sure their children have all necessary school supplies and school clothing prior to the start of school. Parents are also responsible for ensuring that their children have the appropriate documentationimmunization records, physical examination records-in order for their children to enroll into the public school system. Charged with several responsibilities, parents encourage their children to strive for academic success.

Teachers, family resource coordinators, guidance counselors, principals, and assistant principals also share some of this very important responsibility. School personnel must provide their students with proper resources and a safe environment in which to grow and learn. Teachers must work to build relationships with their students while identifying their students' strengths and weaknesses. Parents and teachers should work together to ensure that both entities support the student. According to Eisenbach, Clark, and Gooden (2016), connections between home and school are essential to student achievement. 
Parent involvement is vital to student academic success; yet in many cases, school personnel struggle to connect with parents, especially on the secondary level and with immigrant parents (Sobel \& Kugler, 2007). Sometimes there are strained connections between immigrant homes and schools due to the contrasting way immigrant parents practice parent involvement and the way public middle schools view parent involvement. There may be different traditions, educational practices, and beliefs in immigrant homes as compared to American homes. For example, depending on where an immigrant family is from, there will be different holiday celebrations, different religious observations, and different views on education. Prior to the Trump era of immigration bans and threats of widespread immigrants deportations, the population of immigrant families continued to increase in the United States, resulting in an increase of immigrant children into the nation's public schools (Gutierrez \& Almaguer, 2016).

With the election of Donald Trump as the United States' $45^{\text {th }}$ president, the United States of America's immigrant population lives in fear. Since he took office, he has moved to restructure the United States immigration policies (Smith, 2018). Donald Trump expressed concern that many of the immigrants currently living in the US threaten the nation's safety. "We will find you, we will arrest you, we will jail you, and we will deport you," Trump promised last summer (Smith, 2018, p. 11). President Trump stated that there should be penalties for immigrants who overstay a visa. President Trump expressed concern regarding immigrants stating that they are a threat to National Security.

With this living threat, many immigrant families have chosen to maintain private and low key so they go unnoticed. This is another reason for school principals to develop 
outreach efforts to ensure their immigrant population is welcomed and supported in the community and in the school building. Smith (2018) expounds that the Deferred Action for Childhood Arrivals (DACA) is also under question by our latest president. He announced the end of DACA protections unless Congress can develop a viable plan to salvage it. DACA protects immigrant children who were born here to be able to stay in the US and work legally.

According to the Child Migration Data Portal (2019), immigrant and refugee children represent the fasting growing population in the United States at this time. The data implies that schools must be vigilant and proactive to develop programs and outreach specific to immigrant and refugee students and families. There must be programs and outreach to provide both groups with services since both are leaving their native home countries for personal reasons to a new country, hoping for better opportunities and safety. The current reality cannot be ignored any longer. This contradicts the current administration's efforts. Knowing that the current president is actively fulfilling his campaign promises strikes fear in many hearts and minds of immigrant families living in the US, whether they are living here legally or illegally. If the president continues to make the changes he is making now, who is to say he will not work to deport all immigrants, regardless of their legal status, even though research shares that by the year 2050, it is estimated that one third of all children living in the US will be immigrant children (Zong \& Batalova, 2017).

The focus of my study was on one middle schools' outreach efforts to involve immigrant parents. Through such exploration, I sought to inform our knowledge and understanding of outreach programs directed at immigrant parents. 


\section{Research Questions}

In this study, the following research questions were addressed:

What outreach efforts exist, in one urban middle school, to involve immigrant parents? What are the participants' perceptions regarding the current outreach efforts to involve immigrant parents of the selected middle school?

\section{Barriers to Parent Involvement}

According to the U.S. Census Bureau, the immigrant population in the United States grew to reach 42.1 million people in 2012 (Dondero \& Muller, 2012). In America's public schools, the immigrant population of students is increasing as well. According to the Department of Education, the immigrant population is the fastest growing student population in the United States (USDE, 2006). Projections predict that by the year 2025 , one in four public schools students will be an immigrant.

While the majority of students in the public school speak English and English language lessons predominate, many immigrant students speak a native language other than English (Garcia-Reid, Peterson, \& Reid, 2013). Immigrant parents choose to enroll their children in American public schools to gain an educational advantage and learn the American way of life. The issue is, more than likely, immigrant parents have limited English-speaking skills leading to a significant language barrier, causing them to not feel welcome in the school house and rely on the information their children bring home (Eisenbach et al., 2016). This action directly affects their involvement in their child's education and limits the possible connection between home and school.

Language plays an important academic and social role in the community and in a child's life (Peterson \& Ladky, 2007). Language functions as a vital means of 
communication in all settings. It is imperative that language acquisition occur as early in life as possible because as people get older, there is an innate difficulty to acquire new languages successfully. While not impossible, language acquisition becomes more difficult as one ages (Bower \& Griffin, 2011). Immigrant parents face many barriers, such as language barriers, finding housing, finding jobs that support their families, and avoiding deportation, they rely on the schools to provide education and safety for their children while they are trying to figure out how to survive and make a living. They leave the education up to the schools (Bower \& Griffin, 2011).

Since schools usually have more resources accessible than the immigrant parent, the onus is that of public middle school personnel, where the immigrant children enroll, to provide support and outreach for immigrant students and immigrant parents (Auerbach, 2011). Research reveals that parent involvement decreases and changes as students move from elementary school levels to the secondary or middle school level (Linse, 2013). Research suggests that more resources and involvement exist in elementary schools as compared to middle and high schools due to children in elementary schools requiring more direct parent involvement while students on the secondary level strive for more independence and autonomy (Halsey, 2005).

It is the responsibility of the school to know its' students, build relationships with parents and students alike - immigrant and native-born - and develop plans of success that meet the needs of all students (Varela, 2008). Support includes access to translation services, parent involvement, volunteerism, adult education, and instructional services. Studies find that immigrant parents, when compared to U.S. born-parents are less likely to visit their children's school, attend school functions, help with homework, and talk 
with teachers (Garcia-Reid et al., 2013; Turney \& Kao, 2009). For these reasons, outreach efforts that involve immigrant parents are so important. While immigrant parents appear to demonstrate less parent involvement at school, they still play an important role in their children's education (Garcia-Reid et al., 2013). Both entities need to understand each other's viewpoints. Additionally, the need for educators to learn about the various cultures, traditions, and practices of the students and families who enroll in their schools is paramount (Marschall \& Shah, 2016).

I sought to explore one urban middle schools' outreach efforts regarding immigrant parents. I used Epstein's framework of six types of involvement (Epstein, 2009) and community cultural wealth theory (Yosso, 2005), to frame the outreach efforts of middle school personnel, how they support student achievement, and increase involvement among immigrant parents. I probed both school personnel and immigrant parents to analyze their perspectives of the outreach efforts and the effects of these outreach efforts.

My rationale for incorporating two theoretical frameworks was because Epstein's framework addressed the fact that parent involvement in schools looks different for each household. It is imperative for school personnel to identify which type of involvement is most effective for each of their families. School personnel must develop ways and means allowing ach family to be involved. Yosso's community cultural wealth is necessary when considering the fact that each family needing different types of involvement also have different beliefs and traditions. School personnel should respect these different cultures and beliefs and remain diligent in learning about and respecting all of the cultures of the families enrolled in their schools if they are going to reach each student. 
This is where professional development and training come in. Using both frameworks also added to the triangulation of my study. Both frameworks were relevant and vital to understanding the phenomenon of immigrant parent involvement.

\section{Purpose of the Study}

In this study, I sought to add to the existing literature regarding middle school parent involvement. Specifically, my goal was to explore outreach efforts to involve immigrant parents and gain participant perceptions of these efforts. As the researcher of this study, I sought to bring awareness to the middle school community and central office regarding the practices of one middle schools' attempts to reach out to immigrant parents. Through thorough examination, I highlighted stakeholder perceptions of the selected middle school's efforts of immigrant parent outreach. Additionally, my study promoted immigrant parent voice and promotes on-going dialogue between immigrant parents and school personnel in an effort to expose the knowledge, experience, and beliefs immigrant parents bring with them as well as what school personnel can share with immigrant parents in order to increase student achievement of their immigrant student population.

Increasing immigrant parent voice and dialogue between the two entities that are vital for student's achievement, lead to greater social justice and support for the immigrant parent and their children (Auerbach, 2011). I sought to add to the existing literature regarding immigrant parent involvement by increasing awareness of immigrant parent perception and middle school personnel perception. I highlighted immigrant parents' interest and involvement in their child's educational journey from their perspective. Furthermore, I explored the perceptions of school personnel and immigrant parents regarding the various outreach efforts implemented by the middle school. 


\section{Significance of the Study}

Immigrant families are choosing to make their homes in cities across the country, where public school provides the opportunity to educate immigrant students and to work with immigrant parents. Once immigrant parents enroll their children into school, the onus is that of school personnel to identify and address the needs of their students and their immigrant parents. Similar to all parents, immigrant parents must be educated on school procedures, practices, and routines.

One middle schools' outreach efforts to increase and stabilize immigrant parent involvement was the focus of my study. The numbers of immigrant students enrolling in this urban public school system increases steadily and annually. In order to meet the needs of the increasing immigrant population across the country, and since research confirms that parent involvement promotes student achievement, outreach efforts on the middle school level are crucial to immigrant student achievement. The findings from my study have implications for both educational leaders and immigrant parents on how to increase and sustain immigrant parent involvement as well as increased cultural awareness and competency (Auerbach, 2011).

Implications include school personnel learning more about their immigrant population, a "coproduction" of student achievement amongst educators and parents, increased positive communication between the home and school, and increased immigrant parent efficacy (Marschall \& Shah, 2016, p. 6). Coproduction refers to home and school, parents and teachers working together to build and promote student achievement (Marschall \& Shah, 2016). Finally, school officials learn from the experiences and strategies used to involve immigrant parents and use such strategies to 
meet the needs of immigrant students and immigrant parents more effectively. A commitment must exist to continue research on the topic of involving immigrant parents in the very important parent involvement process. The need is for all parents to be involved.

Bower and Griffin (2011) state that parent involvement looks different school to school and home to home. They also posit that parent involvement stems from differing perceptions depending on the parent and the school. I shared stakeholder perceptions of why this is and what may work to increase and strengthen middle school parent involvement (Bower \& Griffin, 2011). School personnel must always be mindful and intentional to include immigrant parents by developing school programs that are committed to serving a larger, more diverse population of students and parents, and to be a part of the examination and the struggle toward social and racial justice (Yosso, 2005). Thus, the need for research on the outreach efforts that involve immigrant parents in our local school district in order to, ultimately, positively affect student achievement exists.

\section{Overview of Methodology}

My qualitative, dual-perspective case study was based on constructivism, assuming that both the perspectives and realities of the interviewed participants were socially constructed from their perceptions and life experiences (Creswell, 2014). Crotty (1998) defined constructivism as "the view that all knowledge, and therefore all meaningful reality as such, is contingent upon human practices, being constructed in and out of interactions between human beings and their world, and developed and transmitted within an essentially social context" (p. 42). Embedding the paradigm of constructivism supported exploration of participant perceptions because everyone has different 
experiences and live in different environments, yet interact with one another. This included the voices of school personnel and immigrant parents (Epstein, 2011; Yosso, 2005).

As a means of data triangulation, I used semi-structured interviews, observations at immigrant parent events, and member-checking (Creswell, 2014). Data collection and analysis using these methods contribute to this study's trustworthiness (Glesne, 2011). One middle school in a large urban school district in the southeastern United States of America serves as the context of my study. I assigned the school district a pseudonym, Southeast Public Schools (SPS). I also assigned a pseudonym for the selected middle school-Peace Middle School (PMS). While conducting the study, no artifacts were given to immigrant parents that were different than what was given to all parents. Originally, I thought that a school with a large number of immigrant students would purposely have artifacts-handouts, letters, etc. specific for their immigrant parents to understand. That was not the case.

I used a semi-structured interview protocol, scheduled, and conducted the interviews at the convenience of both the interviewer and the informants. Even though there was a set of interview questions, the participants' responses led the interviews (Glesne, 2011). Once the informed consent was reviewed and signed, I recorded and transcribed all interviews verbatim. I made sure to ask permission of my participants prior to starting the recorder. Transcription took place after each interview for accuracy and effective time management.

Data analysis and writing up the qualitative data were determined based on interviews and observations. To ensure validity, reliability, and trustworthiness, I 
undertook observations of principals, teachers and other school personnel, as well as immigrant parents at school events. I was eager to see their interactions. I had the opportunity to attend and observe at a back-to-school event for parents, parent teacher conferences, and a parent engagement meeting. Triangulation of data through observations, interviews, and artifacts was the goal, but there were no artifacts given out at the events where I observed. Peer review of the interview protocol, and member checking from participants once interviews were transcribed also led to increased validity, reliability, and trustworthiness (Glesne, 2011). Therefore, triangulation of data were completed with participant validation also called member checking.

\section{Theoretical Frameworks}

As mentioned earlier, I utilized two theoretical frameworks in my study-Epstein's framework of six types of parent involvement (2011) and Yosso's community cultural wealth (2005). Epstein’s Framework provides involvement types such as parenting, communicating, volunteering, learning at home, decision-making, and collaborating with the community (Epstein, 2011). This framework focused on strengthening the bond between the school and home by guiding and balancing efficacy amongst school personnel and families. Embedded throughout Epstein's Framework was two-way communication between school and home.

To better understand each type of Epstein's involvement, explanations were provided. Parenting is the first type of involvement. Parenting focuses on school personnel working with parents to ensure they have resources in their homes to support their children as students. Practices include home visits and training classes for parents to extend school learning in the home. Schools provide families with support by sharing 
age appropriate strategies and emphasizing adolescent development. School personnel gain valuable knowledge and insight of families' culture, backgrounds, and goals.

Communicating is the second type of involvement. The focus is to make sure that all families know what is going on at school. Families know when progress reports and report cards are coming home. Families know when open house and conference day. School personnel reach out to parents in a variety of ways to keep all families informed, including telephone calls, emails, and letters.

Another type of involvement is volunteering. Volunteering increases in schools when families feel welcome. Family efficacy increases when schools ask families to participate in school activities. Family confidence regarding working in their child's school and working with their child's teachers encourages family members to consider their own education goals. To guarantee volunteering is strong and effective, recruitment and training. School personnel must reach out to parents and family members and personally ask for help.

Type four is learning at home. Practices include providing families with calendars of activities, summer activities, and family literacy, math, and cultural nights at school. Results from the practices are that family members are informed, parents begin to understand and appreciate their child's teachers, and awareness of their child as a learning is increased. Students gain in skills and abilities leading to student achievement and a positive attitude toward school.

Decision-making is vital to student achievement. The decisions made by school personnel must have all stakeholders in mind. Decisions also must include input from all stakeholder groups. Family members add their input by being members of the school 
based decision-making (SBDM) council, and the parent teacher student association (PTSA). Offering families input leads to increased awareness of school operations, increased understanding of student rights and trust.

Finally collaborating with the community is another type of involvement that is important to identifying resources from the community to strengthen the bond between school and home for the benefit of student achievement. Outreach includes providing families with information on community health, cultural, recreational, and social support. Also included is information on learning skills and summer programs for students. This outreach seeks to engage parents in order to raise student achievement by school personnel and families participating together in community collaborations.

Epstein's framework provides guidance for today's education system because as student populations change in our public school systems, so must our practices. Practices in the classroom that meet all students' needs and practices that include parents must change with the changing times. Epstein's framework guides school personnel through processes to increase parent involvement, empower parents to be essential factors in their children's educational journey, and build parent efficacy and confidence. These characteristics enable parents to extend schoolhouse learning to their homes (Epstein, 2011).

Because White people have been the primary beneficiaries of civil rights legislation, the White middle class is the standard to which every other culture is measured (Ladson-Billings, 1998; Yosso, 2005; Huber \& Solorzano, 2014). Epstein's six types of involvement highlight the importance of school personnel learning about the lived experiences of all parents with school-aged children. This includes immigrant, non- 
English speaking parents as well. This is where Yosso's theory of community cultural wealth becomes relevant. School personnel have to remember that students come to school with a set of routines, procedures, and traditions already in place that they learned from home. Even though the school setting is different, the home practices need to be taken into consideration when educating children. Once again, this is different in every home.

Yosso (2005) defines critical race theory in education as the framework that challenges and analyzes the construct of race and racism and the influences on educational practices. Students gain cultural wealth, routines, and traditions from the adults in their lives; parents and teachers provide students with information, experiences, resources and opportunities to enrich and support students' educational lives. When schools get to know all of their students and when schools are culturally aware, teachers can teach each student while still preserving and respecting each students' culture. It is through building relationships, cultural awareness, and increasing communication with parents that increased student achievement can occur (Epstein, Sanders, Simon, Salinas, Jansorn, \& Voorhis, 2009).

Portes (1998) defined social capital as “one's ability to secure benefits by virtue of membership in social networks or other social structures" (p. 5). Supportive, positive structures increase student achievement by increasing students' capacity to navigate through various educational landscapes. These social networks included the connection between home and school and discourse amongst stakeholders focused on student achievement. The educational setting as a producer of social capital is ideal because, on a daily basis, a variety of interactions between all stakeholder groups occur (Portes, 
1998). According to Cohen and Prusak (2001), social capital bridges all interactions of stakeholder groups in order to work as a larger organization rather than individual experiences.

Perna and Titus (2005) found a positive association between parent involvement as a form of social capital and students' higher education attainment. Epstein's Framework of Six Types of Parent Involvement expands the social capital framework by honoring all cultures and their forms of parent involvement (Epstein, 2011; Epstein et al., 2009). Parent involvement varies from culture to culture. Community cultural wealth focuses on all cultures learning from each other and learning about each other (Martinez, 2012).

According to Yosso (2005), the measure of community cultural wealth is different for each culture; not only middle class values are respected, but every culture's values are important and are the standard. Every set of immigrant parents brings with them their family member's history and stories. Each family's backstory is important, not only to each set of parents, but also to the overall community. Respecting the many different cultures and traditions of immigrant parents and families is a necessity if they are to feel a part of the community to include the school community. This is not easy, but necessary because everyone's story is important to them.

Research supports when immigrant parents feel welcomed, respected, and supported, immigrant parent involvement increases, thus leading to increased immigrant student achievement (Martinez, 2012). Just like American, English-speaking parents, immigrant parents who enroll their children in American public middle schools demand respect for their culture and beliefs. Community cultural wealth honors and includes all 
stakeholders, builds a bridge between home and school, and seeks to open the minds of all school personnel (Yosso, 2005). Community cultural wealth also highlights the fact that all stakeholder groups have value and should be heard and respected. Community cultural wealth allows for a transformation of education, empowerment of all stakeholders, and progression of all involved by educating school personnel and developing schools that serve a larger more diverse population pushing toward more social justice for all (Garcia \& Guerra, 2004). With community cultural wealth, a shift from deficit thinking of immigrants and people of color occurs, changing to positive, progressive thinking due to consideration and respect for all cultures in the middle school setting (Garcia \& Guerra, 2004).

\section{Definitions of Terms}

I used the following definitions in the context of my study:

Capital - assets of members of an organization; the positive resources one brings to an organization (Bourdieu, 1989).

Communication - the act of conveying intended information to another entity through use of mutually understood manner. The exchange of information between school and home and a means of connection between teachers and students, teachers and parents (Halsey, 2005).

Critical Race Theory - focuses on race and its' intersection with gender, ethnicity, sexual orientation, class, and other systems of power. Critical Race Theory seeks to eliminate racial and other forms oppression (Ladson-Billings, 1998). 
Cultural Capital - Individuals' knowledge, skills, awareness, and education that can be translated into social resources (e.g. wealth, power, and status) (Bourdieu, 1989).

Community Cultural Wealth - Includes various types of capital: Aspirational, Cultural, Linguistic, Resistant, Navigational, Social, and Familial capitals are encompassed in cultural wealth theory. One form of capital builds on another, as needed (Yosso, 2005). Respecting the various cultures and traditions of all stakeholders.

Culture - behaviors and values that are learned, shared, and exhibited by a group of people (Yosso, 2005).

Human Capital - literal human resources; the skills, knowledge, and experience possessed by an individual or population, viewed in terms of their value or cost to an organization (Bourdieu, 1989).

Immigrant - a person who comes to live permanently in a foreign country; newcomer, settler, migrant (Guo, 2012).

Immigrant Parent - parent who is born outside of a foreign country where they have taken residence (Auerbach, 2011).

Limited English Proficient (LEP) - a person who does not speak English or whose native tongue is not English (Linse, 2013).

Middle School - Grade levels $6^{\text {th }}, 7^{\text {th }}$, and $8^{\text {th }}$ grade. The level between elementary school and high school (Halsey, 2005). 
Outreach Efforts - the action of extending or reaching out to assist or helping someone or a group; the extending of services or assistance beyond current or usual limits to ensure inclusion of all involved (Sobel \& Kugler, 2007).

Parent Involvement - Parent involvement is the participation of parents in school activities that support student achievement and student success (Overstreet, Devine, Bevans \& Efreom (2005). Activities at school and at home that lead to student achievement; the emphasis is on two-way communication allowing parents to extend what is learned at school in the home. Parent involvement also includes family involvement as other family members raise students in the parents' absence (Epstein, 2009).

Partnerships - mutual relationship existing between school and immigrant parents, where each entity contributes in some capacity (Beauregard, Petrakos, \& Dupont, 2014).

School Culture - refers to beliefs, perceptions, relationships, attitudes and expectations, written and unwritten, that shape and influence every aspect of how a school functions. This term includes physical and emotional safety of students, teaching and learning, academic achievement of students, the orderliness of classrooms and common areas, and the degree to which a school embraces and celebrates racial, ethnic, linguistic, and cultural diversity (Muhammad, 2015). Social Capital - The resources embedded in social relations and social structure, mobilized to increase the likelihood of success in a purposeful action (Lin, 2001). Stakeholders - Anyone associated with school entity such as students, faculty, staff, administrators, and community members. Anyone affected directly or 
indirectly by organization or school functioning; a person with an interest or concern in something, especially a business or organization (dictionary.com).

\section{Organization of Chapters}

The chapters following this introductory chapter included a literature review of relevant research related to the topic, and a detailed, methodology chapter regarding the comparative qualitative case study. After the methodology chapter, careful analysis of data collected during the study, discussion of the implications of the results, and the research questions surrounding the middle school outreach efforts to involve immigrant parents were discussed. Chapter II provided a literature review that detailed Epstein's framework of parent involvement and Yosso's community cultural wealth for comprehensive parent involvement, as the theoretical frameworks of this study, in an effort to provide a foundation. The literature review also delved into discussion on parent involvement, immigration population, immigrant parent involvement, factors affecting immigrant parent involvement, and the outreach efforts on the middle school level that involved immigrant parents in their child's education. Chapter III included a detailed description of the qualitative methodology-transcription, coding processes, rationale for samples used, study participants, data gathering techniques, interview questions, triangulation of data, and methods of analysis for the study. Chapter IV presented significant findings resulting from the study, and Chapter V explored implications for future research, policies, and practices relating to middle school parent involvement, specifically immigrant parent involvement. 


\section{CHAPTER II: LITERATURE REVIEW}

"Everywhere immigrants have enriched and strengthened the fabric of American life." (Kennedy, 1958).

\section{Introduction to Parent Involvement}

The faces of students in our public school systems across America have steadily changed over the years (Stull \& Ng, 2016). Throughout the years, immigrant families migrate to America, find refuge and make homes for themselves in the United States. Dondero and Muller (2012) state that, in the United States, over the past twenty years, the Latino population increased, along with other immigrant populations. With this migration to the US, questions about the outreach efforts of middle schools to involve immigrant parents.

My study explored both immigrant parent perceptions and one middle school personnel's perceptions of the current outreach efforts that involve immigrant parents on the middle school level. I sought to address the following research questions:

\section{Research Questions}

- What outreach efforts exist, in the southeastern United States of America, for one middle school in a large, urban school district to involve immigrant parents?

- What are the participants' perceptions of the current outreach efforts to involve immigrant parents of the selected middle school? 
This chapter contained information regarding why parent involvement matters, factors of parent involvement, racial and ethical differences, engaging parents, middle school parent involvement programs, and summary of findings.

Similarly, I discussed the literature on current outreach efforts and need for this outreach, along with the implementation of parent involvement initiatives specifically for the inclusion and information of immigrant parents. Implications from my study included increasing and improving the home school connection between school and immigrant parents.

\section{Parent Involvement: What It Is and Why It Matters}

Overstreet, Devine, Bevans and Efreom (2005) define parent involvement as participation of parents in school activities that support student achievement and student success. Parental involvement refers to parents' roles in educating their children at home and in school (Christenson \& Sheridan, 2001). Involvement occurs in many different ways: help with homework, talking about school events, attending school events, and volunteering at school. Parent involvement appears to have enduring benefits beyond middle school (Deslandes \& Bertrand, 2005). The confirmation of a strong correlation between parent involvement and student achievement challenges schools to develop programs that encourage parents to be involved.

Researchers Epstein and Dauber (1991), proposed that principals and teachers should collaborate in depth to figure out effective ways to increase parent involvement in all of their parents. School personnel must modify their efforts to meet the needs of their ever-changing populations of students and parents. A population that is, in many cases, ignored or marginalized, is the immigration population (Crosnoe \& Ansari, 2015). Even 
though educators seek parent opinion and perspectives via annual school surveys and other protocols, rarely are these survey instruments done with consideration of other nationalities and in any other language but English. More efforts are necessary to accommodate all parents, not just English speaking and English reading parents (GarciaReid et al., 2013).

Furthermore, Epstein and Dauber (1991) proposed that school personnel provide communication with parents usually in the English language, adhering to American norms and rarely share immigrant-friendly information. Immigrant families are sometimes viewed as needy and the stigma is ever present that if they choose to live in America, they must adapt to American ways, and fast (Crosnoe \& Ansari, 2015). Schools rarely act proactively to meet immigrant parent needs before the immigrant parent brings the situation or issue to school personnel attention (Christianakis, 2011). Schools have a lot of work to do to change this mindset and create a more inclusive way of doing things. My study seeks to identify the current middle school outreach efforts to reach out to immigrant parents through various parent involvement activities in a large, urban district.

Linse (2013), submit that many immigrants living in America have limited English proficiency or LEP, defined as a person who does not speak English or whose native tongue is not English, and is unable to perform or assist with ordinary classwork because of the language barrier. Turney and Kao (2009), propose that students benefit tremendously when educators welcome immigrant parents into their children's schools and attempt to decrease the language and logistical barriers that parents face by providing outreach efforts through various parent involvement opportunities. 
From a different perspective, the Tomas Rivera Policy Institute Study (2009), asserted that Latinx parents define parent involvement in two categories, academic involvement and life participation. Academic involvement includes activities associated with homework, educational enrichment, and academic performance. Activities such as attending parent-teacher conferences, knowing when to expect report cards, purchasing materials needed for classes, asking questions about homework, and driving their children to the library and school performance events fell into this category of academic involvement. Life participation includes ways in which parents provide education about life in school and away from school. Participation includes parents being aware of their child's life, child's friends, providing general encouragement, making sure their child is in school, giving their child advice, getting to know their child's teachers, observing the school environment, and encouraging siblings to look out for one another (Zarate, 2007). This supports the idea that immigrant parents want their children to be successful both academically and socially in school just like any American parent.

A vast amount of literature currently exists regarding parent involvement on all grade levels (Epstein et al., 2009; Hill \& Tyson, 2009; McNeal, 2015). According to Deslandes and Bertrand (2005), parent involvement is highly correlated to student achievement. Along with this, parents' perception and support of student learning and social environment has a strong correlation to student outcomes, such as student achievement, attitude, and motivation towards school (Whitaker \& Hoover-Dempsey, 2013). 
Likewise, Masten and Coatsworth (1998), proposed that parent involvement is one of the key components aimed at improving academic success in children. The belief is the more parents are involved in their children's school experience, the more success their children will experience. This involvement refers to parents assisting their children with homework, parents participating in school activities such as parent teacher conferences, field trips, and parents monitoring their children's grades. Because of the sheer nature of both entities, the two microsystems shaping a child's development are the child's home and school (O’Malley, Voight, Renshaw, \& Eklund, 2015).

Children spend countless hours at home watching their parents as well as spend many hours at school with their teachers. Children are in these two systems for the first 18 years of their lives, thus both microsystems shape children's development. Along with these two microsystems come misunderstanding and misconception as well as productive communication and teamwork, partly because the two microsystems have two different perceptions and set of experiences. It is necessary that both of these very important entities to work together, communicate regularly with one another, and keep the focus-which is student achievement both academically and socially.

Even though the vision may be the same, student achievement and success, the mission between home and school is sometimes not in alignment. Henderson, Mapp, Johnson, and Davies (2007) postulated that "the evidence is consistent, positive, and convincing: Families have a major influence on their children's achievement. When schools, families, and community groups work together to support learning, children tend to do better in school, stay in school longer, and like school more" (p. 28). Thus the need 
for effective and intentional outreach efforts to involve all parents and make the connection (Epstein, 2011).

Specifically, Archer-Banks and Behar-Horenstein (2008) stated parents who regularly talk with their children about school, provide their children with opportunities such as tutoring, enrich learning by participating in family activities, and support their child's school expectations, are instrumental in increasing student achievement. Parents, who are in regular communication with their children's schools, are also instrumental in instilling in their children the important of education (Archer-Banks \& Behar-Horenstein, 2008). Hill and Tyson (2009), concluded engagement of a parent in their child's learning, both at home and in school, provides students with the essential pathway to positive academic and social outcomes. Similar to teachers in the classroom, parents are part of the recipe that is vital to continued student achievement.

\section{Factors of Parent Involvement}

School outreach efforts matter to all parents. When parents perceive that school personnel care about their children and have their children's best interest at heart, they are supportive of the school's programs and more involved. Including parent voice and meeting parent needs are crucial to effective parent involvement-when parents feel that school personnel care about their child and what goes on at school and at home, parents want to be more involved; parents feel more comfortable and respected by the school personnel (Garcia-Reid et al., 2013). Garcia-Reid et al., (2013), reinforced the need for my study because it explored perceptions of the current outreach efforts' efficacy.

Likewise, Halsey (2005) highlighted keys to nurturing and maintaining middle school parent involvement. To keep parents informed while maintaining a positive 
relationship with middle school parents, Halsey's keys state school personnel should use varied types of communication with parents such as personal contacts inviting parents into the school along with more positive than negative communication when trying to grow parent involvement within the school (Haley, 2005). Outlining for parents what they need to do and how they can do it is helpful. Including parents in the planning and decision-making processes of the school is very effective and meaningful to parents. Lastly, acknowledging parents' cultural contributions through expressions of appreciation and acknowledgement provide meaning and connection between home and school (Auerbach, 2011).

Namely, the aforementioned actions allow parents to develop a sense of ownership in their child's education journey. Parents perceive involvement differently than teachers. In some situations, immigrant parents feel uncomfortable and unwelcome with regard to interacting with school personnel (Christianakis, 2011). Additionally, while attempting to teach middle school students various enduring skills and dispositions, teachers focus most of their communication on students, leaving parents out of the communication circle in hopes of increasing student responsibility and organization skills (Altschul, 2012). Unfortunately, in many cases, teachers in middle school initiate communication with parents only when something is wrong (Epstein, 2009); whereas parents, according to Knapp, et al., (2013), rarely initiate conversations regarding instructional issues, due to the fact that parents, especially immigrant parents, in many cases, feel inadequate with respect to helping their children with middle school homework. Along with feelings of inadequacies regarding middle school homework, in 
many cases, there are language issues and other barriers threatening the home school bond (Dondero \& Muller, 2012).

Parents are seldom, if ever, included in the instruction of middle school students. In elementary school, school personnel ask parents to volunteer in the classroom, volunteer in the library or cafeteria, and chaperone field trips; so there is additional assistance with instruction, procedures, and classroom management (Altschul, 2012). In middle school, this is not the case. In middle school, invitations to parents may extend to chaperoning field trips, assistance during state testing with bathroom breaks, and assistance requested by the teacher regarding supportive behavior modification (Whitaker \& Hoover-Dempsey, 2013). Many times, educators contact middle school parents requesting they sign a behavior or safety contract or parents receive information regarding an upcoming conference day, enrollment forms, and expectations of the school. For middle school parents, involvement usually exists on the extracurricular activity and behavior level when students play sports or are in trouble (Knapp, Jefferson \& Landers, 2013). Even though parent involvement changes once students enter middle school and students seek more independence, communication is still key to increased, effective parent involvement. Communication is even more vital when working with immigrant parents who experience the English language as a second language.

Yan (2009) examined a school in a Canadian school system focusing on communication between the English as a second language (ESL) teachers and Chinese immigrant parents. Based on observations at several parent night events, interviews of the ESL teachers, and focus groups. Yan found that the parent nights were effective in sharing important information with the immigrant parents while building positive 
relationships with them as well. Because of the schools' outreach efforts, proactive relationships formed and immigrant parents were included and informed regarding how they can effectively support the school's program and their children's education. How school personnel reach out to immigrant parents is extremely important. School personnel need to know their population and develop outreach programs accordingly.

A related study by Overstreet et al. (2005) examined the predictors of parent involvement within a population of 159 African American parents living in an urban setting. Overstreet et al. examined predictors such as parent demographic, parent attitudes towards school, parent perception of school receptivity, and parent community engagement. Using a mixed method approach with interviews and surveys, the results of the Overstreet study revealed that for both groups of parents - elementary and middle/high - parent perception of school receptivity was the strongest predictor of parent involvement with parent educational aspirations for their children and community engagement behaviors as strong seconds. In other words, how inviting school personnel were was very important and meaningful to parents.

Equally important, for the middle/high school parents, parent level of employment was a significant predictor of school involvement. The findings of Overstreet et al. (2005) support the use of the ecological perspective framework (Bronfenbrenner, 1989), in that parent behavior is influenced by multiple factors within the various contexts of their environment. Both English-speaking parents and immigrant parents experience these factors, but immigrant parents struggle on two levels - navigating in a new country and navigating within a new school system. 


\section{Racial and Ethnic Differences in Parent Involvement}

Archer-Banks and Behar-Horenstein (2008) examined factors that cause parents to become involved in their children's education. This study also emphasizes how nonWhite parents perceive the middle school climate. African-American parents made up the two focus group informants. Archer-Banks and Behar-Horenstein (2008) found that racial biases within schools have dissuaded many parents of color from visiting their child's school and getting involved and that, in many cases, school personnel view parents of color as uneducated and uninterested in their child's education experiences (Christianakis, 2011).

According to Abdul-Adil and Farmer (2006), there are perceptions that AfricanAmerican parents are less engaged in their children's academic experiences than White parents are. On the other hand, Field-Smith (2005) found that even though school personnel perceive African-American parents as uninvolved and disinterested in their child's education, African-American parents value their children's education and make it a priority in their lives. Equally true, immigrant parents believe in the importance of education. Archer-Banks and Behar-Horenstein (2008) sought the perceptions of African American parents and their involvement in their child's middle school experiences and how their beliefs about this involvement impacted the educational experiences of their children. Data collection emerged through use of audiotapes, researcher memos, and descriptive and reflective notes. Archer-Banks and Behar-Horenstein (2008) employed open-ended questions such as "What motivates you to become involved in your child's middle school experience?" Five central themes emerged from the interviews and data analysis, one of which was expectations of parents and school personnel. Parents 
stressed the need for strong relationships between school personnel and AfricanAmerican parents. The parents revealed that negative stereotypes of African-American students influenced teacher interaction with African-American students. This study was important because it focused on perspectives of middle school parents and their perceptions on what is needed to maintain middle school parent involvement that secures student achievement. The importance of social capital and cultural wealth are emphasized as part of this study.

Moreover, Archer-Banks and Behar-Horenstein (2008) offered several suggestions regarding middle school practices - (1) set higher expectations for all students, including all students of color, (2) establish flexible meeting locations to accommodate parents, (3) offer workshops for homework help at home, and (4) create cultures that support the belief that all parents care about their children's education. According to Archer-Banks and Behar-Horenstein (2008), the participants' voices provided evidence-based information on African American parents' involvement or noninvolvement in their children's education.

Confirmed by the aforementioned studies, parents need to feel invited, welcomed, respected, and supported with regard to becoming involved in activities that promote student achievement. This is a call for cultural competency and cultural awareness. Nistler and Angela (2000) further emphasized the need for creating strong relationships between parents and school personnel for the sake of the children. School personnel must gain knowledge of their stakeholder population and the various cultures and traditions that their families bring. Delpit (2006), proposed that school personnel must learn about all cultures of students enrolled in their schools in order to serve all students 
in their schools. In learning about other cultures, inclusion and appreciation of other cultures occurs.

According to Banks (2013), "a major goal of multicultural education is to change teaching and learning approaches so that students of both genders and from diverse cultural, ethnic, and language groups will have equal opportunities to learn in educational institutions" (p. 109). Multicultural education allows school personnel to see what other cultures have to offer and assists immigrant cultures in learning how to navigate the school process. Multicultural education also adds to a school's culture by increasing all stakeholders' capital and meaning to the school as a whole. School personnel learn about other cultures, while those of other cultures learn about the school culture. This reciprocation demonstrates the best and most proactive way to engage immigrant parents, address the increasing immigrant student population and show respect and acceptance, thus improving the overall capacity of schools with immigrant students and parents (Banks, 2013).

Immigrant parents experience competing barriers (Christianakis, 2011; Turney \& Kao, 2009). Barriers such as low English language proficiency, lack of formal education, lack of knowledge of the U.S. school systems, and work time constraints cause deficient active involvement in their child's education (Christianakis, 2011). Immigrant parents feel inadequate and sometimes embarrassed when having to come to school and talk with teachers because of language and other barriers (Turney \& Kao, 2009). Christianakis (2011) also identified barriers imposed by teachers in the form of communication.

Many times teachers communicate positive news in a mass mailing, yet communicate negative news in a personal manner. Mass mailing communication 
sometimes builds barriers, not decreases them due to the possibility that some parents may not get their mail or the possibility that some immigrant parents may not be able to read the mail because of the written language. Although unintentional, using only this type of communication strengthen existing barriers.

Auerbach (2011) and Halsey (2005) agree that all parents feel more connection with their child's school when a positive telephone call of face-to-face meeting occurs. School personnel should use a variety of forms of communication to meet the needs of their diverse group of parents. Other forms of communication may include sponsoring parent information nights at the school or in the community to provide their parent with needed information and answer parent questions. School personnel could send home information either hard copy or electronically in more than just the English language. Additionally important, school personnel must make sure to communicate intentionally with parents in a positive fashion prior to reaching out to a parent because of a behavior issue.

Yosso (2005) posited that immigrant parents, as well as all parents of color possess much to offer schools because of the many differences in the various cultures they have experienced and can share with others. The many different lived experiences of people bring various different backstories of students and their parents. These backstories should not be ignored, but embraced in the education process. In most school settings, educators expect students to conform to the already equitable school system, based on middle class norms (Yosso, 2005). The backstories, mentioned before, help shape students' lives and their educational journeys. The diversity of these backstories exist because of the diverse cultures from which their parents derive. It is crucial that 
school personnel consider the various different cultures, traditions, at-home practices when developing curriculum and establishing routines and procedures at school to truly meet the needs of all of their students and keep all parents informed, including immigrant parents.

Educators agree that parent involvement correlates with student achievement (Halsey, 2005). Knowing this causes school principals to develop parent involvement programs that inform parents on a regular basis (Sobel \& Kugler, 2007); as student demographics change across the country and immigrant student enrollment continue to increase, parent involvement efforts must include outreach for immigrant parents as well (Christianakis, 2011). Additionally, the challenge exists to include parents who speak languages other than English, which contributes to immigrant parents not being informed, and immigrant students falling behind their counterparts academically and socially (Sobel \& Kugler, 2007).

The onus falls on school personnel to put forth extra effort and develop strategies to include immigrant parents intentionally, helping immigrant parents feel welcome and respected regarding participation in their children's education. Epstein's framework of six types of involvement does this, allowing schools to reach out to families in a variety of ways. Epstein's framework includes parenting, communicating, volunteering, learning at home, decision-making, and communicating with the community. Incorporating both Epstein's and Yosso's theories ultimately leads to effectively reaching out to immigrant parents and all parents, educating all involved, which will, in turn, lead to greater immigrant student achievement and overall student achievement. Several ideas exist regarding parent involvement and outreach efforts, but the question remains as far as 
which activities are the most effective and meet the needs of all stakeholders. The question remains about the average outreach efforts made by school personnel to involve parents and their effectiveness for their immigrant parent/family population.

For the purposes of my study, I explored one middle schools' outreach efforts to involve immigrant parents in a large and diverse school district in the southeast United States. In the district, there are 91 elementary schools, 23 middle schools, and 22 high schools. This district educates 101,000 students on average annually. The district also provides transportation for its students who live more than one mile from their school. Elementary schools start at 9:00am and middle and high school start at 7:40am.

Therefore, the shared responsibility of educating all students exists amongst school personnel and families. In many school districts, the face of the average student looks very different from in years past. Students, parents, and families of all economic, racial, ethnic, cultural, and educational backgrounds now make up the faces of public schools across the country.

According to Cornell (1995), the education of the immigrant student with limited English proficiency creates a growing concern. In part, due to ineffective teacher training. In many cases, teacher education and training does not include how to teach students whose first language at home is not English. When students from other countries who do not speak fluent English, enter the public school system, many times, they are immersed into an English-speaking classroom with hopes of eventually acquiring the language. This does occur, but at different rates for each student because of the demands of the task itself. 
For example, researchers Collier and Thomas (1989) noted that, in order, for students to acquire the English language from special English instruction classes, it takes anywhere from five to seven years. This length of time is necessary for these students to function effectively in other academic courses as well. To facilitate this process, school personnel seek to hire teachers who are bilingual and can teach immigrant students in two languages-their native language and in English (Cornell, 1995). During the 1970s and 1980s, a large influx of immigrant families in the western United States entering the public school systems occurred including Cambodians, Haitians, Chinese, Vietnamese, Laotians, and Koreans. This resulted in some classrooms where there were up to six different languages being spoken at any given time. This resulted in legislation creating a variety of classroom instruction models to attempt to meet the needs of all students.

Students who showed greater success in acquiring the English language and other academic success came from homes where families actively supported their goals (Rumberger, 1983); whereas students from low-income households might take longer than the five to seven years to successfully acquire the English language. For many immigrant families, they fall into this category because many school programs could not provide an effective amount of hours per day to teach English to the immigrant students (Dondero \& Muller, 2012). Homework practices accompanies students home to supplement in-class instruction. In many cases, immigrant parents are unequipped to assist their children with this homework. As previously discussed, when children transition from elementary school to middle school, barriers affecting parent involvement on the middle school level persists (Auerbach, 2011; Garcia-Reid et al., 2013). 
The same being true and amplified for a parent who enrolled their child into an American public school, yet speaks very little English. Not only do these parents experience the barrier of learning a new school structure and more difficult courses, immigrant parents battle simply being able to decipher the English language that the assignments and the flyers that come home are written in. Peterson and Ladky (2007) state that language continues to be a barrier to successful parent involvement. Immigrant parents experience language barriers resulting in decreased confidence in their abilities to assist their children with their schoolwork.

Barriers lead to many undone homework assignments and many parents who are reluctant to call the school for help. They do not know what questions to ask. Peterson and Ladky (2007) analyzed the perspectives of teachers and principals. They found that school personnel need more information about the culture and language of their students to serve their students. Teachers also need to increase their awareness of cultural diversity and parent perceptions.

Sobel and Kugler (2007), contend that school personnel should implement effective strategies to engage immigrant parents and reduce existing barriers. The existing barriers include inflexible work schedule that preclude immigrant parents from attending school functions. Childcare issues also exist, causing parents difficulty in having to find someone to babysit a younger sibling while the parent attends a school event (Varella, 2008). Language differences also make communication between school personnel and immigrant parents very difficult (Bitew \& Ferguson, 2010; Walker, Ice, Hoover-Dempsey \& Sandler, 2011). To increase immigrant parent involvement and 
decrease existing barriers, building relationships amongst all stakeholders is crucial for student achievement (Anfara \& Mertens, 2012).

From this perspective, school principals must guide the work for school personnel to create effective strategies and build relationships with their immigrant parents. School personnel must seek first to understand the backstory and culture of their immigrant population and respect the fact that immigrant parents want the best for their children just like American parents. This issue is important because research supports the fact that all parents care about their children's education and want their children to do their best (Anfara and Mertens, 2012). Research also informs us that the common school practices and procedures appeal more to parents whose cultural capital identify as middle class (Bourdieu, 1989; Garcia-Reid et al., 2013). As stated previously, educators should practice effective outreach towards their immigrant parent population who do not identify as middle class.

Immigrant parents may appear apathetic about their child's education because of their low attendance at school-sponsored events (Garcia-Reid et al., 2013; Walker et al., 2011). On the contrary, immigrant parents follow the unspoken norm of their native countries that the teacher dictates schoolhouse education. Immigrant parents often perceive parent participation or questioning educational activities in the school as disrespectful (Sobel \& Kugler, 2007). Varela (2008) states that immigrant parents feel respected and appreciated when their child's school embraces and welcomes them and recognizes that immigrant parents have a lot to contribute to their child's education.

Family cultural variables persist, yet not taken into account either. Family cultural variables include lack of knowledge of the education system due to little 
experience within the American school system, language differences, and childcare issues. These childcare issues pose a problem because many times in immigrant households, no immediate family lives nearby to assist with childcare (Dondero and Muller, 2012). Christianakis (2011) posits that deficit perspectives increasingly come into question. The deficit concept perpetuates the myth that immigrant parents live on a low socioeconomic level, unable and unwilling to participate, with low advocacy for their children (Garcia-Reid et al., (2013). The deficit concept does not take into account the many variables that affect and influence parent involvement and achievement of all students. The school variables include relationships between students and teachers, peer interactions between students, school resources, linguistic needs, and extracurricular activities. Every family enrolling their children into public middle schools are not White middle class. In fact, in recent years, the number of families enrolling their children into public middle schools are families of color (Gutierrez \& Almaguer, 2016). Such trends reveal more reason why school personnel must welcome all cultures and embed culturally relevant curriculum, instruction, and intervention to meet the needs of all stakeholders (Christianakis, 2011).

It is imperative for schools serving immigrant families to implement effective, helpful immigrant parent involvement programs leading to positive student outcomes. School personnel must analyze their current parent involvement programs and modify their current practices when considering what is best for their immigrant population. Modified practices that meet the needs of all students and look to increase parent involvement of all parents are key to student achievement. Modified practices, in order to be effective, must include social and cultural capital frameworks include all 
stakeholders' needs and realities, education and information for immigrant parents regarding the school system navigation, and cultural wealth identification on school personnel's part (McNeal, 2015). In addition, school personnel must value the cultural wealth that immigrant families bring to their school and to their school district. If this valuing is not present, outreach efforts to engage immigrant parents will not be meaningful or effective.

Yosso (2005) went further to state that middle class culture maintains as the standard families aspire to. Many theories and studies indicate that if one is anything but middle class, one is less than normal. Thus presenting a parent deficit model. Yosso (2005) argued that, "an array of knowledge, skills, abilities, and contacts possessed and utilized by communities of color currently exist to survive and resist all forms of oppression." (p. 154). Yosso maintained that in communities of color, there are already effective systems in place that work. Just because these systems may be different from the middle class norm does not make these established systems wrong. Educator mindset is key to addressing all students, not just a select demographic. Educators must believe that all students can learn; that all students have the right to a quality education. The question continues to exist as to what are the best practices and outreach efforts for immigrant parents and school personnel that have a positive effect on immigrant student achievement. Speaking to this question remains important, especially since parent involvement identifies as an effective strategy used to impact student outcomes (Altschul, 2012; Halsey, 2005).

Traditional methods and models of outreach efforts that involve parents do not take into consideration immigrant parents or immigrant parents' perceptions of how they 
should be involved in school activities (Christianakis, 2011). Immigrant parents' social context and culture plays a very important role in how they interact with school personnel and participate in school-sponsored (Guo, 2012; McNeal, 2015). Additionally, research that examines conventional models of parent involvement to reach out and involve immigrant parents is warranted. It is important that research examine existing efforts and strategies that have been instrumental and successful in engaging immigrant parents.

Kugler (2009) shared that many Hispanic and Asian parents believe that it is more helpful and respectful to maintain a distance from school, trusting that school personnel know what is best for their children while they are at school, and thus, they do not get involved in their child's education by coming to the school. This is a cultural practice and respect for the teacher and what they are teaching. This is not the Hispanic or Asian parent's way of not being involved. From the immigrant parent perspective, this is their way of showing respect and staying out of the way. Middle school educators should provide parents, as well as students who have limited English proficiency and other cultures and beliefs, more opportunity to experience success and inclusion in middle school while preparing for the next level. Effective outreach must be a priority.

\section{Engaging Parents-District and School Level Efforts}

Throughout the years, many studies exist regarding parent involvement from the point of view of both the education institution and the parent, with little to no consideration for immigrant parents (Auerbach, 2011; Christianakis, 2011). Parent perspectives are sought after for years in various studies, yet these studies position schools and school personnel as the ones with the power and the voice to make all educational decisions. These studies show the immigrant parent as needy and working in 
opposition to the teacher (Auerbach, 2011; Crosnoe \& Ansari, 2015; Fine, 1993). For years, the building of school-parent connections originated from the institutional standpoint and ideology and not from the formation of community, which includes input from all stakeholders, especially parents (Murphy, 2005). Murphy (2005) adds most initiatives developed on school terms and convenience do not include parent input. In many cases, school officials plan programs for parents rather than involving them in the planning of the events.

According to Whitaker and Hoover-Dempsey (2013), the primary participants of school organization and school climate are teachers. Teachers are charged with communicating school norms and expectations to students and parents. Teachers also control the wealth of knowledge with regard to curriculum, instruction, assessment, behavior, and student progress when it comes to student achievement. Parents are the receivers, just like their students, of all of this information. Parents are very reliant upon school personnel to convey pertinent information regarding their children. Whitaker and Hoover-Dempsey (2013) proposed that the way this information is shared with parents is crucial to student progress. This sharing also dictates, in many cases, parents' perception of the overall school climate. It is very important that teachers understand this and make every attempt to exhibit cultural competence to all parents.

Similarly, researchers Torre and Murphy (2014) expounded, in many cases, as school institutions create programs directed at inviting parents to participate, they are actually alienating some parents. Planning events at school at certain times and for the convenience of the school staff, is not conducive to building positive relationships with parents. Many minority and impoverished parents have no transportation to school for 
participation, while some parents are working during the time of the school event. School personnel must think "out of the box" and attempt to engage parents, first, by asking for input, inviting parents to events, and having events at diverse sites and times in the community that are accessible to parents.

Focusing on the parents' perception allows school personnel to gain a more true meaning and genuine viewpoint of parent perception and need as well as develop a deeper understanding of parents' perceptions of involvement, parent perception of school climate and culture, and in turn, informs school personnel of the cultural competency needed in schools today. The analysis of parents' perception provides vital information for teachers, policy makers, and school officials and personnel attempting to create or enhance parent involvement initiatives and diverse parent outreach (Whitaker \& HooverDempsey, 2013). Literature focused on school climate and its' association with parent involvement primarily exists on the elementary school level (Goldkind \& Farmer, 2013). It is necessary to investigate the creation of effective partnerships between home and school, specifically between middle school immigrant parents and middle school personnel.

Additionally, Mapp (2003), investigated parents' perception of involvement and sought to identify factors that lead to successful partnerships between school staff and families. A four-year case study involved parents responding to interview questions regarding their children's education and mitigating factors that influence their participation. Parents shared their descriptions of parent involvement and participation in their children's education. Mapp (2003) emphasized that parents, similar to children, seek a positive relationship with school personnel because of the educational benefits of 
increased parent involvement and increased test scores for students. Parents want connections with schools that lead to positive, progressive student outcomes. The researcher sought to see if parent descriptions matched existing typologies of parent involvement - parenting, communicating, volunteering, learning at home, decisionmaking, and community involvement-developed by Epstein (2009). Interviews were conducted in parents' homes and job locations. Memos, field notes and interview transcripts were analyzed as part of the researchers coding system.

Implications from Mapp (2003) included the suggestion that school personnel must not assume how certain parents feel about their children's education or that certain parents do not understand or know how to assist their children. School personnel must always be open-minded. The findings of the study suggest that school personnel should always attempt to be welcoming, honoring, and connecting with parents, as well as keeping the positive lines of communication open and consistent. That way, when there is a time for school personnel to contact parents with negative information, the relationship of trust will already be in existence. The language used by the 18 parents interviewed for this study emphasized relationship and trust as important influences on their involvement. Parents send their best children to school, so parents expect school personnel to take good care of their children and treat them as if they are their own. Data from this study suggest that the support of the school leadership and staff remains a crucial ingredient for the success of family involvement initiatives. Including parent input along with education institution input ensures inclusion of stakeholder voices.

In need of parent voice and parent perspective for cultural competency purposes, a study conducted by Halsey (2005), focused on stakeholder input. Knowing that parent 
involvement changes as children enter middle school, all stakeholders must be aware that parent involvement means something different for different stakeholder groups. According to Halsey (2005), teachers, parents, and students all value parent involvement, but define it differently. Teachers' and parents' perceptions of communication are explored in this study. Findings of this study show teachers and parents view communication efforts differently. Teachers implement institutional communicative methods, which tend to be impersonal, but efficient and time saving. Parents prefer a personal communicative method, one on one support that is not condescending. When communication is ineffective, both groups become discouraged and stop communicating altogether. Halsey (2005) added that including parent perception of parent involvement informs teachers that parents are willing to be involved in their children's education and challenges school personnel to modify their programs and procedures to meet the needs of all stakeholders for the benefit of the students. This case study included eight teachers, twenty parents, and nineteen students, in grades six through eight. During a seven-month period, data collection using semi-structured interviews and observation ensued.

Findings indicated that all participants of the study agreed that parent involvement is important. However, obstacles or conflicts exist. With the difference in communication, two types of communication exist. There is institutional interaction and individual interaction. According to Epstein (2009), from the school comes institutional interaction - where parents and family members are invited to open houses, Parent Teacher Organizations, conference day, and extracurricular activities. This allows the school to invite large groups of parents and family members into the school. With individual interaction, school personnel find other ways to connect with parents-positive 
postcards and phone calls, school sporting event attendance, emails, and community events.

In Halsey's study, most teachers relied on institutional interactions with parents. Teachers interviewed in this study felt like institutional interactions were an effective and efficient way to invite parents into the school. Parents, on the other hand, felt just the opposite. Parents feel individual interaction is the best and most effective way to invite a parent into the school. Parents felt that individual interaction was more personal and therefore more genuine. When teachers want to recruit parents to chaperone a field trip or volunteer at a school event, personal or individual interaction is most effective. It is more time consuming for the teacher, but in the end, provides lasting results. This is simply a good example of two groups of people not being culturally aware of the other group's wants and needs (Halsey, 2005). This is why including parent input is important to have when developing outreach programs for parents. Between home and school, perspectives are different. Parent perception is different from school personnel perception. An even greater difference in perception exists for immigrant parents.

Similarly, DePlanty, Coulter-Kern, and Duchane (2007), conducted a study, including input from teachers, students, and parents regarding the types of parent involvement and their effect on student achievement. Overwhelmingly, parents surveyed felt that making sure their child is at school every day and attending parent-teacher conferences were the most significant indicators of student achievement. Regularly checking homework and talking to their child about school came in a close third and fourth place. Teachers participated in a focus group where they answered a set of questions. Through surveys, a collection of student input was obtained, administered 
during the school day and parents were given a survey during their attendance at a parentteacher conference day.

In order to get true parent input, parent data could have been collected in a different setting, not compounded during conference day. This practice increased the limitation in this study. This may add pressure to parents to provide socially acceptable answers instead of being truthful. It is understandable why parents received the surveys during conference day. That is the best opportunity to get more parent response as opposed to sending the surveys home and having parents complete them on their own time. The hope exists that schools use traditional and non-traditional avenues to get parent feedback to serve students. With this in mind, the researchers concluded that school personnel must find more effective ways to invite parents in and increase parent involvement in order to strengthen academic achievement.

In an effort to increase student achievement and meet the needs of students, more attention is needed for true parent involvement. Relationships between home and school must be nurtured (Anfara \& Mertens, 2012). In looking at the big picture, all stakeholders benefit from increased parent involvement and effective outreach; increased, authentic involvement, higher rates of return for classwork and homework, higher morale, and a greater sense of efficacy of all stakeholders leading the way to expected outcomes of effective parent involvement and appropriate outreach efforts to engage parents.

In an article by Mistretta (2013), a program focused on educating parents and student simultaneously in a four-month period involved 18 preservice teachers, enrolled in a university career-change masters degree program. The program included all 
stakeholder groups-18 teachers, 30 families, including 30 students. The program also included a diverse group of families. This study included 9 Hispanic families, 10 African American families, one Asian family, and 10 White families. The program focused on educating parents on how to assist their children at home with mathematics. In addition to providing opportunities for parents to learn about instructional strategies that occur in classroom learning, according to Mistretta (2013), the two-hour sessions allowed the teachers to investigate families' collaborative efforts while engaging in completing school work. Additionally, the study included a diverse parent population, including some immigrant parents.

Using surveys, observational field notes and interviews, the focus is on perspectives of parents and teachers in how they influence children's education. The program conducted monthly two-hour sessions for four months. Parents learned how to increase discourse amongst children and deepen questioning. Students also participated in activities with their parents that taught the same enduring skills. During the interviews, parents expressed previous frustration when helping their child with homework, in general, because many parents felt that ways to do math and other assignments differ so much since they were in school.

Parents also expressed a need for overall assistance in all content areas with regard to helping their children at home. During the program, findings included many parents care a great deal about their students' achievement and desire for their children to go to college. Participation in the program and interacting with the parents and their children also revealed to the teachers that parents' genuine commitment and desire to serve as active participants in their children's educational journey exists (Mistretta, 
2013). Research informs us that teachers can influence the success or failure of efforts that seek to change the ways parents participate in their child's education (Civil \& Bernier, 2006).

The practical experiences of the program allowed parent voices to be heard and, in turn, inform teachers' future practices for building a foundation and continuation of teacher-parent-child collaboration. The results of this study may lead to modifications of current parent outreach efforts, especially after revealing how parents feel about their children's education and the fact that teachers were able to realize that all parents want the best for their children, including immigrant parents and parents of color. According to No Child Left Behind (2002), parent involvement involves the participation of parents in regular, two-way, and meaningful communication with their child's school. Parents play an integral role in assisting their child's learning and parents are actively involved in school activities. A requirement that school personnel build capacity by intentionally involving parents strengthens school-home connection. Additionally, on December 15, 2015, President Barak Obama signed into effect an updated and modified version of No Child Left Behind (NCLB), called Every Student Succeeds Act (ESSA).

With ESSA, educators and families voiced their concerns that more needed to be done to promote all students' achievement, NCLB, was unrealistic and unattainable for some vulnerable populations (Hough, Penner, \& Witte, 2016). Something needed to be put into place to prepare students for college and career. ESSA provides wraparound support and interventions for all families and students, emphasizing provisions for marginalized populations. ESSA allows states to make curriculum decisions based on what is best for their students. Unlike NCLB, ESSA includes differentiation and is not 
"cookie-cutter", with one size fitting all. Mapp (2003) emphasizes if school staff support the diversity of their enrolled families, where all members of the school community are heard and respected, parents will respond by engaging in relationships and partnerships with school personnel that support student learning.

Griffith (2000) conducted a study focused on student and parent perception of school climate. Griffith examined the relationship of consensus between students and parents with regard to their perception of school climate analyzing survey responses of 25,557 elementary school students and 23,107 parents of elementary school students. This included 122 schools. The results revealed schools where there was greater consensus among students and parents showed positive evaluation of the school climate. Where there was more racial diversity and transience among the students, less consensus existed, thus resulting in less positive perceptions of the school climate. This is due to differing social environments in schools. Schools may be in the same district, yet the demographics of each school can be and usually are different. Griffith (2000) hypothesized that student satisfaction would be determined by what students defined as a supportive school environment and the relationships built between the students and adults in the school building. For parents, Griffith hypothesized that parent satisfaction would be related to parent perspective with reference to academics and their children's educational progress. Individual student and parent background characteristics were taken into consideration as well.

While school personnel develop parent involvement activities and outreach programs, it is crucial, that all parent voices, regardless of race, socioeconomic status, 
educational background, country of origin, cultures, and beliefs be taken into consideration in order to meet the needs of all stakeholder needs.

\section{Middle School Programs and Immigrant Parent Involvement}

Parents influence their children from birth and from the home. Because of this long formed relationship between parent and child, it is imperative for school personnel to consider this bond when planning curriculum, instruction, and assessment focused on cultural relevance and achievement of all students (McClay, Peterson, \& Nixon, 2012). Along with this, school personnel need to be well informed about the varieties of immigrant students and parents who enter their school building every day. Informing school personnel of parent beliefs, values, culture, perception, and needs to support student achievement more effectively.

One of the cornerstone characteristics of successful middle schools, according to This We Believe: Keys to Educating Young Adolescents (National Middle School Association, 2010), focuses on actively involving all families in the education of their children. Schools, of course, have the ability to do this in their own way to meet their stakeholder needs. With the growing immigrant population enrolling in our public schools, it is imperative and necessary that two-way information and connection occur between home and school. When parents receive information and invitation from school personnel focused on student achievement, they can affect change in the education system that supports and sustains student achievement (Bolivar \& Chrispeels, 2011).

Personal, positive relationships between school and home are vital for increased student achievement (Minkle, Sheridan, Ryoo, \& Koziol, 2014). The methods of inviting parents into the partnership between school and home are extremely important because 
when parents feel valued and respected, the student wins on all sides and benefits from this positive partnership. The first method occurs by sending home notes regarding the positive behavior of children. Parents always want to hear what their kids are doing right before they hear the negative. It takes more effort and time to do this, but in the end, it is well worth it.

Another effective method, according to Wedel \& Cornell (1991), acknowledged immigrant parents by having translators at school events. This demonstrates understanding, friendliness, and compassion for the language barrier struggle they experience daily. For many immigrant parents and students, the task may be difficult to address. Immigrant parents rely heavily on their children to translate what the school needs. Approximately $70 \%$ of all Latinx students shared that, at home, the first language spoken was not English and of these Latinx students, $18 \%$ of them admitted that speaking and understanding English was very difficult for them (Dondero and Muller, 2012). These Latinx students have an increased likelihood of enrollment in lower classes and stereotyped by school personnel because of their limited English comprehension.

With the language and education level barrier, immigrant parents are reluctant and unsure about talking with teachers about their child's educational specifics. In one study by McClay et al. (2012), a teacher participated in an interview regarding her school's outreach efforts of inviting parents into the writing process. She spoke of her immigrant parents from different countries where they were educated professionals. In Canada, however, there are parents who do not speak English, which creates a barrier that limits the amount of help they can provide their children in the writing process. This teacher 
expressed the need for training and professional development to include immigrant parents, because teacher lack of training contributes to the existing barriers.

An effort to engage immigrant parents and families in their child's education creates partnerships between home and school. Dotson-Blake et al., (2009) propose a template for partnerships when taking on this endeavor. The template includes six steps to successful partnership building. To meet the needs of all stakeholders, school counselors begin the process of fostering respect and culture of equal engagement, creating a welcoming, collaborative climate, identifying cultural brokers and community leaders, planning intentional opportunities for families and school personnel to interact, bolster investment through community engagement and reciprocity, and reflecting on the success and effectiveness of partnership efforts (Dotson-Blake et al., 2009). It is suggested that the school counselor start this process because the school counselor position is a nurturing position, not a disciplinary one, so parents, students, and families do not feel intimidated.

By including parents, family members and school personnel in collaborative conversations, all stakeholders feel valued, respected, and involved in the educational process (Dotson-Blake et al., (2009). Since the teaching force is predominately made up of white middle-class teachers and the public school population of students is increasingly diverse and multicultural, establishing partnerships of collaboration and communication are imperative (Fleischer \& Pavlock, 2012). Establishing partnerships is imperative so that the challenges of teaching this diverse student population can be met with education, information, knowledge, and understanding. 
A study conducted by Dondero and Muller (2012) regarding the new and established populations of Latinxs in America points the need for research focused on schools and their accommodation of students and parents with reference to academics, social, and linguistic needs. The researchers examined various schools' composition, instructional resources, standards, and access to advanced math classes. The comparison was between new and established Latinx destinations. The findings include that schools in new destinations displayed offered less linguistic support services than the established destinations. The researchers defined new and established destinations by various geographic levels including region, state, metropolitan area and county, as well as, two components-the concentration of Latinxs in a specified geographic area in 1990 and the percent change in the Latinx population in that area between 1990 and 2000.

Findings reveal less linguistic support services in the new destinations than in the established settings. Established and experienced settings are better equipped to meet the needs of all of their students because of their years of experience and the supportive surrounding community. Schools in newer destinations tend to cater to a certain type of family, usually middle class, two parent homes and have lower proportions of minority students enrolled (Dondero and Muller, 2012). These schools tend not to have the behavior problems or academic problems of older, more experienced and established schools do.

Established schools are well known and attract all types of families, including low income, minority families. With this in mind, teachers in the established schools are better equipped to work with all students and adapt to their individual needs. In the newer destinations, immigrant parent involvement is at a level of concern. The increased 
amount of parent involvement in the new destination results from White parents being involved and advocating for their children to take higher level courses; unlike immigrant parents who do not have the knowledge or skill to do so, they rarely contact the school when in need or when they have questions.

A great need, now, more than ever, exists for outreach efforts that engage immigrant parents and their students to inform immigrant parents of public middle school practices and expectations, answer immigrant parent questions, and create a positive connection between the public middle school and immigrant parents to support student achievement. There is a need for school personnel to become more educated on different cultures, student backgrounds, and the immigrant students enrolled in their schools. Immigrant parents feel welcome and confident and thus increase their involvement because they feel that they opinion and needs matter. The goal is to identify all outreach efforts that directly affect and involve immigrant parents as well as explore the perceptions of both middle school personnel and immigrant parents.

The pursuit of strengthening middle school parent involvement, specifically immigrant parent involvement, remains a challenge. For the already established reasons that parents are or are not involved in their child's educational journey, these reasons are amplified with regard to parents of middle school students who experience limited English proficiency on a daily basis. Many schools currently implement a host of goals and plans to establish and increase immigrant parent involvement. These goals and plans include hosting family nights, cultural nights, and employing the use of translators at various events to assist immigrant parents. School personnel must ensure that their immigrant stakeholders feel respected and included. 
Similar to ESSA, there should always be two-way communication between school and home (Halsey, 2005). The promotion and support of responsible parenting should always be encouraged. Schools should include parents in the decision-making process pertinent to the school and promote a safe and open atmosphere for parents and guardians to visit, and provide resources available to parents to strengthen student achievement (Trevena, McGhee, \& Heath, 2015). These are the general tenets of effective parent involvement, yet they do not speak to the specific needs of immigrant parents, contributing to why many schools fail to hear immigrant parent's voices.

Knowing that most immigrant parents migrated to a new land in search of finding a better life for themselves and their families, Auerbach (2011) proposed that schools take steps to improve their understanding of immigrant stakeholders. This will allow school personnel to serve their immigrant population better. Knowing of the correlation between parent involvement and student achievement, once again, a school's outreach efforts to engage their immigrant parents is very important. School personnel must face their own traditions and biases, acknowledge parent and student differences, and think about these differences when planning lessons and events.

Cultural competency and cultural awareness are key to better serving all students and including all parents. The community cultural wealth framework embeds awareness of different cultures and focuses on the fact that not every parent identifies with the middle class measure (Christianakis, 2011; Yosso, 2005). How does school personnel address this conundrum? How are teachers and other school personnel able to address each student who speaks a different language? What training do teachers get to help 
students who are in the immigrant category, while helping the English-speaking students during a regular school day?

Interviewing 38 immigrant parents from 15 countries, Guo (2012) sought to highlight the need to incorporate immigrant parent knowledge into the environment education. Other studies represent parent perception from a deficit standpoint, inferior to school personnel. Guo (2012), posited that community cultural wealth was needed when making educational decisions that directly affect students. This study exposed the fact that parent value and knowledge were misunderstood and ignored by school personnel. Immigrant parent perceptions' were sought and valued in this study to show the importance of valuing all stakeholders' perceptions to encourage change that is studentcentered.

Increasing immigrant parent involvement creates difficult decisions for educators. Davis (1989), stated that parent involvement involves collaboration and stakeholders, not a list of programs or meetings. It requires time and energy on the school personnel's part. Davis (1989) went on to say schools must keep in mind their growing immigrant student population by considering parent involvement policies that reflect linguistic, cultural, and educational backgrounds of immigrant parents and effectively develop a parent involvement outreach program that educates immigrant parents on their rights, roles, and responsibilities as partners in their child's education journey.

The current president of the United States is challenging the notion that immigrants are valuable to the nation, making immigrant parent involvement in schools more difficult. Because of the new immigrant laws, many immigrant parents desiring to be involved may decrease. Immigrant parents face the fear of deportation now more than 
ever. Along with this, immigrant student attendance is dropping (Kugler, 2017). According to Costello (2016), a new theory called the "Trump effect", results in bullying of immigrants and open racism. This has created a "silent crisis".

Outward negative displays of violence towards immigrants and people of color are on the rise. Americans who want to "make America great again" agree with the "Trump effect" that all immigrants need to return to their home countries and that they do not deserve the same respect that "real" Americans deserve. They feel that immigrants are not welcome here in the United States. They have forgotten that immigrants built the United States. School personnel are noticing the decrease in student attendance and are searching for ways to combat this. According to Kugler (2017), immigrant parents are concerned about the threat of being deported and do not want to experience deportation, so they definitely are staying away from the school building.

Along with the fear of exposure to the authorities, other factors exist that affect immigrant parent involvement. Parent involvement varies according to families' ethnic and language backgrounds, socioeconomic status, and educational background (Valdes, 1996). Immigrant parent involvement varies based on their schedules, language skills, and feelings of discrimination stemming from their own personal school experiences, economic stress leading to feelings of discomfort and fear when having to meet with and talk with school personnel (Peterson \& Ladky, 2007).

Moles (1993) explains that, "disadvantaged parents and teachers may be entangled by various psychological obstacles to mutual involvement such as misperceptions and misunderstandings, negative expectations, stereotypes, intimidation, and distrust". Which explains the need to outreach efforts that foster immigrant parent 
involvement. Many immigrant parents do not feel comfortable to reach out to the school for help. Some immigrant parents feel it is disrespectful to question school personnel (Moles, 1993). Because of cultural beliefs, many immigrant parents feel that maintaining a distance between the home and school as far as decision-making is best. The other side of this two-way communication is on the school personnel to explain that there is no need for any parent to feel this way and maintain any distance from their child's school.

Cummins (1996) explained that in many cases, school personnel gage effective parent involvement on which parents are always at school, volunteering in classrooms, going on fieldtrips, and whose children at on the honor roll. Because of lack of English proficiency and knowledge of American traditions, these parents appear apathetic and uncaring. Some teachers and principals stereotype their immigrant and minority parents as uncooperative and unconcerned with regard to their child's education. Immigrant parents' absence from the school building when school events occur is perceived by school personnel as the immigrant parent not being interested and not being concerned about their children's education (Comer, 1996). Comer (1996) found that when asked, the immigrant and minority parents stated that they merely did not come to the school building and participate because they did not feel welcome, wanted or needed. They felt uncomfortable at the school.

Building on the culture and experiences that immigrant parents bring, connecting bridges between school and home, especially with immigrant parents and students, and assisting immigrant parents to perceive themselves as their child's most important teacher, are vital recommendations for fostering greater parent involvement amongst immigrant parents (Pecoraro \& Phommasouvanh, 1992). Some schools act on this by 
performing home visits prior to the start of the new school year. Coming to where immigrant parents and students live creates a completely new dynamic in the relationship between home and school. Performing home visits informs the parent that school personnel care about them and welcome the immigrant population into their school. Some schools have cultural nights where immigrant parents can participate by showcasing food preparations from their home countries, thus showing that their culture and traditions are important to the school.

In other words, several ways to foster increased immigrant parent involvement exist. One effective way to include all stakeholders and identify middle school outreach efforts includes talking with all stakeholders involved. In my study, I sought to identify these outreach efforts by conducting semi-structured interviews with school principals and immigrant parents with children enrolled in local middle schools in the district. The data from this study informed the school district of authentic parent concern and involvement, thus allowing collaboration to build capacity, programs, and systems that incorporate and embed input from all stakeholders. The examination of middle school outreach efforts to engage immigrant parents of urban middle schools, sought to raise awareness in the systematic approaches to effective and meaningful immigrant middle school parent involvement as well as create candidness and increase respect amongst immigrant parents and principals.

\section{Summary of Findings, Data Trends and Future Research}

According to Bower and Griffin (2011), the question remained if schools could build relationships across cultures. Studies showed that the need for relationship building across cultures exits, but the implementation appeared questionable with regard to 
effectiveness (Christianakis, 2011; Dixson, 2008; Peterson \& Ladky, 2007). I chose Epstein's framework for parent involvement and Yosso's community cultural wealth as the two theoretical frameworks to guide my study (See Figure 1). Community cultural wealth adds value to immigrant parents and their traditions and beliefs. Immigrant students bring these traditions and beliefs to school. Epstein's framework for parent involvement puts the onus on school principals and school personnel to explore the many different possibilities that exist to encourage and facilitate parent involvement for every parent. Epstein's framework provides schools with several different options and opportunities to connect home and school and get all parents involved in a way or ways that all parents feel comfortable. Epstein's framework is differentiated to meet all parents' needs.

Naturally, as students work together in their classrooms, different cultures automatically collide and educate those involved. While some may look at this diversity as a negative or deficit, this growing diversity offers new opportunities for school personnel, students, and parents to learn from each other, for educators to modify their curriculum, and for school personnel to modify their parent involvement practices. Potential for increased immigrant parent engagement and inclusion, leads to the potential for increased student achievement.

Future research may include studying the relationship between immigrant parents and people in authority or teacher efficacy regarding immigrant parent involvement. Implications include analyzing and possibly revising current outreach practices to meet the needs of the school's immigrant population. 


\section{CHAPTER III: METHODOLOGY}

\section{Introduction}

Chapter III explained and rationalized my methodology. The following tenets of immigrant parent involvement were explored: a) a middle school's outreach efforts and programs focused on immigrant parent engagement; b) immigrant parents' perception of the middle schools' outreach efforts; c) school personnel's perception of the middle school's outreach efforts, and d) implications of middle school outreach efforts to involve immigrant parents.

A detailed description of the methodology, including the constructivist framework to inform the research design, information about the specific case, participant selection criteria, methods, data collection, data analysis, and delimitations was provided (Roberts, 2010). This chapter is concluded with a discussion of the validity of the data and the reliability of the interview protocol.

The questions of this case study were:

- What outreach efforts are used to involve immigrant parents in a large, urban middle school in the southeastern United States?

- What are the participants' perceptions of the current outreach efforts to involve immigrant parents of the selected middle school? In addition, this chapter included: research design, study context, participants, data collection, data analysis, study validity, ethical 
considerations, delimitations, and research positionality. A summary of the chapter is also provided.

\section{Research Design}

This qualitative research approach explored and examined the meaning given to specific situations by participants (Creswell, 2014). This study's qualitative approach involved the collaboration between researcher and participant, seeking to build emerging themes and new ideas by interpreting participant data (Creswell, 2014). Stake (2000) stated that the case study design focuses on experiential knowledge of the case and pays close attention to the case's influence on the social and political contexts. A case study design was the platform toward identifying emerging themes to understand the facets of middle school outreach efforts that involve immigrant parents (Peterson \& Ladky, 2008).

Likewise, the revelation of stakeholder perspectives was paramount. Guided by constructivism (Creswell, 2014), Epstein's framework (Epstein, 2011), and community cultural wealth (Yosso, 2005) for comprehensive parent involvement, the possibility existed that my study may invite or activate more questions than answers because of its nature. This possibility was due to the multiple interpretations at the same event and of the same data by two different stakeholder groups.

\section{Study Context}

My study was conducted in a large, urban school district in the southeastern United States. Specifically, one middle school's outreach efforts to involve immigrant parents, in a large urban southeastern school district were explored. This urban district, Newton Public Schools (NPS), was located in a major city, with parents and families of 
different socio-economic levels. Newton Public School (NPS) was a pseudonym for the actual name of the school district.

Similarly, in this major city, native and immigrant families coexist with differing family orientations, different cultures, different beliefs, and various parent education levels. NPS operates 90 elementary schools, 25 middle schools, and 20 high schools. This district educates more than 100,000 students on average annually. The majority of the students enrolled in NPS middle schools for school year 2018-2019 were 3,995 Black female, 3,871 Black male, 4308 White female, 4,673 White male, 1,165 Hispanic female, and 1,191 Hispanic male students. Equally important, this district served 64\% students who received free and reduced lunch services. Only $6 \%$ of the middle school enrollment were LEP students.

The district provides transportation for its students who live more than one mile from their school. In a district where greater than 100,000 students are educated every day, transportation is huge undertaking. Within NPS, many students travel more than 30 minutes to their school. This system does not operate with neighborhood schools, so bus transportation is a must. A student's address determines to which school he or she will be assigned. In many cases, the assigned school is not within walking distance. Thus parents of this district rely greatly on bus transportation of NPS. As stated previously, all names used in this study are pseudonyms to protect the identity of all participants.

Elementary schools start their school day at 9:00 a.m. and middle and high schools start at 7:40 a.m. Of the 25 middle schools, four of the middle schools have $10 \%$ or greater immigrant student enrollment. The middle schools are Peace Middle School (PMS), Jefferson Middle School (JMS), Cardinal Middle School (CMS), and University 
Preparatory Middle School (UPMS). The aforementioned names are pseudonyms to protect the identity of schools that were analyzed and used as part of this study.

In addition, in NPS, immigrant students are recorded as Limited English Proficient (LEP), Latinx, and English as a Second Language (ESL) students. LEP is defined as referring to a person whose primary language is other than English and who has limited English proficiency in one of the four domains of language proficiency speaking, listening, reading, and writing (Linse, 2013). LEP describes non-English speaking parents and families of students. On a side note, many social justice educators choose not to use the term LEP because it focuses on a deficit rather than a strength. Immigrant is defined as a non-native person who chooses permanent residence in a foreign country and has obtained the legal right to seek citizenship and employment (Outley \& Skuza, 2019).

Next, the demographic information of the four middle schools for the 2018-2019 school year, with the highest percentages of LEP enrollment were shared.

Peace Middle School (PMS) is located in the south end of the school district. The total enrollment for PMS is 619students, 136 students are labeled LEP, 54 students are labeled Latinx, and 130 students are labeled ESL. JMS has 192 LEP students, 113 Latinx students, and 176 ESL students. The total enrollment for JMS is 1083. JMS is located in the south end of the city. CMS has 127 LEP students, 35 Latinx students, and 114 ESL students. CMS is located on the south side of town. The total enrollment for CMS is 727. UPMS has 149 LEP students, 82 Latinx students, and 135 ESL students. The total enrollment for UPMS is 1070. UPMS is located in the south end of the city. The following table provides a display of the LEP enrollment as it compares to each schools' 
total enrollment. For the purposes of this study, the LEP data identified the focus school. The middle school with the highest percentage of LEP enrollment is Peace Middle School (PMS), 22\%.

The table below shows the four middle schools' LEP enrollment, LEP percentage, and total student population enrollment for school year 2018-2019.

Table 1. Middle School LEP Enrollment Data 2018-2019

\begin{tabular}{lccc}
\hline $\begin{array}{l}\text { School Name } \\
\text { Enrollment }\end{array}$ & LEP & \%LEP & Total School \\
\hline Peace MS & 136 & $22 \%$ & 619 \\
Jefferson MS & 192 & $18 \%$ & 1083 \\
Cardinal MS & 127 & $17 \%$ & 727 \\
University Prep MS & 149 & $14 \%$ & 1070 \\
\hline Note. LEP = limited English proficiency, Public Schools Data Books
\end{tabular}

\section{Site Selection}

Given the above mentioned data points, it was established from the district data books that two of the four middle schools had the highest percentages of immigrant LEP students enrolled. So the focus of site selection was on Peace Middle School and Jefferson Middle School. I drew upon trend data from the district's data books in order to analyze each schools' demographics.

The trend data for PMS in school year 2016-2017, the enrollment was 578 students with $12 \%$ White students enrolled, 27\% African-American students enrolled, 42\% Latinx students enrolled, and 0\% Other students enrolled. In school year 2017-2018 
the student enrollment was 586 with $14.8 \%$ White students, 26.9\% African-American students, 37\% Latinx students and 24\% Other. In school year 2018-2019, the student enrollment increased to 619, with $11.8 \%$ White students, $36 \%$ African-American students, 39.7\% Latinx students, and 12\% Other. Currently there are 136 LEP students enrolled and 130 ESL students enrolled.

Over the past three years, the total school enrollment of PMS increased by 41 students. The enrollment of White students remained about the same, the enrollment of African-American students increased slightly, while the enrollment of Latinx students has remained constant at approximately 40\%. PMS offers its' students gender specific classes for boys only, advance program, hands-on, project-based learning experiences, engineering and music program.

With that in mind, trend data from JMS showed an enrollment of 910 students in 2016-2017, 1079 in 2017-2018, and 1083 in 2018-2019. In 2016-2017, JMS' student demographics were $13 \%$ White, $17 \%$ African-American, 51\% Latinx and $18 \%$ Other. In school year 2017-2018, there were 10\% White students enrolled, 20.1\% AfricanAmerican students enrolled, 56.8\% Latinx students enrolled, and 17\% Other students enrolled. For school year 2018-2019, 8.3\% White students enrolled, 18\% AfricanAmerican students enrolled, 58.9\% Latinx students enrolled, and 14\% Other students enrolled.

Through these three school years, as the White and African-American student population decreased, the Latinx and Other student populations increased. At JMS, the school offered their students a broadcasting/journalism magnet program as well as 
advanced, honors and comprehensive classes. Currently, 192 LEP students enrolled and 176 ESL students enrolled.

With the data documented previously, the question remained how do middle schools reach out and involve their immigrant parents and family members? My participant selection started with the identification of the one middle school with the greatest enrollment of immigrant students, using the local district's secondary data. The reason this site was selected was that this school had the greatest number and percentage of immigrant students enrolled, therefore, the school would have offered more immigrant-specific programs. Additionally, the identified school should have offered a greater number of immigrant parent involvement activities than a school with fewer enrolled immigrant students. This was important because identifying the various ways PMS reached out to and welcomed their immigrant parents was the essential question of the study.

\section{Participant Selection}

While selecting the school site, it was obvious that the principal of the school be interviewed. It was also obvious that teachers who work directly with immigrant students and who communicate with immigrant parents be interviewed. Snowball sampling and homogeneous sampling were used to select participants (Glesne, 2011). When selecting school personnel, snowball sampling (Miles et al., 2014) was employed, in that, the principal was asked who he thought would be willing to participate in an interview. The principal recommended the youth services coordinator (YSC) and one teacher. Once the interviews of the YSC and teacher were concluded, both participants were asked if they 
know of any other teachers who would be willing to participate. The teacher provided names of two more teachers.

Homogeneous sampling was employed when selecting immigrant parent participants. According to Miles et al. (2014), homogeneous sampling focuses on participants with similar characteristics or belong to the same group. All teachers interviewed were asked if they knew of an immigrant parent who would be willing to participate in an interview. The teachers provided four names of potential informants. This was a combination of snowball and homogeneous sampling.

Additionally, snowball sampling was necessary, in that, the only way to communicate with, gain access to, or contact the immigrant parents was to ask the school personnel for information (Glesne, 2011). Snowball sampling was effective because the school personnel know the immigrant parents, developed relationships with them, and knew that the immigrant parents they recommended were likely to participate willingly in the study. As demographic information was gathered from the participants, in an attempt to better understand each participant's backstory and perception, I asked where each participant was born. This information allowed for an additional research opportunity to learn more about each participant's country and state of origin (See Table 2). 
Table 2. Demographic Information of Participants

\begin{tabular}{|c|c|c|c|}
\hline Participants & Race \& Sex & Birthplace & Enrolled \\
\hline Principal & White Male & Kentucky, US & NA \\
\hline Teacher \#1 & Black Female & Virginia, US & NA \\
\hline Teacher \#2 & Black Female & Kentucky, US & NA \\
\hline Teacher \#3 & White Female & California, US & NA \\
\hline $\begin{array}{l}\text { Youth } \\
\text { Services Coo }\end{array}$ & $\begin{array}{l}\text { White Male } \\
\text { dinator }\end{array}$ & Kentucky, US & NA \\
\hline Parent \#1 & Palestinian Male & Jerusalem & $\begin{array}{l}\text { one male } \\
\& \text { Female } \\
\text { student }\left(8^{\text {th }}\right)\end{array}$ \\
\hline Parent \#2 & Latinx Male & Mexico & $\begin{array}{l}\text { two male } \\
\text { students } \\
\left(6^{\text {th }} \& 8^{\text {th }}\right)\end{array}$ \\
\hline Parent \#3 & Senegalese Female & Senegal, Africa & $\begin{array}{l}\text { two male } \\
\text { students } \\
\left(6^{\text {th }} \& 8^{\text {th }}\right)\end{array}$ \\
\hline Parent \#4 & Latinx Female & Mexico & $\begin{array}{l}\text { two male } \\
\text { students } \\
\left(7^{\text {th }} \& 8^{\text {th }}\right)\end{array}$ \\
\hline
\end{tabular}

\section{Data Collection}

To collect primary data, school personnel of the identified middle school were invited to participate in semi-structured interviews. Those interviewed included the principal, youth services center coordinator, and the teachers who work with the schools' 
immigrant students. Additionally, school personnel were asked to provide names of immigrant parents who were active at their school and who may be interested in discussing the school's outreach efforts to address immigrant parent involvement. Furthermore, as interviews occurred, the identified immigrant parents were asked for additional names of potential immigrant parents who may have been interested in participating in the study.

Prior to conducting any interviews, the informed consent document (See Appendix A) was explained to each participant. Each participant was asked if they had any questions and then they were asked to sign the informed consent document. Once all questions were answered and the consent form was signed, a copy of the recruitment correspondence (See Appendix B and C) was given to each participant. There was a separate recruitment correspondence form for school personnel and a separate form for immigrant parents. Once this form was given and explained to each participant, the interviews commenced, using an interview protocol developed by the researcher of the study (See Appendix D and E).

Along with a consent form, recruitment correspondence, and interview protocol, data also were collected using an observation protocol (See Appendix F). The school events where observations occurred included parent teacher conferences, annual back-toschool bash, and a parent engagement meeting. In between conducting interviews, observations were being completed at the various school events.

Similarly, semi-structured interviews were conducted with participating school personnel (See Appendix D) and selected immigrant parents (See Appendix E). The interview protocols were developed, drawing from the work of Peterson and Ladky 
(2007), who explored school outreach for immigrant parents. The immigrant parents' presence at specific school events spoke to the fact that these immigrant parents expressed some measure of involvement. The observation protocol was created by the researcher based on the two theoretical frameworks-Epstein's (2011) typology of parent involvement and Yosso’s (2005) community cultural wealth (See Appendix F).

Moreover, any informal conversation and observation at the school site that was deemed pertinent to the study was documented on the observation protocol (See Appendix F). The school's environment, parent presence, interaction between immigrant families, and interaction between immigrant families and school personnel were recorded and analyzed. To prepare for this study, the secondary data from the local district were explored. These secondary data included the selected school's student demographics, state test scores, resides areas, programs offered, and teacher information in order to gain a better sense of the school as a whole.

Observations and interviews began once institutional review board (IRB) approval. As I visited each school event, data relating to the school environment was documented in a notebook and on the observation protocol to address the school's culture and climate. These data included posters on the walls, paint color of the hallways, how the classrooms were decorated, the entry way of the building, the exterior of the building, cleanliness of the building, and access to the building. The semi-structured interviews were conducted at locations most comfortable for the informant. Open-ended interview questions were used and were developed by the researcher of this study.

The open-ended format allowed for emergent data from the informant that could directly address the essential question of the study (Creswell, 2014). This allowed some 
leeway to ask additional related questions that may not have been part of the original interview protocol. Using the open-ended format allowed me to gain the opportunity to restate informant responses and confirm their meaning during the interview (Miles, Huberman, \& Saldana, 2014). The interviews were transcribed verbatim. To ensure trustworthiness, member checking or participant validation, as part of the data collection process, was employed. An electronic copy of the transcript was sent to each participant for their review, approval and feedback to ensure all collected data were accurate (Glesne, 2011).

At the beginning of each interview, introductions were made, names were shared, consent forms were explained and signed, recruitment documents were explained and the interviews commenced. Before the interviews began, permission was granted by the participants for the interviews to be recorded via researcher cell phone. A copy of the interview protocol was provided to each school personnel participant prior to each interview. For the immigrant parents, a copy of the interview protocol was emailed to an assisting teacher who worked at the selected school and shared with the immigrant parent. At the end of each interview, each participant's contact information was confirmed for the purposes of sending them a copy of the transcribed interview so each of the participants could validate and check its' contents (Glesne, 2011).

Embedding elements of Yosso's (2005) community cultural wealth and Epstein's framework (2011) throughout the data collection and data analysis process allowed for greater understanding of each immigrant family's traditions and beliefs, as well as parent involvement in general. Community cultural wealth, a tenet of critical race theory (CRT), centered on analyzing the experiences of historically underrepresented 
populations, such as immigrants and learning from their experiences and culture (Lumbreras \& Rupley, 2019). Lumbreras and Rupley (2019) believed that we must learn to listen and appreciate the wealth of knowledge immigrant families bring to education. Immigrant parent perspective was highlighted while specific family involvement strategies were identified and narrowed down to strengthen school personnel awareness. Parents are at different levels of parent involvement as well as have different parenting styles and routines. Teachers can serve as a "cultural bridge" between the home and school (Lumbreras \& Rupley, 2019).

Incorporating the two theoretical frameworks, community cultural wealth and Epstein's parent involvement model, connected the home and school for the benefit of the student. Home patterns and school outreach can support each for positive student outcomes for all students, especially immigrant students (Wong, 2015). Referring to and embedding the two frameworks honors each individual immigrant family. The two frameworks also provide each family with various ways to improve and strengthen their child's achievement, while exploring the many facets of how parents can be involved, contribute to, and be connected to their child's school. Integrating these two frameworks into the research methods as well as the constructivist framework helped to extract participants' lived experiences and create theory based on collected data analysis (Creswell, 2014).

I was afforded the opportunity to gain access and interview participants from the selected school, as well as conduct observations at several school-sponsored events after speaking with the principal of the selected school. While scheduling interviews with school personnel of the school regarding the outreach efforts their school offers and 
school personnel's perceptions of these efforts, I asked ask school personnel to identify some immigrant parents who were active in their school. I explained to school personnel that my goal was to interview the identified immigrant parents to obtain their perceptions of the schools' outreach efforts.

From this request, I was able to interview five school personnel and four identified immigrant parents. All interviews of school personnel occurred in the school building. Interviews of immigrant parents occurred where the parents were most comfortable. The immigrant parent interviews occurred in the home, at the workplace, and in the school building.

Observations were conducted at PMS' annual back-to-school bash, parent teacher conferences, and a parent engagement meeting. At the back-to-school bash, parents and family members were welcomed into the school building to meet school teachers, other school personnel and community health partners. The principal met each family and greeted them at the front door of the school building. The principal shook each and every person's hand. At the back-to-school bash, community partners, included the local police department, local dentists, eye doctors, and physicians offering information about immunization, physicals and eye exams. Toothbrushes and school supplies were passed out to every parent and family who attended. Music and food was also provided to each family who attended.

As I drove passed the school to find a parking spot, I was amazed at the long line of mothers, fathers, grandparents, students who attend the school, and older and younger siblings who were waiting in the line to enter the school. The line began at the front entrance of the school and wrapped all the way around the corner of the school to the 
back parking lot of the school. As families waited to enter the building, they held several conversations, in their native tongue, with each other. As I observed and listened, I was amazed at all of the different languages I heard. There were water stations on the school sidewalk for families to use while they waited in the heat.

Once parents entered the building, they sat at a table with school personnel to assess their needs. School personnel told them about the school, had them sign in and directed them to the gym, where the community partners were located. The community partners included YMCA, Girl Scouts, local eye doctors, local dental services, and a host of other services. For entertainment, there was a DJ playing music, someone was making balloon animals for the younger siblings, and in the back courtyard, lunch was served for all who came. In order for this event to be successful, it required that a large number of school personnel were present at the school to serve each family who attended the event. Also at the entrance table were two bi-lingual teachers to help with translation. This observation lasted two hours.

Another observation was conducted at a parent engagement meeting held by the school. This was their first meeting of its kind for the school. At this meeting, school personnel, which included the principal, assistant principal, three teachers and a parent, sat and brainstormed on how to better meet their parents' needs and keep their parents informed and involved. They planned two holiday events in an attempt to get parents into the school building and decided to provide parents and family members the opportunity to complete a needs assessment. During the observation, there was very little talk amongst the school personnel specific to how to include immigrant and refugee 
parents. There was talk, in general, regarding ways to get more parents involved in the school programs. This observation lasted one hour.

The final observation was conducted at the school's spring parent teacher conference day. Observations included sixth grade teachers talking with parents regarding their children's grades and behavior. Each parent who attended brought their child or children with them. Many of the parents had limited English-speaking skills, so each room had a bilingual teacher present to translate. Of course, the teachers did most of the talking, the parents did most of the listening, and the students sat and watched. Each teacher attempted to bring the students into the conference by asking them questions for the students to answer to show the parents that the students know what is going on in class. I observed eight conferences-all but one were immigrant parents or parents born in another country other than America. This observation lasted two hours and forty-five minutes.

Although relatively small, the sample size of my study shines light into educators and immigrant parents' perceptions and awareness within the local school district (Yin, 2014).

\section{Data Analysis}

The participants' view of the situation being studied is most important (Creswell, 2014), because perception is reality. Guided by the frameworks of Yosso's community cultural wealth and Epstein's framework of involvement, the words of each participant were actively listened to and recorded. Analysis and interpretation of each transcript was completed. From this analysis and interpretation, inductive codes emerged, which are discussed, in detail, in Chapter IV. Inductive reasoning was embedded to guide the 
collected specific interview data into broad generalizations. NVIVO12 qualitative software was used to organize and analyze the collected data.

The following figure (Figure 1) showed how two theoretical frameworks, Epstein (2011) and Yosso (2005) applied to immigrant parent involvement and their effects on student academic outcomes. With the increase in immigrant student enrollment, there was a natural need for increased immigrant parent involvement. This was based on research supporting the fact that parent involvement directly correlated to increase student achievement. The figure addressed biases and barriers to immigrant parent involvement that some school personnel may have possessed. Guided by deficit thinking, fixed mindsets, attitudes and perceptions can directly affect outreach efforts to involve immigrant parents. Guided by growth mindset, school personnel can enrich their immigrant parent involvement by embracing the change and learning from their immigrant parents and family members.

How school personnel think directly affected the effectiveness of the immigrant parent involvement efforts as well as what was offered to involve immigrant parents. With the growth mindset, school personnel had the opportunity to talk with and listen to immigrant parents to better meet their needs. Applying both six types of parent involvement and community cultural wealth theoretical frameworks added to the various ways to increase immigrant parent involvement as well as overall parent involvement. This application also added value and recognition to all parents of the school. Applying both theoretical frameworks led to increased trust, sense of belonging, and better, more effective outcomes for all students enrolled at this specific school. 
Figure 1. Two Theoretical Frameworks and their Application to Immigrant Parent Involvement

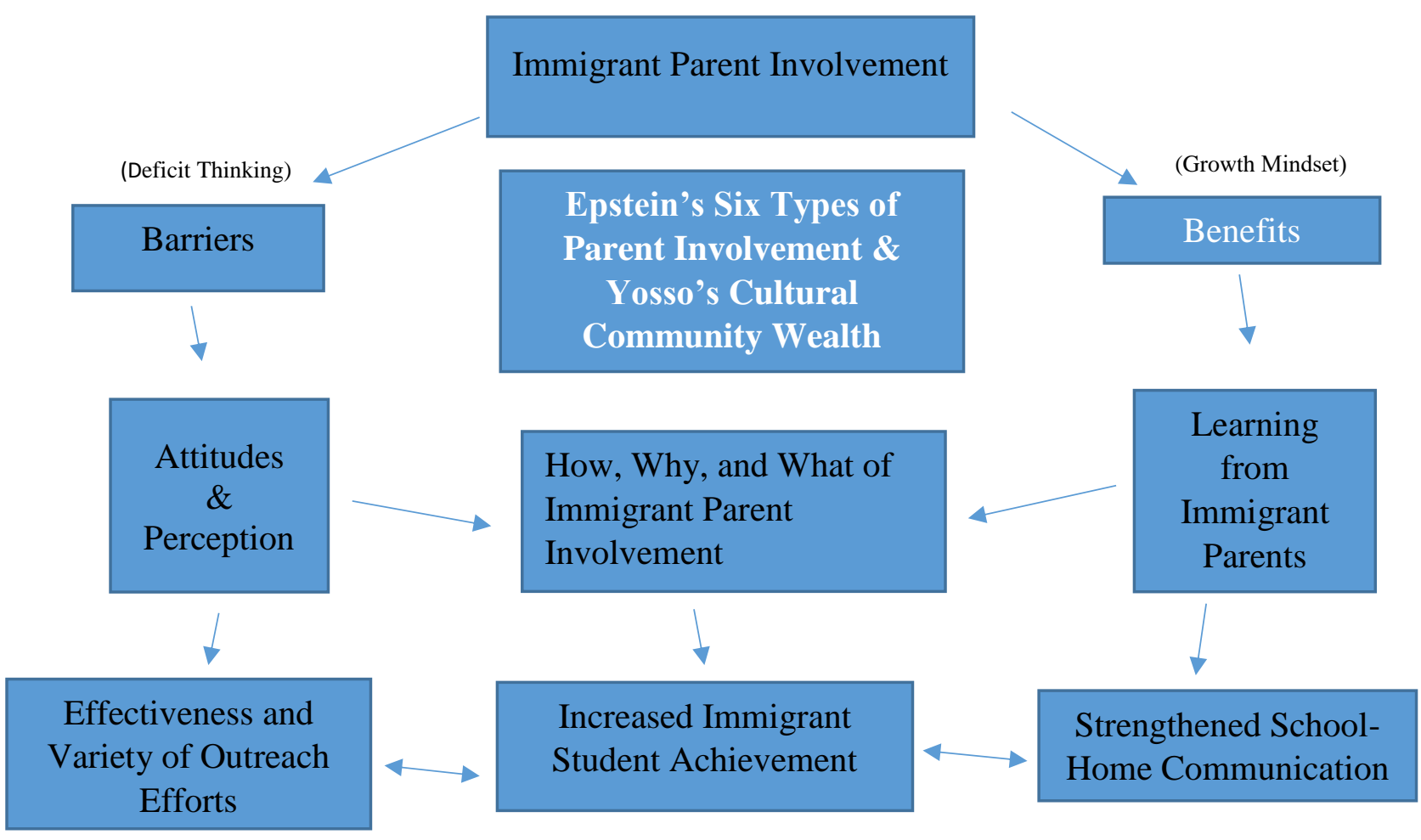

Figure 1: Two theoretical frameworks and their influence on immigrant parent involvement, by M.D. Franklin-Williams, 2018.

As the transcription process occurred, the collected data were assigned codes.

Miles, Huberman, and Saldana (2014) suggest that researchers start coding with general themes derived from the literature (etic codes) and then add more codes as the data is collected and analyzed by the researcher (emic codes). As the data were collected, I analyzed and organized the data to identify themes. This coding process allowed me to reflect deeply on the data and its organization. The coding process is a form of discovery that allows the researcher to condense data and enables the researcher to retrieve the most important and meaningful material (Saldana, 2013). This process occurred repeatedly to identify all themes. 
These phrases were documented within quotation marks to denote that they came straight from the participant. This demonstrated a brilliant way to honor the participants' voice. Using NVIVO12, each interview was analyzed line by line and deduced important codes or words (Glesne, 2011). From there, two cycles of coding were implemented, first codes were organized and in cycle 2, themes were identified. Prior to using NVIVO12, and as part of the provisional coding, a list of deductive codes were developed that were deemed important and would be represented during data analysis (Miles et al., 2014).

Descriptive, holistic, and provisional coding were executed to highlight each participant's perspectives and feelings about the subject, while capturing their philosophies about the specific topic and questions (Miles et al., 2014). Three types of coding were used to gain a well-rounded and real sense of how each participant really felt about their schools' immigrant parent programs. I gained knowledge of both participant groups' feelings about the outreach programs. From these, potential implications for practice, policy, and future research were synthesized.

Deductive codes were displayed during analysis in a table in Chapter IV. Both inductive and deductive coding were engaged to allow for emergent and theoreticallydriven codes and themes during the data collection and analysis processes (Miles et al., 2014). This was helpful when first looking at the raw data. I implemented two cycles of coding. The first cycle of coding focused on reading each line of each interview transcription and deciding under which category it belonged (Saldana, 2013).

This allowed the opportunity to complete the table of codes. The second cycle of coding focused on the relationships and analysis of each line that were present (Glesne, 2011). The second cycle of coding allowed themes to emerge. As interviews were 
conducted and concluded, the aforementioned process of coding ensued. Interview transcripts were reviewed for coding accuracy. Implementing cycles of coding allowed for accuracy and the opportunity for the researcher to analyze actual words and phrases from the participants and not leave anything out (Miles et al. 2014).

Along with inductive coding, I implemented deductive coding reasoning prior to data collection for organizational purposes and to create a list of starting codes to work from (Miles et al. 2014). This was done in an attempt to address my research questions and develop potential and specific conclusions to each research question. During careful review of my research questions, theoretical frameworks, and other factors, the initial codes were documented. Once data collection began, additional codes were created based on the collected data. The start list of inductive codes (See Figure 1) developed were parent involvement, middle school, immigrants, teaching, experience, and student achievement. Under each of these categories, subcategories were developed and used during the coding process (Miles et al, 2014).

The first cycle of coding began with the collected interview data being uploaded into NVIVO 12 (Bazeley \& Jackson, 2013; DeMatthews, 2018; Saldana, 2013). I purposely interviewed the school personnel first, then the parents. This was done so I could better organize the collected data and gain potential interview information from the school personnel. I determined since the school personnel worked directly with the immigrant students every day, they were my best chance of connecting with the parents to be interviewed. In-between interviews, I visited and observed at various schoolsponsored events to see the interaction and relationships of the school personnel and the immigrant parents. 
My groups were coded separately because I was able to schedule the school personnel interviews first, which led to my immigrant parent interviews. I did not want to confuse the groups and wanted to keep each role group grouped together, yet separate from each other to clearly identify emerging themes (Saldana, 2013). While conducting each interview, I used the recording device on my cell phone and recorded each participants responses so I would not miss any information the participants were sharing (Creswell, 2014). Once I completed each transcribed interview, using NVIVO 12, I coded each transcribed interview. I read each line of each interview and made the decision of which coding category each line best fit.

\section{Ensuring Credibility, Confirmability, and Dependability}

Credibility, confirmability, and dependability were addressed by providing substantiating evidence. Credibility was evident by data triangulation, which included semi-structured interviews, observations conducted, and participant validation in the form of member-checking (Miles et al., 2014). Credibility was evident in that the accounts of the study are clear, easy to follow, and make sense (Creswell, 2013). Confirmability was evident in the study's general methods and the ease of following the sequence of data collection (Miles et al., 2014).

The clarity of the research questions and the study design speak to this study's dependability. Dependability is another precept of trustworthiness. It focuses on stability and consistency of a study (Anney, 2014). To ensure dependability, I employed coderecode strategies and stepwise replication. Once I coded the data, I repeated the coding process at different times in order to assess whether the codes were consistent across both rounds of analyses. During this process, some codes were revised and new codes were 
created and added. Since the codes were similar, dependability was greater. Stepwise replication was also a part of my study. A peer researcher, Dr. Kathy Fisher (pseudonym) and Dr. Gary Stovall (pseudonym), doing similar research, analyzed the same data. From there, we analyzed and compared the results. The goal was for both data analyses to be similar, thus enhancing dependability (Anney, 2014).

Additionally, ensuring that member-checking was a part of the data collection process as well as peer review added to increased dependability (Glesne, 2011). Furthermore, observing at the selected school events regarding parent involvement outreach activities allowed for continued data collection and credibility.

Persistent observations ensured my study's validity and trustworthiness. By physically being at the site, using the observation protocol, recording notes of communication and interaction between school personnel and parents, greater insight was gained regarding the parent involvement culture of the school site. Observations were performed at three school-sponsored events. During these observations, I learned about the culture of the school and established trust and familiarity with school stakeholders. Triangulation of data were ensured (See Figure 2) by collecting data through observations, using my observation protocol, semi-structured interviews with school personnel and immigrant parents, and member-checking. The observed events included the school's annual back-to-school bash, a parent engagement meeting, and parent teacher conferences (Miles et al., 2014).

I sought to undertake observations at parent teacher conferences, family nights, PTSA meetings, and SBDM meetings. However, it was brought to my attention at various observations and discussion with the principal that there was not an active PTSA 
at this time. Additionally, because of persistently low state test scores, the SBDM of the school had been dissolved. The principal also informed me that I had already missed their family night where they meet with their parents to educate them on how to properly use technology issued to each student to use at school and at home.

\section{Figure 2. Data Triangulation}

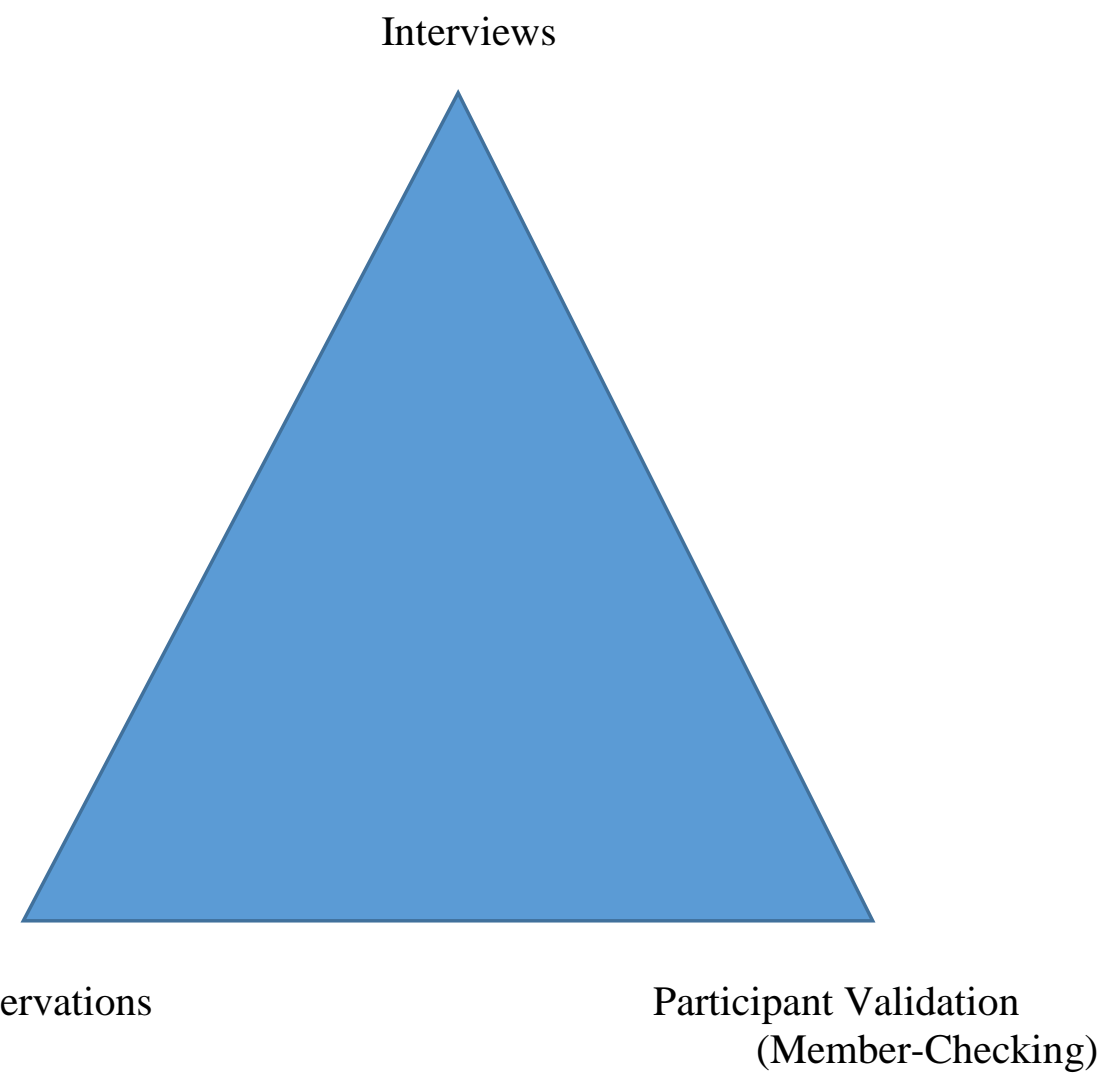

The figure above displays this study's triangulation of data. To increase the validity and trustworthiness of the study, semi-structured interviews, observations at school events, and member checking were performed (Glesne, 2011). Member checking, also known as participant validation, was a key component in this study's validity 
because it gave the participants the opportunity to provide feedback regarding the interview in which they participated. It also valued them and their participation in the study. Lastly, participant validation helped to confirm that the information they shared was documented accurately.

During the transcription process of this study, detailed descriptions were written to provide the reader descriptive entry into the context of the research (Glesne, 2011). With the assistance of the principal investigator of my study and continuous peer review, colleagues had the opportunity to conduct a thorough external audit throughout the research process to ensure validity and trustworthiness. These colleagues were two educators who recently earned their doctorates in education. Finally, member checking was implemented to guarantee and honor participant input. Accuracy and representation of each participant is very important to increase the validity and trustworthiness of this study (Glesne, 2011). During each interview, I obtained email information from each participant and explained to them to be expecting their transcribed interviews, via email, for them to read through and provide me with feedback. Each participant was willing to do so and was glad that I added that to our work.

\section{Ethical Considerations}

My study posed no ethical problem because of several considerations. Interviews were conducted with participant consent, comfort and convenience in mind-the place and time of the interviews were determined by each participant. Observations were performed at the participants' school, by invitation of the principal of the selected school. The goal was to ensure participant comfort and honor the participant's time as much as 
possible during the study (Creswell, 2013). And, for anonymity purposes, pseudonyms were used throughout the study, to protect the identity of all participants.

During the transcription process, all interviews were recorded with participant knowledge and once transcription was complete, member checking occurred. As stated above, each participant was provided the opportunity to review their transcribed interview data. This ensured information accuracy and ethical strength. I shared and discussed possible impact on student outcomes and middle school parent involvement, and its implications for future research with each participant so they were fully aware of why the study was being conducted in the first place. No harmful information or material was shared with participants and no intimidating tone was used.

The interview protocol was shared, via email, with school personnel. The protocol was shared with the immigrant parents at the beginning of each interview session. I asked the bilingual teachers to share the interview protocol with each immigrant parent, if possible, and review the document with them. The bilingual teachers were glad to help in this process. The goal was for each participant to feel relaxed, confident, and comfortable while sharing their experiences and perceptions of the outreach efforts of their school. My goal was to ensure that participants fully understood that their identity and privacy would be protected.

\section{Delimitations}

My study is delimited in the following ways:

Only one middle school served as the context of my study. The reason for this was the LEP student enrollment. This site had the highest percentage of LEP students enrolled. I 
chose the district because it was one of the largest public school districts, with the most diversity, in the state. Additionally, the selected school enrolls male students only.

I selected school personnel to participate in the study because they work directly with immigrant students and immigrant parents on a regular basis.

Only immigrant parents who provided consent to participate were included as participants in the study.

A variety of school events were observed. Observations occurred at the specific school's back-to-school event, a parent engagement meeting, and winter parent teacher conferences. From these events, the goal was to identify potential participants.

\section{Researcher Positionality}

As a middle school principal who works with immigrant students and parents all of the time, I have worked on retaining and supporting my immigrant population as well as other marginalized populations. I have experienced successes, failures, barriers, and difficulties with my immigrant parents. I always have worked to set aside time for parent voice and communication. When parents have questions and they request to speak with me, I do the best I can to honor them and call them back or fit them into my schedule to see if I can help them with their issue.

From assisting an immigrant family with completing a high school entrance application to having my school resource officer translate during a conference with an immigrant parent who speaks very little to no English, finding ways to serve the marginalized population of stakeholders was always a struggle. We, on many occasions, have relied on students to translate and communicate for us. All we can do is trust that 
they are delivering accurate information. Using Milner's framework, while performing this study, I constantly reflected, searched my views and my biases while keeping in mind the focus was on the larger social context. I had to separate my professional role from my graduate student role. I had to constantly remind myself of this and ensure that when I was conducting interviews, talking with participants, and observing at the schoolsponsored functions, I did so as a student and not as a principal, an active practitioner.

Middle school personnel and immigrant parents were interviewed and observed. I could relate to all of these types of informants because I am a principal, I am a parent, and I am a Black female, which, in many instances, represents another marginalized population. At my school, systems are in place to ensure that my immigrant stakeholders feel welcome, supported and have access to needed resources. We have an open door policy for any and all family members to come into our school and observe in the classroom, have lunch with their family member, and attend any and all school events.

Parents' and guardians' input is sought on a regular basis with regard to our school's strengths and weaknesses through informal conversation with our school resource office and whenever they visit our school. We send surveys and other vital information to the homes of all parents, remembering to send information home translated in other languages as needed. We rely on our district support to assist with translation and internet translation apps to do this. Also living in America during this time when immigrants are living in fear of deportation while trying to raise their children and build better lives for themselves and their families is at the forefront of my mind and my heart. This study is imperative because it gives voice to the immigrant parent. 
In order for me to be open to the school personnel's perceptions and points of view based on their experiences, and members of their immigrant population, I worked to pursue a more critical open mind that is accepting of their experiences and perceptions (Milner, 2007). To better understand the school's population used in this study, I learned more about the school and its' demographics by doing some research and talking with this school's stakeholders. This also included learning where the school's immigrant population hail from. According to Milner (2007), the research and work was presented with my participants knowing that my similar role and experiences are a part of the process and outcomes of education research. This served as both a positive and an innate bias.

I was aware and kept in mind that each narrative was valuable as data because they each exposed their life experiences, feelings, and perspectives. This drove home the fact that perception is reality. The immigrant parents who participated in this study trusted the teachers who work with their children. They trusted that the teachers would not put them in any danger, as part of the study relied on school personnel to recommend immigrant parents to participate in the study. The school personnel communicated with the immigrant parents, initially, to ask if they would participate and then the school personnel passed their contact information onto me. I, then, reached out to each immigrant family.

\section{Summary}

Chapter III outlined the methodology supporting the qualitative case study research, described my case study, and recorded the specific methods used to collect and analyze data. I presented in Chapter IV, the analysis of the collected data including 
responses of the case study participants and their views on middle school outreach efforts to involve immigrant parents. I addressed my research questions, shared the most frequently used codes, and displayed the emerging themes from the analysis. 


\section{CHAPTER IV: ANALYSIS AND FINDINGS}

The context of my study was one middle school, in a large urban school district in the southeastern United States of America. This middle school was selected because it has the largest percentage of enrolled immigrant students in grades 6 through 8 in the school district. In total, I conducted 9 interviews, 5 with school personnel and 4 with immigrant parents. To recall, the two research questions to be addressed are:

- What outreach efforts exist in one urban middle school to involve immigrant parents?

- What are the participants' perceptions regarding the current outreach efforts to involve immigrant parents of the selected middle school?

Two primary sources of data, semi-structured interviews and observations, along with member checking for participant validation served as means of triangulation for the study (Glesne, 2011).

The data were collected and analyzed concurrently (Miles et al., 2014). This process was done so that the data would be current, each interview experience would be remembered easily, and so the etic and emic documentation could be considered and analyzed simultaneously. Interview transcriptions served as the primary units of analysis for my study, so I wanted to ensure that no information or data being provided by the participants was missed (Lumbreras \& Rupley, 2019). NVIVO 12 was used to analyze 
the collected data. Once transcribed interviews were uploaded into NVIVO 12, inductive codes were developed initially and during the analysis process, deductive codes were added as part of the data analysis process (Bazeley \& Jackson, 2013; Miles et al., 2014). Specific code frequency resulted from the data analysis and themes emerged. Results of the data analysis were shared in three sections: Codes, Emerging Themes, and Results by Research Questions. A chapter summary followed.

Epstein (2011) highlighted the importance of communication between the home and the school. Immigrant parents participating in this study directly addressed this tenet of the six types of parent involvement by sharing their perceptions of the school's outreach that focused on them. In addition to the usual ways the school communicated with their parents, their voices were definitely heard as being a part of this study. One of Epstein's (2011) types of parent involvement centered on the school designing effective forms of communication about student progress. Asking immigrant parents to participate in this study and other programs strengthened the relationship between teacher and parent and built trust among the two groups. One parent shared that he liked the school because at one school event the principal asked him to share his childhood experiences with other parents. This parent shared that he felt really respected because he took that as the school personnel respected him and his struggle.

NVIVO 12 software was utilized to organize and analyze each transcript. Three types of coding were utilized-descriptive coding, holistic coding, and provisional coding (Miles et al., 2014). These three types of coding were employed concurrently during the coding process. Descriptive coding assigns codes or labels to participant's words or phrases (Miles et al., 2014). For example, one of the participants shared, with frustration, 
that there was no such thing as an honest day's work back in his native country. He said they were paid very little money for the long hours of hard work they did. He continued to say that for many years he had heard that in the United States, there is much more opportunity and more money for people.

The afore mentioned participant was responding to a question of why he came to the United States. As this parent spoke, I could see the passion and drive in his eyes and hear the inflection in his voice. This suggested that he was very determined to flee his birthplace no matter what. He had the attitude that no matter what, he and his family would be okay because they were willing to work for it. This response was coded under the categories of Parent Involvement-Parent Education (PI-PEE) and Experience and Immigrants-Beliefs (IMM-B).

Yosso (2005) stressed the need of education institutions to recognize and help students draw on the life experiences and wisdom of their family members. This helps to preserve the cultural traditions and beliefs of the immigrant families. Also, Yosso (2005) promoted opportunity for the education institution to learn more about the traditions and beliefs of the immigrant family. This also strengthens the connection between home and school. Yosso (2005) indicated that schools must honor immigrant parents' and immigrant students' experiences and allow the sharing of their stories as part of the education process.

The second type of coding used was holistic coding (Miles et al., 2014). Holistic coding applies a single code to large unit or sentence of data.

Teacher \#1 expressed: 
A lot of the teachers who are involved in leadership positions are involved in other leadership positions across other things in school, so there are so many roles that we have to take on here that, again, we don't have the time to dive deep into it. Plus, we don't have the support. I go again into the district, the things that they do don't always make sense. Maybe that is a state thing. Where we have been identified as a struggling school, so if we know we need support across the board, how are we being accountable to that information and where is the support?

This portion of text were coded under Teaching-Frustration (TCH-FRUST) and Teaching-Efficacy (TCH-EFF). It was evident that this teacher felt like teachers were working hard with no guidance or support, which led to teacher frustration and burn-out. Teachers wanted to help their immigrant students and build relationships with their immigrant parents, but questioned if there was time and support to address all of the requirements from the state that accompanied being identified as a struggling school based on state test scores? This is where Epstein's six types of parent involvement become relevant to the analysis. According to Epstein (2011), collaboration with community members helps to coordinate resources and assistance with regard to social support, community health, and other programs and services. Having community partnerships would address the need of assisting struggling students and families, thus directly affecting more positive student outcomes (Epstein et al., 2009).

The third type of coding used in this study was provisional coding (Miles et al., 2014). Provisional coding was implemented when the list of researcher-generated codes prior to data analysis was created. These specific inductive codes were based on what the preliminary investigation suggested. As data analysis occurred, the originally created 
codes were modified and revised, as well as new deductive codes were added based on participant interview data. The researcher-generated codes separated into six categories: Parent involvement, middle school, immigrants, teaching, experience, and student achievement. Under each category were several subcategories (See Table 3). As data analysis occurred, deductive codes emerged (See Table 4).

Table 3. List of Inductive Codes

\begin{tabular}{|c|c|}
\hline Inductive Codes & Abbreviations \\
\hline Category: Parent Involvement & PI \\
\hline Motivation & PI-M \\
\hline Parent Involvement Perception & PI-PIP \\
\hline Category: Middle School & MS \\
\hline Programs & MS-P \\
\hline Communication & MS-C \\
\hline Category: Immigrants & IMM \\
\hline Beliefs & IMM-B \\
\hline Culture & IMM-C \\
\hline Traditions & IMM-TR \\
\hline Category: Teaching & $\mathrm{TCH}$ \\
\hline Parent as Teacher & TCH-PAT \\
\hline In Loco Parentis & TCH-ILP \\
\hline Motivation for Student Success & TCH-M \\
\hline Teacher Reflection & TCH-R \\
\hline
\end{tabular}


Category: Experience

Interactions

Volunteerism

Teaching Tradition

Category: Student Achievement

Belonging

Work Completion
EXP

EXP-INT

EXP-V

EXP-TT

SA

SA-BEL

SA-WC

Note: Coding structured model (Miles et al., 2014) 
Deductive Codes

Abbreviations

Category: Parent Involvement

PI

Parent Perception of School/Trust

PI-PPS

Parent Education/Experience

PI-PEE

Parent Sense of Belonging

PI-PSB

Parent Efficacy

PI-PE

Category: Teaching

$\mathrm{TCH}$

Teacher Frustration

TCH-FRUST

Teacher Professional Development

TCH-PD

Teacher Perception of IS \& IP

TCH-PSP

Teacher Expectations

TCH-EXP

Teacher Knowledge of Students

TCH-KOK

Teacher Efficacy

TCH-EFF

School Outreach

TCH-SO

District Outreach

TCH-DO

Teacher Trust of IP

TCH-TOP

Teacher Welcome IP

TCH-WIP

Note: Coding structured model (Miles et al., 2014) 
The parent involvement category focused on what motivated parents to be involved, parent perception, parent trust of the school where their child was enrolled, parent efficacy, and parent sense of belonging at the school. The middle school category focused on the middle school programs offered to students and parents and the types of middle school communication with parents. The third category focused on immigrants' community cultural wealth and immigrant parents' beliefs, culture, and traditions. The next category was teaching and it focused on the various aspects of teaching from the teacher and parent standpoint. This category also focused on teacher perception of immigrant families.

Experience was the next category and it focused on building relationships, interactions between teacher, student, and parent, and ways teachers and school personnel attempt to meet the needs of their immigrant populations. The last category was student achievement. Since the main student outcome is growth and achievement, this was a very important code to add. This code involved student sense of belonging and student work completion. These codes were created, revised, and added based on participants' interviews and previous research and investigations (Miles et al., 2014).

As stated previously, the two groups were coded separately to ensure that no details were lost, to ensure deep analysis, and to protect the interpretation of data meaning (Miles et al., 2014). School personnel, being educated in similar, accredited universities would, more than likely, share similar ideas about how they reach out to their immigrant parents and families. Some felt that they were doing all they could to involve all parents, while others felt that their school could do more. Their responses had to be coded separate from the immigrant parents because each group is coming from a different 
perspective. Each informant also possessed different points of view, life experiences, and values.

The data suggest that the school personnel viewpoint was more wishful thinking. School personnel knew of the programs they offered for their immigrant population and how they went above and beyond to make sure that their immigrant population felt included. The immigrant parent viewpoint was the actual result, perception, and feeling of how the middle school was actually reaching out to them. The question to be answered was whether or not the programs sponsored by the school to welcome the immigrant population were actually doing what these programs set out to do. Are the immigrant population programs effective and welcoming?

One of the questions asked of each school personnel was regarding them providing me with names of potential immigrant parents to interview. That did not go as planned and took much longer than expected. During the interviews, each school personnel gave a very confident answer of yes to the question, yet none of them followed-up initially. I had to ask several times to get names of potential immigrant informants. Finally, names starting coming in. The first interview took place in the home of an immigrant Palestinian parent. As the father participated in the first interview, his family sat quietly nearby and listened in. As I entered their home, I observed the front room to contain two small couches, a bed, and a large dining table. That let me know that several activities occurred in this one room. Based on my observations, these activities may include entertaining guests, family dinners, and sleep.

The father was very inviting and was eager to share his experiences. As the father listened to the interview questions, he had me repeat or restate some of the questions 
from the interview protocol. He stated that he wanted to make sure he understood exactly what I was asking him. At the end of the interview, which took about an hour, the mother asked me to stay and have dinner. Out of respect, I said yes.

In Figure 3 and Table 5, visual and tabular frequency representation of each code was shown. NVIVO 12 software was employed to create a colored and sized representation to distinguish between each code and sub-category. Table 5 displayed the number of times each code was referenced during the coding process. 
Figure 3. Visual Frequency of Coding

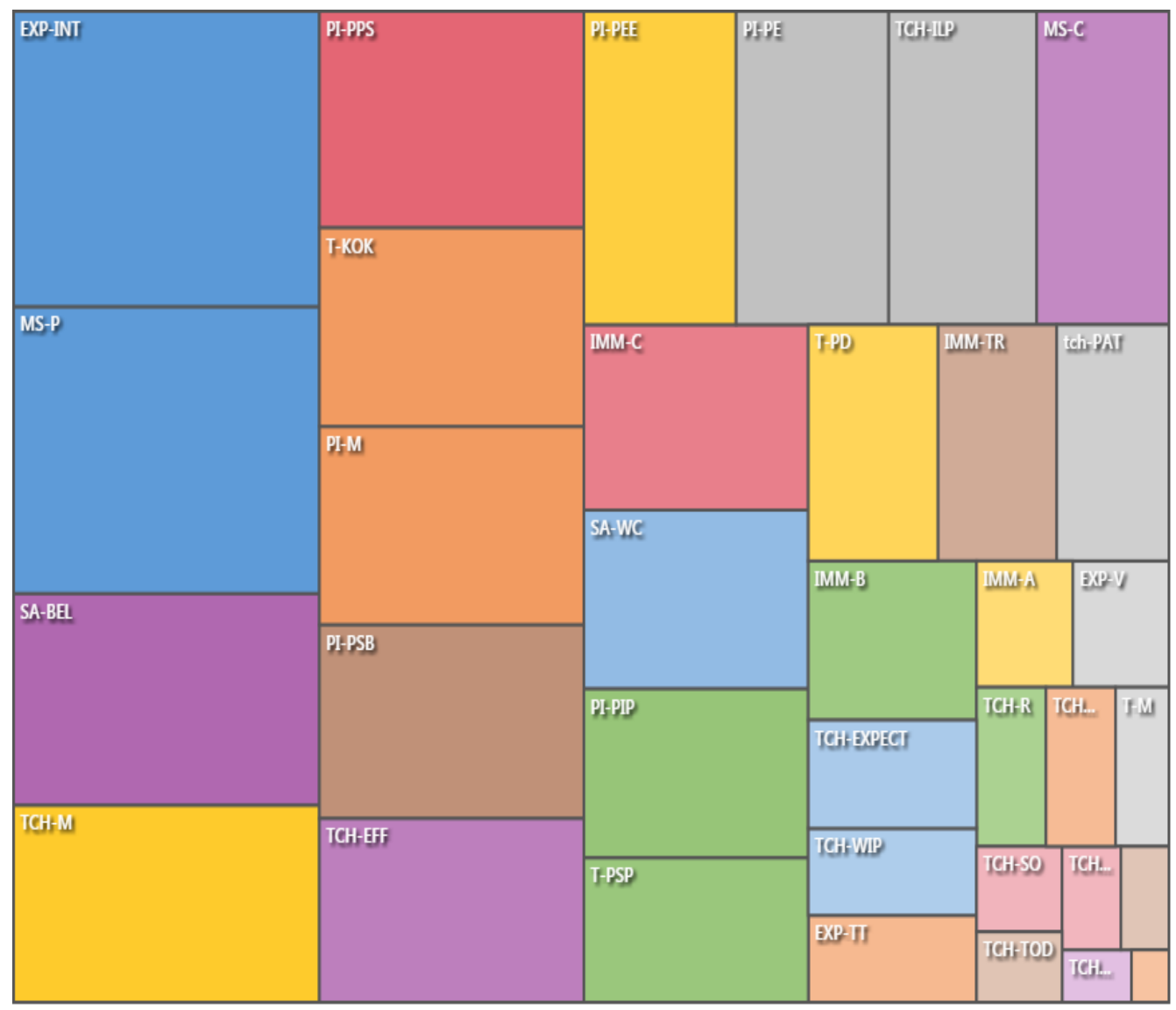


Table 5. Most Frequently Referenced Codes

\begin{tabular}{llc}
\hline Code & Abbreviation & Frequency \\
\hline Experience-Interactions & EXP-INT & 74 \\
Middle School-Programs & MS-P & 72 \\
Teacher-Motivation & TCH-M & 57 \\
& & 53 \\
Student Achievement/Sense of Belonging & SA-BEL & \\
& & 47 \\
Parent Involvement-Parent Perception & PI-PPS & \\
\hline
\end{tabular}

Note. NVIVO 12 analysis 


\section{Codes}

Based on the codes referenced above (Figure 3), the five codes that emerged most frequently were Experience-Interactions (EXP-INT), Middle School -Programs (MS-P), Teacher-Motivation (TCH-M), Parent involvement-parent perception of the school (PIPPS), and Student achievement-sense of belonging (SA-BEL). The participants' transcribed interviews resulted in the experience-interaction (EXP-INT) code being assigned 74 times, the middle school-programs code (MS-P) being assigned 72 times, teacher-motivation code (TCH-M) was assigned 57 times, student achievement-sense of belonging code (SA-BEL) was assigned 53 times and parent involvement-parent perception of the school (PI-PPS) was assigned 47 times.

Based on the transcribed interviews of both groups, five codes had the highest frequency of reference in this study. Let us explore these codes more closely.

Experience-Interaction (EXP-INT) referred to building relationships and talking with others. In many cases, this is the one mechanism that increased communication and trust-the ability to make someone feel welcome (Wong, 2015). In many cases, the connection between the school and home is the key to increased student achievement. One of the interview protocol questions for the parents asked if they felt welcome at their child's school. All of the parents answered positively based on the interaction with the school personnel. One parent stated, "Yes! They love me there!" Another parent responded, "Yes, I feel very comfortable there!” Another parent responded, "They are always sending things home for us."

Middle School-Program (MS-P) emerged frequently based on participant response. This code referred to the programs offered by the middle school. For example, 
many schools have tutoring, sports and academic teams, translation services for families, conferences, open house, back to school events, multicultural events that highlight different cultures, and committees on which students and parents may participate. This also referred to magnet and special academic programming for students. The parents interviewed in this study expressed overall satisfaction with the middle school program. Parent \#1 added that even though he liked and supported the school, he stated "the school needs to control the bad words that other kids say. Plus they talk too much in the class when the teacher is teaching." This parent stated he agreed with whatever the school said because in his home country, school was a privilege to attend. Not everyone was afforded the opportunity to go, so he appreciated the teachers' hard work.

Teacher \#3 added:

I schedule kids based on their ability. I try to look at what we are trying to achieve with certain classes. I have a class where they are all one or two year of each other. There are three categories-straight out of Newcomer, intermediate, and ready to go into regular class. Based on language groups. A lot of targeted groupings, groups by their access scores and for enrichment and intervention, their MAP scores are used to group. I prefer to use MAP, because it's more specific and current. There are two types of language - "bix" language to get your needs met such as "Can I go to the bathroom? Where is my jacket? And "kalp" academic language - which take a lot longer to master than "bix". i.e., similes and metaphors, etc.

Teacher-Motivation (TCH-M) was a code with the third highest frequency. This code represented the teacher or any school personnel who was willing to go above and 
beyond to ensure that each student succeeded and that parents were informed about what was going on in the school. Lumbreras and Rupley (2019) stated that teachers must be "cultural bridges" for their immigrant students and families; teachers must be adults who fight for immigrant students and families no matter what. In this code was also teacher efficacy. Teachers have to have the confidence to increase student sense of belonging and achievement.

Teacher \#1 stated:

I think they [immigrant parents] can help by just taking a chance on me, that I will have your son's best interest at stake, take a chance on me that I'm trying to work hard for your child and that if they could give me a mustard seed of that, well, you know what they say about mustard seeds. That moves mountains. So if I could just have just a little bit of that, that's all I need.

Student Achievement-Sense of Belonging (SA-BEL) was the next most frequently used code. Research supported when students possessed a sense of belonging in their schools, student achievement increased (Hos, Murray-Johnson, \& Correia, 2019). Teacher \#1 shared a brief story of why she became a teacher. I asked did she know she wanted to be a teacher when she was in high school.

She replied:

Oh yes! Because again, I really, really liked my teachers and then I saw the impact of what a bad teacher does. I experienced it first hand and so I did not want that for children that would look like me or children I gave birth to. 
The fifth code that emerged most frequently was the Parent Involvement-Parent Perception of the School (PI-PPS) code. Based on parental experience and their children's stories of what happened at school, parents listened to their children when judging their child's school and the school's programs (Wong, 2015). Parent perceptions of their child's school were determined by their own lived experiences, information communicated by the school, and interactions between parent and school personnel. Parent perception was also determined by interactions experienced by their children attending the school. Parent perception of the school was also impacted by current immigration enforcement. Parents were questioning whether or not their local public school was really a safe place, especially with the current administration's threats of deportation (Sanchez, Freeman, \& Martin, 2018).

Two of the four parents interviewed chose to be interviewed on school property. I attribute this to possibly a strong relationship between school personnel and the parent and the hope that the parent felt comfortable participating on school property, in the library or classroom, because of this specific school's outreach efforts. One of the parents, specifically, stated that he would not do the interview if the teacher could not be present. This demonstrates trust and comfort.

Parent \#3 stated:

Yes! I rarely come into the school, but when I do, staff is very helpful and always smiling. The school sends out a weekly parent newsletter and has a website. I check those from time to time. Or I will call the school. The office staff knows me, so they are helpful.

Parent \#4 responded to the question of where his child studied: 
At the kitchen table. My middle schooler stays after school for tutoring 4 days a week, which I love. He gets help with his school work and I get free childcare in a place that I trust. So when he gets home, he helps the younger ones get their work done.

Another question Parent \#4 responded to was if she was able to help her child with their homework. She responded:

Yes, when I have to, but thank goodness, I don't have to. After school tutoring takes care of that. They even give him a nice snack afterschool before tutoring. Now that I think about it-I really like what his school offers. They make it easy on me.

\section{Emerging}

Five major themes that emerged from my data analysis are:

- Immigrant parents trust and rely on teachers at the school

- School personnel and immigrant parents want what is best for their students

- Needs assessment is necessary to better identify needs of immigrant parents and families

- Specific school programs and outreach efforts are needed focused on immigrant families

- Immigrant parent input and voice is needed to ensure programs ae developed that respect immigrant families culture, beliefs, and traditions. 
The data revealed that the immigrant parents trust their children's teachers and the school programs in which their children participate. The parents spoke positively about the afterschool tutoring and the fact that the tutoring has many benefits. The afterschool tutoring provides their children with the chance to complete and understand their schoolwork, as well as act as childcare until the parents can come and pick up their children. One parent was grateful that the principal had asked him to participate in the cultural fair, allowing this parent to share his culture and traditions (Epstein, 2009). Based on the parent responses, the parents expressed trust in the teachers more so than any other school personnel.

The data revealed that both school personnel and immigrant parents want only the best for their children. After listening to the principal, teachers, YSC, and immigrant parents, it was evident that each group wants what is best, but don't exactly know what the answer is. Which leads to the next emerging theme. In order for school personnel to effectively involve immigrant parents, school personnel must know the needs and dreams of the parents. A needs assessment is necessary to better serve the immigrant parents. From the needs assessment analysis, specific programming can be explored to ensure increased immigrant parent involvement (Epstein, 2009).

Some immigrant parents may need assistance with housing, food, school supplies, information regarding school programs and extracurricular activities, child care, healthcare, and employment (Moncloa, Erbstein, \& Subramaniam, 2019). Implementing a needs assessment or asking parents to complete surveys after parent teacher conferences, open house, or any school-sponsored events gives school personnel vital information needed to better serve their immigrant population. There should be a needs 
assessments for all stakeholders-parents, school personnel, and community partners. A needs assessment also lends itself to greater cultural competency and cultural proficiency within the schools, depending on what school personnel do with the collected assessment data (McAllister-Parsons, 2019). How can you serve your customers and how can you know your stakeholder's needs, if you do not ask for their input? Lastly, a needs assessment provides direct stakeholder involvement.

In order to build trust, all stakeholders need to be heard. To increase parent involvement and trust, parents' voice must be heard (Moncloa et al., 2019; Snell, 2018). Parents need a platform, like a survey, school event, or committee, to share their opinions and voice. The principal and Teacher \#2 shared that all of their school programs are geared towards all parents, but there is nothing specific to immigrant parents. There was some concern from Teacher \#1 about the fact that the school did not have Parent Teacher Conferences in the fall. Teacher \#1 had to ask the principal if she and her team could have conferences in the spring semester. At conferences and other outreach events, great opportunity is provided for parents to ask questions, feel welcomes and wanted, and learn about the content their children are learning (Crea, Reynolds, \& Degnan, 2015). When parents are not afforded these opportunities and are left out of the conversation regarding their children's educational journey, a connection is lost between the home and the school (Crea et al., 2015) and community cultural wealth is threatened.

Teacher \#2 shared that she acts like a surrogate for her immigrant students and parents. She shared that prior to one of the multicultural fairs, she would call the parents and personally invite them to the event. She would also ask them if they would like to participate-dance, share recipes, cook and bring a native dish, or share a form of artwork. 
She shared that to do this, she relied heavily on the school's bilingual instructors. This was her way of making immigrant parents feel welcome and allowing them the chance to show a side of themselves and provide the school with input (Yosso, 2005).

Teacher \#1 expressed concern when she talked about how welcoming the school is to immigrant parents as well as all parents.

She added:

The warmth is within the classrooms with the students, but it is not warm with the parents. Like our student feel welcome but that's because when my students come in they have built relationships with safe adults. Our parents are coming to, again not very warm, previously stark white hallways, like a hospital view type environment. They are coming into a sterile environment where they don't know if they can trust or communicate with the individuals in the school. They don't know if there is a willingness for the teachers here to build a relationship with them.

Teacher \#1 went on to say:

We have tried this many, many, many times and it has fallen through every single year. But I think with more hands on deck, with more teachers saying yes this is what we need in our classrooms, and teachers willing to educate themselves on what our families need and what we can do for them, then we can start building an environment where our immigrant and refugee parents feel welcome.

The data revealed that other than willing, dedicated, hard-working teachers, there are no specific programs or outreach specific to immigrant parent involvement. Teacher \#1 shared her frustration with this fact. She shared that even though they meet and 
discuss, nothing comes to fruition when it comes to increasing immigrant parent involvement and intentionally attempting to make them feel welcome and comfortable at the school. Teacher \#1 spoke from the voice of someone who wants to do what is right for each of her students and their parents, yet gets little to no support or resources to make this happen. She shared that the orientation is not what the immigrant parents need. She said they come because they have to, not because they feel like they are a part of the school community.

What emerged was evidence of two groups and two sets of perceptions. The school personnel, overall, felt like they were not doing enough, yet the immigrant parents, overall, were satisfied with what the school had to offer and how their children were treated. The immigrant parents, based on their experience and how their children feel, were content with the school and the school personnel. The school personnel, knowing what was lacking or what more should be done, were not happy with the school's effort to involve immigrant parents. There is a sense that each school personnel member wanted to do more, but did not quite know what else to do with the resources they had available. According to Snell (2018), even though there are clearly two different perspectives from the two groups, this study exposed stakeholder perception and took into account the perspectives and ideas of parents as well as school personnel.

One overarching theme to this study could have been the current environment of fear in which many immigrant parents live (Fernandez \& Paredes Scribner, 2018). With threats of deportation or ICE raids or possibly ending up in a detainment camp, a question arose regarding if the immigrant parents who participated in this study felt comfortable enough to be honest when they responded to the interview protocol questions? There is a 
possibility that each immigrant parent spoke highly of the school and its efforts so as not to draw negative attention to themselves or it could have been that the immigrant parents wished to remain in compliance and not stand out. As stated before, it was stressed to each participant that pseudonyms would be used to protect their identity. According to Sanchez et al., (2018), living in fear of possible separation from your family takes a toll on one and decreases one's visibility in the school and community as well as trust of others.

\section{Results by Research Questions}

In addressing the two research questions of the outreach efforts to involve immigrant parents and participant perceptions of these outreach efforts, school personnel's responses were analyzed. The principal, who had been in this position for more than five years, shared the demographics of the school. The principal shared that there were 619 students enrolled, $40 \%$ of the students were African-American, $32 \%$ were White, and the rest were classified as Other, in his words. Forty percent of the total population made up the special education (ECE) and English as a second language (ESL) students. This broke down into 21\% ESL students and 19\% ECE students.

The principal went on to say, "We get usually two notifications per week saying "this new student for ESL is being assigned to your building so it continues to grow." The principal inferred that this process is sometimes overwhelming because it makes it almost impossible to keep up with the influx of immigrant students, thus school personnel struggle to meet each new immigrant student's needs. After the notification, usually the immigrant students show up at the school parentless. The principal said that in many 
cases, there is a fight to get enrollment forms completed and returned to school. They also have trouble reaching parents via phone or email.

The principal continued that, within the last five years, there has been a shift in enrollment from immigrant students to refugee students; with this shift comes more challenges. These refugee students need more support, a different kind of support than other students. The principal and the staff rely heavily on their Youth Service Center Coordinator (YSC), who addresses student need by reaching out to their parents. "The YSC can give you a good idea of all the amazing things he does for our students and families." The principal spoke very highly about the YSC.

I asked the principal to expand upon what he said about the refugee students needing more support. The principal shared, with frustration, that with the number of ECE and ESL students enrolled in the school, there was never enough funding or staff to adequately work with these special populations. In the last year, there were $110 \mathrm{ECE}$ students with only eight ECE teachers, 130 ESL students with only 2 ESL teachers and 4 bilingual teaching assistants.

The principal stated, "We paid for a third ESL teacher out of our school-based allocations. The ESL department has bumped us up to four bilingual assistants, but it is not nearly enough."

The principal responded to another question I asked. What opportunities do you create for your immigrant or refugee parent population to be involved in classroom activities? The principal stated that regarding classroom activities, they had very little participation for immigrant parents within the classroom. The principal shared that in the 
past, they had Peace family mornings which invited parents into the building to have donuts and juice with their students.

The principal shared that they had a large population of students who don't live with their biological parents, so they focused on calling this event family mornings to include everyone. This event was held four times throughout the school year. Background checks were not necessary. The principal shared, with concern, that many of their parents, immigrant or not, may apply to volunteer at the school, but are denied for undisclosed reasons. Peace Middle School started Peace Family mornings because it was easy to do, very inviting, and allowed family members to come into the building and see their children and a few teachers and administrators. The event is very informal and provided the opportunity for conversation and communication.

The principal continued to say that they have had a big parent involvement activity regarding a new one to one electronic devices initiative offering digital citizenship to both students and parents. As part of this initiative, each parent had to come to the school, learn about the device and how to care for it, and sign the agreement that they would be responsible for the device. But as far as events specifically focused on immigrant parents and their involvement, those do not exist at this school. Their goal is to involve all parents. The principal cited the vast amount of different languages as a huge challenge.

\section{Summary}

In Chapter IV, I presented a detailed account of the results from nine interviews and school-based observations. Data triangulation stemmed from semi-structured interviews of school personnel and immigrant parents. These data collection methods 
revealed five codes most frequently referenced across all forms of data. The five codes were: 1) Experience and Interaction (74 codes) (i.e. interactions and positive connection), 2) Middle School Programs (72 codes) (i.e. programs offered for students and parents), 3) Teacher Motivation (57 codes) (i.e. Teacher motivation to ensure that immigrant parents are involved and immigrant students achieve), 4) Student Achievement and Student Sense of Belonging (53 codes) (i.e. student efficacy and feeling like a part of the school community), and 5) Parent Involvement and Parent Perception of the School (47 codes) (i.e. Immigrant parents perception of the school climate and culture).

From these codes, the data analysis yielded five overall emergent themes. The themes were immigrant parent trust their child's teachers, school personnel and immigrant parents want what is best for their students, a needs assessment is needed to better serve immigrant parents, the need for school programs and outreach efforts specific to immigrant families, and immigrant parent input and voice is needed to ensure schoolsponsored programs are developed that respect immigrant culture, beliefs, and traditions, especially at schools where there is a high percentage of enrolled immigrant students.

One of Epstein's (2009) six types of parent involvement, volunteering, included the need for parents to have the opportunity to provide feedback to their associated education institution to identify strengths and areas of improvement that meet stakeholders' needs, thus leading to positive student outcomes. Yosso (2005) posited that including parents and family members in school programs assisted students in drawing on the wisdom and experiences of their home communities, thus promoting confidence and success during their educational journeys. 
My study centered on the semi-structured interviews. To support these interviews, additional data were gathered for triangulation. Observations were performed to capture interactions between immigrant parents and school personnel at schoolsponsored events. Member-checking or participant validation was implemented to reinforce the data collection process. It was imperative that each participant have the opportunity to read through their transcribed interview.

Each participant had the opportunity to provide feedback for the transcribed interviews. Participant validation created the environment that honored what school personnel and immigrant parents had to say (Yosso, 2005). Additionally, semi-structured interviews and participant validation invited immigrant families to participate and let their voices and stories be heard (Yosso, 2005). Through the process of a two cycle coding scheme and data triangulation between the three data entities, the chance of increased biases were greatly reduced (Creswell, 2013, Miles et al., 2014). 


\section{CHAPTER V: DISCUSSION AND IMPLICATIONS}

\section{Summary of Findings}

In this chapter, I summarized the analysis and findings of the study and discussed their implications for educational practice, implications for policy, and implications for future research. Limitations of the study were presented, along with a chapter summary. The research questions addressed in this study were:

- What outreach efforts exist in one urban middle school to involve immigrant parents?

- What are the participants' perceptions regarding the current outreach efforts to involve immigrant parents of the selected middle school?

This qualitative case study sought to identify and analyze the specific outreach efforts of one middle school in Southeastern United States of America. This case study also sought the perceptions of the selected school's two stakeholder groups-school personnel and immigrant parents-regarding the immigrant parent outreach efforts. Additionally, this case study used Epstein's (2011) Typology of Involvement and Yosso's (2005) Community Cultural Wealth as the two theoretical frameworks. These two frameworks were chosen because they focused on parent involvement and student success. Each theoretical framework focused on how schools and institutions provided outreach for parents. Each of these frameworks promoted high educational aspirations 
despite persistent education inequities. Each theoretical framework seek to meet parents where they are, as parents come to school from a variety of experiences and backgrounds, respect and understand the beliefs of parents, identify what parents have to offer schools, and what schools can learn from increasing parent involvement.

\section{Outreach Efforts}

The findings of this study revealed that school personnel of this select middle school offered outreach efforts for all parents. School personnel found several ways to welcome parents into the school building. These efforts were in the forms of parent teacher conferences, school-sponsored sporting events, back-to-school bash, ad hoc committee meetings, and technology night, where students were issued their own technological device to use at school and at home. Parents were required to attend this event to sign for and learn about the device issued to their child. It was revealed that at these outreach effort events, there were several translators to assist school personnel and immigrant parents as needed.

As part of the parent teacher conferences, immigrant parents and school personnel were assisted by translators to communicate student progress and answer any questions that parents may have. Translators assisted with making sure immigrant parents understood teachers' answers. School personnel had designed an effective was to communicate student progress and information regarding additional school programs to their immigrant parents (Epstein, 2011). At the back-to-school bash, at the sign-in table, there were translators ready to assist in communication. Once again, an effective way to connect immigrant parents and school personnel was established. 
Similarly, this process of providing translators strengthened immigrant parent linguistic capital because it showed the immigrant population of the school that their culture and language preservation was important to the school (Yosso, 2005). Likewise, this action also showed that the school personnel valued communication between the home and school. The principal shared that, when possible, school literature was sent home in the primary languages of several immigrant families. The principal shared that this process was difficult to continue because the process to get literature translated took too much time because it was translated by the school district materials and production office. Because this office had so many requests from many different schools across the district, this process took considerable amounts of time to get the literature back in a timely manner, the principal made the decision to discontinue this service.

\section{Perception of Outreach Efforts}

School personnel perceptions of outreach efforts were concentrated on communicating with immigrant students and immigrant parents, while building trust with the immigrant student. The interviewed school personnel shared that there were programs developed, yet none specifically developed to meet the needs of their immigrant population.

Immigrant parent perception of outreach efforts was one of trust and confidence in school personnel. The immigrant parents whose children were enrolled in the selected school were happy with the programs offered and relationships formed between the school personnel and their children, as well as, between school personnel and the immigrant parents themselves. Originating from the fact that the immigrant parents involved in this study were simply thankful to be in the United States where they felt 
some sense of safety and opportunity, they were satisfied that their children had teachers who took care of them every day and offered different opportunities for their children to be successful on a daily basis. Each immigrant parent shared their respect for the school personnel. The immigrant parents' statements inferred that what they had now was much better than from which they came. For these immigrant parents and many other immigrant parents who seek asylum in the United States of America, the public school system where their children are enrolled is truly a "safe place". The immigrant parents shared their happiness that their children could join the soccer team, could participate with the quick recall team, and could stay after school for free tutoring, where they were offered a snack.

Analysis of data from the two stakeholder groups (school personnel and immigrant parents) revealed thought-provoking perceptions of the outreach efforts of Peace Middle School. Educator informants suggested that immigrant parents trusted school personnel, where their children were enrolled, to educate their children and prepare them for their futures. Immigrant parent informants shared information about the school's outreach efforts. The interviewed immigrant parents wanted their voices to be heard. These immigrant parents demonstrated their efficacy and inclination to share their experiences, while expressing their wants and hopes for their children. Immigrant parents, just like American parents, have expectations and aspirations for their children (Outley \& Skuza, 2019). Another key finding of this case study was the lack of any specific outreach efforts to increase immigrant parent involvement. This was a concerning discovery, considering this school was selected as the context of this case 
study because it had the highest percentage of enrolled immigrant and refugee students when compared to all other middle schools in this school district.

Curiously, the school personnel, principal, youth services coordinator, and three teachers, perceived that outreach efforts were in place, but not where they should be to have a real impact on the lives of the immigrant students and immigrant parents. School personnel expressed that there were programs in place, such as a parent engagement committee, afterschool tutoring, parental support for sporting events, and relationships established between teachers and students. They also expressed the need for more, effective parent involvement focused specifically on their immigrant and refugee population, yet did not know exactly what to do to increase immigrant parent involvement or create these immigrant parent-specific outreach programs. There was an air of frustration in the tones of the teachers and the principal. It was evident that each teacher and school administrator wanted to do more for their immigrant students, but with all of the managerial and instructional responsibilities that educators have, there just wasn't enough time in the day to truly meet the needs of their immigrant population, including their immigrant parents. As the principal stated, even though their immigrant and refugee populations continue to grow, their staffing has not.

\section{Implications for Practice}

Research suggests that when there is authentic relationship developed between teacher and student, there is a positive association with student outcomes (Sormunen, Kirilina, Goranskaya, \& Tossoveinan, 2018). To that end, it is incumbent of educators to develop strong, authentic relationships with students and their parents-immigrant or otherwise. The school may want to consider offering more opportunities for immigrant 
parents and school personnel to interact if immigrant parent involvement is going to increase at Peace Middle School. Data analysis revealed that immigrant parents needed more interaction with school personnel and needed more opportunities focused on immigrant parent growth than what was offered. The foundation of immigrant student growth and achievement are the relations that develop between school personnel, immigrant students, immigrant parents, and targeted school programs.

With the high percentage of immigrant students enrolled in this school, the need for more specific outreach was evident. Having the usual parent involvement events, such as open house and parent teacher conferences was tried, true and effective for some parents, but less so for immigrant parents. This was because of the variety of language barriers. School personnel must think "out of the box" and create new ways to include marginalized populations of parents and families into their school buildings for immigrant students to grow and achieve at a steady rate (Lumbreras \& Rupley, 2019). This cannot occur if immigrant parents and families are not intentionally included.

I found evidence of deficit thinking among school personnel in some of their perceptions that immigrant parents had little to nothing to offer the school or that more barriers or problems could have arisen when school personnel attempted to communicate and work with immigrant parents. This was consistent in other research (Wong, 2015). Educator informants indicated that it was more work to include a parent whose first language was not English. It was more work to make sure that there were ample amounts of translators present who could facilitate conversations and communication. It was more work to have programs at the local place of worship or the community recreation center 
where the immigrant children played and where the immigrant parent or family member felt more comfortable.

Regardless, it was the responsibility of school leaders, teachers, and support staff to ensure that marginalized groups, immigrant students and parents, for example, were considered when programs and school events were created. The traditional practices of parent teacher conferences or open house did not meet the needs of immigrant parents. The inclusion of multiple perspectives, including immigrant parent voice, was and is still vital when discussing and developing programs focused on all student outcomes (Outley \& Skuza, 2019). Informants revealed it was more work to do home visits to make sure that immigrant parents knew what was going on and could put a face to a name, but at the case study middle school, informants suggested that not enough teachers and other school personnel were willing to do that. It was not a school-wide practice at Peace Middle School. If the real goal was student growth and achievement, these extraordinary measures should have occurred regularly throughout the school year.

My analysis revealed that a parent needs assessment was needed. There would have to be more than one version of the parent needs assessment to truly gain the parent perspective and perception, English-speaking or otherwise. This needs assessment should be created with all stakeholder input as well (Outley \& Skuza, 2019). To be meaningful, the collection of and resultant data must be taken seriously, analyzed, and results shared with all stakeholders. This would help immigrant parents and all parents feel respected and included, thus trust grows along with parent involvement (Wong, 2015). This would also assist school personnel in better serving their immigrant 
population, better understanding this population, and developing programs specific to their immigrant population.

Teachers spoke about working with immigrant students in the classroom and after school in various activities, but these same teachers had very few stories and situations to share where they communicated with or sat down with immigrant parents throughout the school year to discuss school concerns and issues. Other than the scheduled school-wide events held throughout the school year, there were not many specific interactions between school personnel and immigrant parents. The school-wide scheduled events included parent teacher conference day, the annual school-wide back to school bash, where school supplies were given out, and the annual family breakfast, where family members are invited into the school to share some time with their children and school personnel. These school-sponsored events were open to all parents whose children were enrolled. This lack of immigrant-focused events widened the pre-existing disconnect between the home and school.

The principal spoke about relying heavily on the Youth Services Center Coordinator to work with the students and reach out the parents, but overall, there appeared to be no intentional plan to involve immigrant parents other than the regular parent involvement activities for all parents. This selected school had many engaging programs for students as well as dedicated teachers. Yet there were no specific outreach programs offered or implemented by this specific school focused on involving immigrant parents.

Research support the premise that parent involvement has a positive and direct correlation to student achievement (e.g., Eisenbach et al., 2016). The connection between 
the home and school is paramount with regard to positive student outcomes and student achievement. When a school has such a high enrollment of immigrant students, there must be more intentionality to include and involve their immigrant parents. One of the immigrant parents spoke of a past school event where he was allowed to share his life experiences with the other parents at a cultural event sponsored by the school. He was very proud of that experience. However, the other immigrant parent informants did not speak of that event. They spoke of communication between them and the teachers and they spoke of parent teacher conference day. They did not speak of any school sponsored events specific to immigrant and refugee parents.

Immigrant parents who participated in this study did not express any concern regarding the school's invitation to participate in school activities, yet the teachers who were interviewed did. The teacher informants felt that the school could do more to involve their immigrant parent population, yet the teachers offered few concrete suggestions for what should be done. This school had a parent engagement committee who met throughout the school year, yet with the high enrollment of immigrant students, there were no immigrant family members on this committee. While observing one of the committee's meetings, I asked to be invited to their meetings as they met. I wanted to see progress of the committee and how they discussed and planned ideas regarding parent engagement specific to immigrant parents.

I wanted to see how their committee membership grew, possibly to include some parents with immigrant status. The one meeting I observed was made up of two teachers, one principal, one assistant principal, one librarian, and one Black parent. However, there were no immigrant parents on the parent engagement committee. Once the meeting 
concluded, I asked one of the committee members to inform me of their next meeting, because I wanted to attend and continue my observation. I never received any information about any subsequent parent engagement meetings. This was after I communicated with two of the committee members two separate times.

This led me to believe that their parent engagement meetings were either not regularly scheduled or, they did not have any more meetings after the one I observed. To grow their immigrant family involvement, this school should consider having more family fun nights, multicultural nights focused on traditional foods, artwork, or dance. To grow their immigrant family involvement, this school may consider more intentional opportunities for immigrant voices to be heard.

With the large enrollment of immigrant and refugee students, the school may consider policies, or practices, and procedures that facilitate working with and welcoming immigrant and refugee families into the school for multiple purposes. These include academic, behavior, and extracurricular events focused on student growth and achievement. Utilizing Epstein’s Six Types of Parent Involvement and Yosso’s Community Cultural Wealth, this school could work towards highlighting what this school's immigrant population had to offer with regard to their lived experiences and education background.

To effectively inform the world of middle school education and educational leadership, teachers and educational readers should reflect upon current practices (or lack thereof) that seek to create opportunities for relationship-building, trust-building, and engagement opportunities between the school house and the home. Or are we doing what is best for students and their parents or what is easiest for educators? This process of 
self-reflection may lead to determining next steps for increased parent involvement, which, hopefully, leads to increased student growth and achievement. Inviting immigrant parents and families into the school building, reassuring them that the school is a safe place, soliciting their input, listening to their feedback and concerns, and developing authentic partnerships is key and must occur. Being intentional and inviting immigrant parents, as well as all parents, into the school building, to sit on committees, provide input, and participate in school activities, parent teacher associations, volunteering in the school, etc., builds trust and mutual respect. When school personnel take the time to communicate with immigrant parents and listen to their stories, cultural wealth grows (Yosso, 2005).

School personnel learn more about the parent and their life experiences and immigrant parents learn more about their child's teachers and how much they care about their children when immigrant parents are invited in to the school. Remembering and honoring what our parents have to offer is very important and school personnel must take a look at their current practices to see if a welcoming and inclusive environment is being built. Schools should take into consideration what immigrant parents have to offer based on their life's journey. Schools should seek to empower immigrant parents to participate and advocate for their children. But this must be initiated by school personnel.

A tool that may assist this venture is a needs assessment for immigrant parents. Intentionally seeking, collecting and analyzing stakeholder responses is healthy for growth of an organization. Doing this allows for healthy culture of the organization. Using demographic data, Peace Middle School should identify each parent group and make sure they are considering their parent demographics and plan programs and 
outreach accordingly. This process allows for development of next steps, which must be developing policies specific to immigrant parents and immigrant students. These policies should include social justice factors, academic structures and offer a safety component. As the data shows across the country, immigrant populations are growing and will continue to grow. There have to be policies in place in our public schools that address and serve all stakeholders, including our immigrant populations (Epstein, 2011; Wong, 2015; Yosso, 2005).

\section{Implications for Policy}

The first implication is for school personnel to seek extraordinary measures to involve their immigrant parents in the school building, in the classroom, and in decisionmaking and planning process. Outside of the usual parent involvement events, school personnel must get creative and take into consideration the cultural wealth of their immigrant families. School personnel must also take into account the increased immigration enforcement that impacts the trust level of immigrant and refugee families (Sanchez et al., 2018). Immigrant parents and family members now think twice before they sign or say anything. Thus, this is where building trusting relationships between the home and school are vital.

Policies must be created to address all stakeholders of schools. In this district, there are required parent involvement policies that are completed for compliance. These policies include Title I parent involvement policies, homework policies, instruction time policies, and parent engagement policies to name a few. There is room for improving the current policies and creating policies that focus on the safety and well-being of all school stakeholders. To go deeper, in today's society, schools must show their awareness of 
their marginalized populations' issues and concerns, and develop specific policies that address the concerns and meet the needs of its immigrant stakeholders.

This must be done; especially as schools' immigrant and refugee populations continue to grow. Current policies must be reviewed and modified and new policies must be created that directly address the needs and concerns of marginalized populations based on data generated from the needs assessment completed by stakeholders. Using an equity tool can make this happen. There must be a rubric or standard that school-based decision councils can use to test the equity and inclusive strength of their current policies. This tool could also be used when creating new policies that directly affect students.

According to Sanchez et al., (2018), educators surveyed stated that immigrant parents stay away from the schoolhouse out of fear of deportation, raids, and detentions. This is a real fear for many immigrant families. Cultural awareness and proficiency must also be embedded in the newly created policies. True reform includes creating policies that focus on informing immigrant parents of their value to their school community and making sure immigrant parents feel welcome in the school (Wong, 2015). Likewise, policies with this focus ensure trust amongst immigrant populations and school personnel.

It was evident that the immigrant parents trusted the teachers in this school building enough to participate in my study. The bilingual teacher shared that prior to the interview, a couple of the parents asked why I wanted to interview them and what my plan was regarding using their shared information. This uncertainty, more than likely, stems from the current ICE raids and deportation and detainment movement in this country. These actions have decreased trust and sense of community within the schools 
for immigrant and refugee families. This could be part of the issue in this selected school.

However, school personnel have to be aware of this and other current events and develop ways and practices that still continue to include their immigrant parents and build sense of trust, value, and safety. Yosso (2005), addressed situations like these through resistance capital and navigational capital. In order for school personnel to assist their immigrant population, social justice, collective freedom, and equal opportunity have to be at the forefront when discussing and creating immigrant parent-specific school programs. Some of this was accomplished at the school's back-to-school bash in the forms of providing all parents with access to translators, general health services and school supplies.

Their immigrant parents' population live in a state of fear and when they participated in their interview, all of their responses were positive about the school. That could have been because the immigrant informants truly felt that the school was doing a great job of outreach. It could also have been because the immigrant informants did not want to share any negative responses out of fear of where the data I collected would be reported. Overall, my immigrant parent informants trusted the school personnel enough to participate and share their perception of Peace Middle School. One takeaway from doing the study was that with such a great sense of trust, the school personnel of Peace Middle School could do so much.

Keeping in mind that PMS was deemed a low-performing school resulting in the dissolution of their school-based decision making council, they must take their lead and direction from their board of education with regard to school decisions and policies. But, 
since these parents were so eager to share their stories and participate in my study, that enthusiasm could be highlighted in other positive ways, leading to the inclusion of their immigrant population voices. Other ways include parent surveys regarding culture and climate, annual multi-cultural night, and idea generation focusing on programs to be implemented throughout the school year. These survey data could lead to possible new policy creation focused on the needs of immigrant parents and immigrant students. For the one immigrant parent informant to share about the one time he was asked to share his life experiences, yet the other immigrant informants were unaware of this or they did not mention it, showed that PMS should consider having those events regularly and schoolwide for all parents to experience. The results of both the survey(s) and needs assessment should be shared with the board of education to analyze and guide the developing of new school policies.

\section{Implications for Future Research}

In considering the limitations of my study, one was the recruitment of immigrant parent informants in a time in U.S. history in which immigration emerged as a key issue of debate and politics. One recommendation for future researchers is to expand the sample of participants to where more immigrant parent voices are heard. Researchers could collect data from multiple schools and do a comparison of findings. The participant sample could also include more than nine participants and could include different stakeholder groups. For example, data could be collected from custodial staff who are behind the scenes and have the opportunity to observe interactions between school personnel and parents. What are the custodial staff member's perceptions of the outreach efforts of their school to involve the various groups of parents? 
Further potential additions to the research literature could include perceptions from office staff or from immigrant or refugee parents who were not referred by school personnel. This could change the whole dynamic of the current study if different stakeholder groups were chosen to participate. This study could be duplicated on the elementary and high school level as well as be modified as needed. The most important aspect is how the findings are shared and used. Another suggestion could be to use the same stakeholder groups, interview them at the beginning of the school year and then again, at the end of the school year.

Another option is to focus narrowly and deeply on specific immigrant communities within specific school or district contexts. For example, scholars have focused on the role of refugees' religion and national identities in secular host nations and schools, such as Somali communities in Toronto and U.S. cities (Collet, 2007; 2010). Researchers have also explored security concerns associated with the education of refugee youth from war torn nations, such as Iraq (Collet \& Bang, 2016).

Knowing that someone is studying your school's practices to actively and effectively involve your immigrant population at the beginning of the school year could possibly prompt school personnel to actually be more proactive and attempt to do more to include immigrant parents. Especially since they know that there would be a subsequent, end of the year interview to see how these intentional practices progressed throughout the year.

The interview protocol used in this study did not address any questions explicitly regarding how immigrant parents felt about the current presidential administration's focus on decreasing the number of immigrants and refugees allowed to come to the 
United States of America. Nor did the interview protocol address immigrant family separations, detentions, and deportations currently happening across this country. I am sure that phenomenon had a huge effect on immigrant parent involvement in so many situations. Increased immigration enforcement and possible deportation must weigh heavily on our immigrant and refugee populations, to the point of where immigrant and refugee families do not trust to share information with anyone, especially school personnel (Sanchez et al., 2018). Future research studies could focus on some of the above mentioned aspects and reveal useful and thought-provoking data that could serve to provide our school system information that could guide their interaction with our evergrowing immigrant population.

\section{Summary}

This study was very eye-opening. I sought to identify existing outreach efforts in an urban middle school with a large immigrant population to involve immigrant parents and to explore the participants' perceptions regarding the current outreach efforts to involve immigrant parents of the selected middle school. As a school leader in a large urban district, I optimistically hoped to observe and document educational leaders and teachers intentionally engaging immigrant parents in the school, interacting with other school stakeholders, participating on committees, assisting other immigrant parents, and volunteering in the school building. However, this was not the case. If the past and present political climate are any indication, immigration is likely to remain a salient policy issue. Immigration levels may decrease and increase over time, but the needs of immigrant families and the role that schools and educators play in meeting their needs will remain. It is in the best interest of all parties involved to engage with each other in 
order to be mutually beneficial. Immigrants and their children become more inoculated in their new adopted country. Schools and districts may benefit from efforts to engage immigrant parents with the hope of yielding improvements in student outcomes by which they are held accountable. 


\section{REFERENCES}

Anney, V.N. (2014). Ensuring the quality of the findings of qualitative research looking at trustworthiness criteria. Journal of Emerging Trends in Educational Research and Policy Studies, 5(2), 272-281.

Archer-Banks, D.A., \& Behar-Horenstein, L.S. (2008). African American parental involvement in their children's middle school experiences. The Journal of Negro Education 77(2), 143-156.

Auerbach, S. (2011). Learning from Latino families. Schools, Families, Communities, 68(8), 16-21.

Auerbach, S. (2007). Visioning parent engagement in urban schools: Role constructions of Los Angeles administrators. Journal of School Leadership, 17(6), 699-735.

Bazeley, P \& K. Jackson (2013). Qualitative data analysis with NVIVO. Thousand Oaks: SAGE.

Beauregard, F., Petrakos, H., \& Dupont, A. (2014). Family-School partnership: Practices of Immigrant parents in Quebec, Canada. School Community Journal, 24(1), 177-210.

Bourdieu, P. (1989). Social space and symbolic power. Sociology Theory, 7, 14-25.

Bourdieu, P., \& Passeron, J.C. (1979). The inheritors: French students and their relations to culture. Chicago: University of Chicago.

Bower, H.A. \& Griffin, D. (2011). Can the Epstein model of parental involvement work in a high-minority, high-poverty elementary school? A case study. Professional School Counseling, 15(2), 77-87.

Child Migration Data Portal. Retrieved June 5, 2019 from https://migrationdataportal.org/themes

Christianakis, M. (2011). Parents as "Help Labor": Inner-city teachers' narratives of parent involvement. Teacher Education Quarterly, 38(4), 157-178.

Cohen, D., \& Prusak, L. (2001). In good company: How social capital makes organizations work. Boston: Harvard Business School Press. 
Collet, B.A. (2007). Islam, national identity and public secondary education: perspectives from the Somali diaspora in Toronto, Canada. Race, Ethnicity, and Education, 10(2), 131153.

Collet, B.A. (2010). Sites of refuge: Refugees, religiosity, and public schools in the Unites States. Educational Policy, 24(1), 189-215.

Collet, B.A., \& Bang, H. (2016). The securitisation of refugee flows and the schooling of refugees: Examining the cases of North Koreans in South Korea and Iraqis in Jordan. Compare: A Journal of Comparative and International Education, 46(2), 272-292.

Collier, V., \& Thomas, W. (1989). How quickly can immigrants become proficient in school English? The Journal of Educational Issues of Language Minority Students, 5, 26-38.

Comer, J.P. (1986). Parent participation in the schools. Phi Delta Kappa, 67, 442-446.

Cornell, C. (1995). Reducing failure of LEP students in the mainstream classroom and why it is important. The Journal of educational Issue of Language Minority Students, 15.

Crea, T. M., Reynolds, A. D., \& Degnan, E. (2015). Parent engagement at a Cristo Rey High school: building home-school partnerships in a multicultural immigrant community. Journal of Catholic Education, 19(1), 223-242.

Creswell, J. (2013). Qualitative inquiry and research design: Choosing among five approaches. Los Angeles: SAGE.

Creswell, J. (2014). Research design: Qualitative, quantitative, and mixed methods approaches. Los Angeles: SAGE.

Crosnoe, R., \& Ansari, A. (2015). Latin American immigrant parents and their children's teachers in U.S. early childhood education programmes. International Journal of Psychology, 50(6), 431-439.

Cummins, J. (1996). Home-school communications and expectations of recent Chinese immigrants. Canadian Journal of Education, 26(4), 455-476.

Delpit, L. (2006). Other People's Children: Cultural conflict in the classroom. New York: The New Press.

DeMatthews, D. (2018). School leadership, social capital, and community engagement: A case study of an elementary school in Cuidad Juarez, Mexico. School Community Journal, 28(1), 167-194. 
Deslandes, R., \& Bertrand, R. (2005). Motivation of parent involvement in secondarylevel schooling. The Journal of Educational Research, 98(3), 164-175.

Davis, B.C. (1989). A successful parent involvement program. Educational Leadership, 47, 21-23.

Dixson, A. (2008). Chapter 6: "Taming the beast": Race, discourse, and identity in a middle school classroom. Counterpoints, 316, 125-147.

Dondero, M., \& Muller, C. (2012). School stratification in new and established Latino destinations. Social Forces, 91(2), 477-502.

Dotson-Blake, K.P., Foster, V., \& Gressard, C.F. (2009). Ending the silence of the Mexican immigrant voice in public education: Creating culturally inclusive familyschool-community partnerships. Professional School Counseling, 12(3), 230-239.

Eisenbach, B.B., Clark, S., \& Gooden, A. (2016). Cultivating connections with diverse families. Association for Middle Level Education, 4(2), 18-20.

Epstein, J.L. (2011). School, Family, and Community Partnerships: Preparing educators and improving schools. Boulder: Westview press.

Epstein, J.L., Sanders, M.G., Simon, B.S., Salinas, K.C., Jansorn, N.R., \& Voorhis, F.L. (2009). School, family, and community partnerships: Your handbook for action ( $3^{\text {rd }}$ edition). Thousand Oaks: Corwin.

Fernandez, E., \& Paredes Scribner, S. M. (2018). "Venimos para que se oiga la voz": Activating community cultural wealth as parental educational leadership. Journal of Research on Leadership education, 13(1), 59-78.

Fine, M. (1993). (A)parent involvement: Reflections on parents, power, and urban public schools. Teachers College Record, 94(4), 682-711.

Fisher, M.J. (2010). "Immigrant educational outcomes in new destinations: An exploration of high school attrition." Social Science Research, 39(4), 624-641.

Fleischer, C., \& Pavlock, K.C. (2012). Inviting parents in: Expanding our community base to support writing. The English Journal, 101(4), 29-36.

Garcia, S.B. \& Guerra, P.L. (2004). Deconstructing deficit thinking: working with educators to create more equitable learning environments. Education and Urban Society, 36(2), 150-168.

Garcia-Reid, P., Peterson, C.H., \& Reid, R.J. (2013). Parent and teacher support among Latino Immigrant youth: Effects on school engagement and school trouble avoidance. Education and Urban Society, 20(10), 1-16. 
Glesne, C. (2011). Becoming qualitative researchers: An introduction. Boston: Pearson.

Gomez, R., \& Greenough, R. (2002). Parental involvement under the new Title I \& Title III: From compliance to effective practice. Northwest Regional Educational Laboratory: Planning and Program Development. Available online: http://www.nwrel.org/ .

Guo, Y. (2012). Diversity in public education: Acknowledging immigrant parent knowledge. Canadian Journal of Education, 35(2), 120-140.

Gutierrez, R.A., \& Almaguer, T. (2016). The new Latino studies reader: The twenty-first century perspective. Oakland: University of California Press.

Halsey, P. (2005). Parent involvement in junior high schools: A failure to communicate. American Secondary Education, 34(1), 57-69.

He, Y., Bettez, C., \& Levin, B.B. (2015). Imagined community of education: Voices from refugees and immigrants. Urban Education, 1-29.

Henderson, A.T., Mapp, K.L., Johnson, V.R., \& Davies, D. (2007). Beyond the bake sale: The essential guide to family-school partnerships. New York: The New Press.

Hos, R., Murray-Johnson, K., \& Correia, (2019). Cultivating capital for high school newcomers: A case study for an urban newcomer classroom. Journal of Ethnic and cultural studies, 6(1), 101-116.

Hough, H., Penner, E., \& Witte, J. (2016). Identity crisis: Multiple measures and the identification of schools under ESSA. Policy Analysis for California Education.

Retrieved from http://www.edpolicyinca.org/projects/pace-core-research-partnership .

Kennedy, J.F. (1958). A nation of immigrants. Retrieved from http://www.ontheissues.org

Knapp, A., Jefferson, V.M., \& Landers, R. (2013). Learning Together: Teaching children mathematics. National Council of Teachers of Mathematics, 19(7), 432-439.

Kugler, E.G. (2009). Partnering with parents to support immigrant and refugee children at school. Washington, DC: Center for Health and Health Care in Schools, School of Public Health and Health Services, The George Washington University. Retrieved from http://healthinschools.org/Immigrantandrefugeechildren.aspx

Ladson-Billings, G. (1998). Just what is Critical Race Theory and what's it doing in a nice field like education? International Journal of Qualitative Studies in Education, 11(1), 724. 
Lin, N. (2001). Social capital. A theory of social structure and action. Cambridge: Cambridge University Press.

Linse, C. (2013). English language learner a term that warrants scrutiny. The Journal of Educational Thought, 46(2), 107-122.

Lopez, G.L. (2001). The value of hard work: Lessons on parent involvement from an immigrant household. Harvard Educational Review, 71(3), 416-438.

Lumbreras, R., \& Rupley, W. H. (2019). A tale of two Hispanic migrants: Lessons in building educational leadership traits. International Journal of Learning, Teaching, and Educational Research, 18(3), 15-35.

Marschall, M.J. \& Shah, P.R. (2016). Linking the process and outcomes of parent involvement policy to the parent involvement gap. Urban Education, 1-31.

Martinez, M. (2012). Wealth, stereotypes, and issues of prestige: The college choice experience of Mexican American students within their community context. Journal of Hispanic Higher Education, 11, 67-81.

McAllister-Parsons, M. (2019). Creating a college-going partnership with Latina/o parents and families of elementary school students. Electronic theses, projects, and dissertations, 863. Retrieved from https://scholarworks.lib.csusb.edu/etd/863.

McClay, J.K., Peterson, S.S., \& Nixon, R. (2012). Parents and communities as partners in teaching writing in Canadian middle grades classrooms: Teachers engage the support of parents and their communities for writing instruction. Middle School Journal, 44(1), 44-52.

McNeal, R.B. (2015). Parent involvement and student performance: the influence of school context. Educational Research for Policy and Practice, 14(2), 153-167.

Miles, M.B., Huberman, A.M., and Saldana, J. (2014). Qualitative data analysis: A methods sourcebook. Los Angeles: SAGE.

Milner, H.R. (2007). Race, culture, and researcher positionality: Working through dangers seen, unseen, and unforeseen. Educational Researcher, 36(7), 388-400.

Moles, O.C. (1993). Collaboration between schools and disadvantaged parents: Obstacles and openings. Families and schools in a pluralistic society. Albany, NY: SUNY Press.

Moncloa, F., Erbstein, N., \& Subramaniam, A. (2019). Guiding principles for reaching and engaging Latinx youth in youth development programs. Journal of Youth

Development, 14(2), 46-63. 
Muhammad, A. (2015). Overcoming the achievement gap trap: Liberating mindsets to effect change. Bloomington: Solution Tree Press.

National Middle School Association (2010). This We Believe: Keys to Educating Young Adolescents. Westerville, $\mathrm{OH}$ : National Middle School Association.

Obama, B.H. (2009). Inaugural address. Retrieved from https://obamawhitehouse.archives.gov .

Outley, C., \& Skuza, J. A. (2019). Special issue: Perspectives on immigrant, refugee, and border youth. Journal of Youth Development, 14(2), 1-9.

Overstreet, S., Devine, J., Bevans, K., \& Efreom, Y. (2005). Predicting parental involvement in child schooling within an economically disadvantaged African American sample. Psychology in the Schools, 42(1), 101-111.

Pecoraro, D., \& Phommasouvanh, B. (1992). Limited English proficient (LEP) parent involvement project. St. Paul, MN: Minnesota State Department of Education.

Perez, A. (2009). Understanding attitudes about education within two cultural contexts: Comparing the perceptions and expectations of Mexican mothers in the greater Los Angeles area to their cohort in Mexico (Doctoral dissertation).

Perna, L.W., \& Titus, M.A. (2005). The relationship between parent involvement and college enrollment: An examination of racial/ethnic group differences. Journal of Higher Education, 76, 485-518.

Peterson, S., \& Ladky, M. (2007). A survey of teachers' and principals' practices and challenges in fostering new immigrant parent involvement. Canadian Journal of Education, 30(2), 881-910.

Portes, A. (1998). Social capital: Its origin and applications in modern sociology. Annual Review of Sociology, 24, 1-24.

Ramirez, A. (2003). Dismay and disappointment: parental involvement of Latino immigrant parents. The Urban Review, 35(2), 93-110.

Rumberger, R. (1983). Dropping out of high school: The influence of race, sex, and family background. American Educational Research Journal, 20(2), 199-220.

Saldana, J. (2013). The coding manual for qualitative researchers. London: SAGE.

Sanchez, S., Freeman, R., \& Martin, P. (2018). Stressed, overworked, and not sure whom to trust: The impacts of recent immigration enforcement on our public school educators. Retrieved from https://escholarship.org/uc/item/0w65087r . 
Smith, P. (2018). The great immigration debate. The New York Times Upfront, 150(9), $10-13$.

Snell, A. M. S. (2018). Parent-School engagement in a public elementary school in Southern Arizona: Immigrant and refugee parent perspective. School Community Journal, 28(2), 113-138.

Sobel, A., \& Kugler, E.G. (2007). Building partnerships with immigrant parents. Educational Leadership, 64(6), 62-66.

Sormunen, M., Kirilina, V., Goranskaya, S., \& Tossoveinan, K. (2018). Interaction between home and school: The view of teachers and parents from Finland and Russia. International Journal about Parents in Education, 10(1), 33-46.

Turney, K., \& Kao, G. (2009). Barriers to school involvement: Are immigrant parents disadvantaged? The Journal of Educational Research, 102(4), 261-271.

U.S. Census Bureau. (2012). The foreign-born population in the United States. 2010 (American Community Survey Reports). Retrieved from http://www.census.gov/prod/2012pubs/acs-19.pdf

USA quick facts from the US Census Bureau (2011). Retrieved from http://quickfacts.census.gov/qfd/states/00000.html.

U.S. Department of Education, Building partnerships to help English language learners (July 2006). Retrieved from http://www2.ed.gov/nclb/methods/english/lepfactsheet.pdf.

Valdez, T.M., \& Lugg, C. (2010). Community cultural wealth and Chicano/Latino students. Journal of School Public Relations, 31, 224-237.

Varela, A. (2008). Embrace multiculturalism to foster parent involvement. Education Digest, 74(3), 59-60.

Villalpando, O. (2003). Self-segregation or self-preservation? A critical race theory and Latina/o critical theory analysis of findings from a longitudinal study of Chicana/o college students. International Journal of Qualitative Studies in Education, 16(5), 619-646.

Wedel, E. \& Cornell, C. (1991). Hispanic parents' non-participation in their children's schooling: Causes and cures. Southern Regional TESOL Conference, Atlanta, GA.

Whitaker, M. \& Hoover-Dempsey, K. (2013). School influences on parents' role beliefs. The Elementary School Journal, 114(1), 73-99.

Wong, K. K. (2015). Implementing parent engagement policy in an increasingly culturally diverse community of new immigrants: How new is "new"? Canadian Journal of Education, 38(3), 1-30. 
Yan, G. (2009). Communication with parents across cultures: An investigation of an ESL parents' night. Journal of Educational Thought, 43(2), 171-190.

Yin, R.K. (2014). Case study research: Design and methods. Thousand Oaks: SAGE.

Yosso, T.J. (2005). Whose culture has capital? A critical race theory discussion of community Cultural wealth. Race Ethnicity and Education, 8(1), 69-91.

Zarate, M.E. (2007). Understanding Latino parental involvement in education:

Perceptions, expectations, and recommendations. TRPI: Irvine.

Zong, J. \& Batalova, J. (2017). Frequently requested statistics on immigrants and immigration and immigration in the United States. Migration Policy Institute. Retrieved from https://www.migrationpolicy.org/article/frequently-requested-statisticsimmigration-and-immigration-united-states-6 


\section{Project Title:}

\section{MIDDLE SCHOOL OUTREACH EFFORTS TO INVOLVE IMMIGRANT PARENTS: WHAT ARE THE PERCEPTIONS OF SCHOOL PERSONNEL AND IMMIGRANT PARENTS?}

\section{Investigator(s) name $\&$ address:}

Detra D. Johnson, PH.D, Co-Advisor and Co-Investigator

College of Education and Human Development

University of Louisville

1905 South $1^{\text {st }}$ Street

Louisville, KY 40292

detra.johnson@louisville.edu

W. Kyle Ingle, PH.D, Co-Advisor and Principal Investigator

College of Education and Human Development

University of Louisville

1905 South $1^{\text {st }}$ Street

Louisville, KY 40292

william.ingle@louisville.edu

M. Denise Franklin-Williams

704 Bedfordshire Road

Louisville, KY 40222

mdfw08@me.com

Site(s) were study is to be conducted: University of Louisville, Jefferson County Public Middle Schools.

Phone numbers for subjects to call for questions: W. Kyle Ingle (502) 852-6097

\section{Introduction and Background Information}

You are invited to participate in a research study. The study is being conducted by Denise Franklin-Williams, working under the supervision of Kyle Ingle. The study is sponsored by the University of Louisville, Department of Educational Leadership, Evaluation, and Organizational Development. The study will take place at the University of Louisville and Jefferson County Public Schools. At least six subjects will be invited to participate. 


\section{Purpose}

The purpose of this study is to examine the outreach efforts of a local middle school with regard to their immigrant parent population. This examination serves to address the question of how the middle school works to keep their immigrant parents involved.

\section{Procedures}

As a part of this study, you will be asked to provide demographic information and your current experience with middle school outreach efforts for increased immigrant parent engagement and involvement. You will be asked to respond to a series of semistructured interview questions. Your interview should take no more than 60 minutes. Your interview will be recorded for transcription purposes only. The goal is to honor your responses, so recording is necessary so that no collected data is lost. I am flexible and will work with your schedule in order to conduct a meaningful, authentic interview with you.

Artifacts will also be collected during observations and interviews. Since the study focuses on how the school reaches out to their immigrant population, artifacts such as meeting agendas, open house hand-outs, newsletters, and informational pamphlets given to parents at school events will be collected by the researcher to analyze if all parents are considered and represented when communications are presented to school stakeholders. The collection of the abovementioned artifacts will also address if all parents' communication needs are being met. Artifacts collected include any form of communication provided to parents by school personnel. The quality of artifacts given to school stakeholders including school parents should represent the school population.

\section{Potential Risks}

There are no foreseeable risks other than providing open and honest responses to the interview questions.

\section{$\underline{\text { Benefits }}$}

The benefits include adding to the existing literature on parent involvement focused on immigrant parents. With the growing population of immigrant families in our local schools and communities, outreach efforts of our public schools is paramount. 


\section{Compensation}

You will not be compensated for your time, but your contribution to this study will be historical and priceless.

\section{Confidentiality}

Because of the use of pseudonyms in the study, privacy and confidentiality will be preserved. If this study is published, the pseudonyms will be used. The following entities may look at the study records, however, unlikely:

The University of Louisville Institutional Review Board, the Human Subjects Protection Program Office, and Jefferson County Public Schools.

\section{Security}

All collected data will be stored on a flash drive and secured on a password protected laptop.

\section{$\underline{\text { Volunteer Participation }}$}

Participating in this study is strictly voluntary. If you decide to be a part of this study your participation will be greatly appreciated and will add to the existing literature regarding immigrant parent involvement. You can stop at any time and you can choose not to answer any question asked of you.

\section{U.S. Department of Education (DOE) Funded Studies}

Because this specific school district receives funding from the DOE, we are required to share the following information with you:

The information collected from this study may only be used to meet the purposes of this study as stated in this consent. This study will be conducted in a manner that does not allow identification of you by anyone other than the study team members or others who may have a legitimate reason to know. All interview protocol and collected artifacts for the research are available for you to see at any time before or during the study. If you wish to view any of this material, please contact Denise Williams (502) 645-0517 and she assist you. Once we have completed the study, we are required by the U.S. DOE to destroy or return to the school system all personally identifiable information. All digital recordings and transcriptions will be destroyed in a timely manner. 


\section{Contact Persons, Research Subject's Rights, Questions, Concerns, and Complaints}

If you have any concerns or complaints about the study, you may contact the principal investigator at (502) 852-6097 or william.ingle@louisville.edu .

If you have any questions, concerns, or complaints about your rights as a study subject, you may call the Human Subjects Protection Program Office (HSPPO) at (502) 852-

5188. You may discuss any questions about your rights as a subject, in private, with a member of the Institutional Review Board (IRB). The IRB has reviewed this study. If you want to speak to a person outside the university, you may call 1-877-852-1167. This is a 24-hour hot line answered by non-university affiliated personnel.

\section{Acknowledgements and Signatures}

This informed consent document is not a contract. This document tells you what will happen during the study if you choose to take part. Your signature indicates that this study has been explained to you, that your questions have been answered, and that you agree to take part in the study. You are not giving up any legal rights to which you are entitled by signing this informed consent document. You will be given a copy of this consent form to keep for your records.

$\overline{\text { Subject Name (Print) }}$

Signature of Subject

Date Signed

Printed Name of Legal Representative (if applicable)

Signature of Legal Representative

Date Signed 
Printed Name of Investigator

Date Signed

Investigators

Numbers

W. Kyle Ingle

Detra D. Johnson

M. Denise Franklin-Williams
Signature of Investigator

Phone

(502) 852-6097

(502)852- 0611

(502) 645-0517 


\section{APPENDIX B: RECRUITMENT CORRESPONDENCE}

\section{Dear School Staff Member,}

My name is Denise Franklin-Williams and I am a doctoral candidate, under the supervision of Kyle Ingle in the College of Education and Human Development at the University of Louisville. I am conducting a case study regarding immigrant parent involvement. I want to explore middle school outreach efforts in our school district that involve immigrant parents. I believe you will be able to provide valuable data and insight for my study.

The primary goal of my study is to examine one district middle school's outreach efforts to involve their immigrant parent population. Thus, I am seeking to interview select school personnel regarding the middle school outreach efforts at specific schools where there is high enrollment of immigrant students. I want to explore how schools involve their immigrant parents.

Your voice and input are of considerable importance to my study and will assist me in developing implications and suggestions for future studies on middle school parent involvement. My hope is that I can talk with you in person, via email, and via phone to gain a better understanding about your own professional experiences with outreach efforts to involve immigrant parents on the middle school level.

I am asking that you participate in a 60-minute interview. I will gladly schedule your interview time and location around your availability and convenience. With your permission, I plan to communicate with you via email, in person, telephone, and via cell phone. Should you have any questions, please contact me at mdfw08@me.com or marcella.franklin-willi@jefferson.kyschools.us or Dr. Kyle Ingle at william.ingle@louisville.edu. You can also reach me at (502) 645-0517.

Thank you in advance and I look forward to your response and your support.

Sincerely,

M. Denise Franklin-Williams

Doctoral Candidate, Education and Human Development

University of Louisville 


\section{APPENDIX C: RECRUITMENT CORRESPONDENCE}

\section{Dear Parent,}

My name is Denise Franklin-Williams and I am a doctoral candidate, under the supervision of Kyle Ingle in the College of Education and Human Development at the University of Louisville. I am conducting a case study regarding immigrant parent involvement. I want to explore middle school outreach efforts in our school district that involve immigrant parents. I believe you will be able to provide valuable data and insight for my study.

The primary goal of my study is to explore a district middle school's outreach efforts to involve their immigrant parent population. Thus, I am seeking to interview select parents regarding the middle school outreach efforts at specific schools where there is high enrollment of immigrant students. I want to explore how schools involve their immigrant parents.

Your voice and input are of considerable importance to my study and will assist me in developing implications and suggestions for future studies on middle school parent involvement. My hope is that I can talk with you in person, via email, and via phone to gain a better understanding about your own personal experiences with outreach efforts to engage immigrant parents on the middle school level.

I am asking that you participate in a 60-minute interview. I will gladly schedule your interview time and location around your availability and convenience. With your permission, I would like to communicate with you either via email, telephone, or via cell phone. Should you have any questions, please contact me at mdfw08@me.com or marcella.franklin-willi@jefferson.kyschools.us or Dr. Kyle Ingle at william.ingle@louisville.edu . You can also reach me at (502) 645-0517.

Thank you in advance and I look forward to your response and your support.

Sincerely,

M. Denise Franklin-Williams

Doctoral Candidate, Education and Human Development

University of Louisville 


\section{APPENDIX D: SCHOOL PERSONNEL INTERVIEW \\ PROTOCOL}

1. What is your role at the school?

2. How many years have you been in education? How many years have you been in this position?

3. Why did you decide to work in a middle school?

4. How are you informed about the cultural backgrounds of your immigrant parents and students?

5. How do you use this information in supporting your immigrant parent involvement?

6. What opportunities do you create for parents of your immigrant students to be involved in classroom activities that support students' reading and writing?

7. What are your goals for involving immigrant parents in classroom activities relating to literacy?

8. Do you do anything differently for your immigrant parents than you would for your American parents?

9. What challenges do you face in achieving your goals to involve immigrant parents?

10. What challenges do you face in teaching immigrant parents the rules and expectations of your school for student success? i.e. language barriers?

11. How do you think your immigrant students' parents could better support you in overcoming those challenges? 
12. How do you assist your immigrant parents in overcoming barriers and challenges to involvement?

13. Describe your experiences in communicating with your immigrant parents.

14. How is your staffing designed/scheduled to meet the needs of your immigrant students? Immigrant parents?

15. What training has the district provided you and your fellow staff members to better serve your immigrant population?

16. Can you give me the names of a few immigrant parents that I may interview to get their perception of your schools' outreach efforts? 


\section{APPENDIX E: IMMIGRANT PARENT INTERVIEW PROTOCOL}

1. What is the highest grade or level of school that you have completed?

$\circ 8^{\text {th }}$ grade or less

- Some high school, but did not graduate

○ High School graduate or GED

- Some college or 2-year degree

- 4-year college graduate

○ More than 4-year college graduate

2. Are you Hispanic, Latino, or Spanish origin?
○ Yes
○ No

3. What is your race?

○ White

- Black or African-American

- Asian

- Native Hawaiian or Other Pacific Islander

- American Indian or Alaska Native

○ Other. Explain.

4. What is your marital status?

○ Single

○ Married

○ Divorced

- Widowed

5. In which income level do you fall?
○ $\$ 0$ - $\$ 20,000$
○ $\$ 21,000-\$ 40,000$
- $\$ 41,000-\$ 60,000$
○ $\$ 61,000-\$ 80,000$
○ $\$ 81,000-\$ 100,000$
○ $\$ 101,000-$ Above

6. How long have you lived in the city?

7. What is your current occupation?

8. What supports are in place, at home, to ensure that your child is successful in school?

9. Do you feel welcome in your child's school? Explain. 
10. You are your child's first teacher. What are some things you do at home to extend what your child learns at school?

11. Describe the area at home where your child studies and completes homework.

12. Are you able to assist your child with their homework or projects? Describe some recent homework or projects you have worked on with your child.

13. What challenges or barriers exist that keep you from being involved in your child's school?

14. How do you describe what middle school parent involvement looks like for a middle school parent?

15. What could your child's school do to better welcome immigrant parents? Programs? Information sessions?

16. Describe a situation where you had to meet with your child's teacher?

17. How do you ensure that your culture and traditions are maintained while your child attends an American public middle school? What are some of the practices experienced in the community? The home? 


\section{APPENDIX F: OBSERVATION PROTOCOL}

School Outreach Efforts to Involve Immigrant Parents (Williams, 2018)

DATE:

TIME: Start:

Finish:

PLACE/EVENT:

\section{SETTING:}

OBSERVER INVOLVEMENT:

\section{PARTICIPANT INVOLVEMENT:}

Epstein and Yosso "Look Fors":

○ Linguistic Capital (What languages are spoken? Translators present?)

- Familial Capital (Who is attending the event?)

- Social Capital (Seating? Friendly? Conversations with whom?)

- Efficacy (Parent Initiative?)

○ Training (SBDM, volunteering, parenting skills, etc.)

○ Communication (What info is given to parents? Translators present?)

\begin{tabular}{|l|l|}
\hline $\begin{array}{l}\text { Descriptive Notes (details; } \\
\text { event \& setting description, } \\
\text { portrait of participants; what } \\
\text { the observer sees, hears) }\end{array}$ & $\begin{array}{l}\text { Reflective Notes (personal reflections, } \\
\text { questions, thoughts, impressions, } \\
\text { reactions, experiences, inferences) }\end{array}$ \\
\hline & \\
\hline & \\
\hline & \\
\hline & \\
\hline
\end{tabular}




\section{APPENDIX G: RESEARCH INFORMATIONAL LETTER}

\section{Greetings School Family!}

A study is being conducted, in your school that focuses on parent involvement in the middle school setting. All research including data collection will be conducted by Marcella Williams, a doctoral candidate at the University of Louisville. She will attend school-sponsored events and observe the interactions of the attendees and specifically interactions between school personnel and parents. Demographic and interaction data will be collected and analyzed as part of the study. Interviews will also be conducted with school personnel and interested immigrant parents.

The purpose of the study is to explore how school personnel reach out to their parents, specifically their immigrant parent population. Additionally, the purpose of this study is to add to the existing parent involvement literature and bring awareness of the outreach efforts of a middle school with regard to their immigrant parent population. Should you have any questions, contact Marcella Williams at mdfw08@me.com or the principal investigator Kyle Ingle at william.ingle@1ouisville.edu . Thank you for your time and cooperation. 


\title{
CURRICULUM VITAE
}

\author{
Marcella Denise Franklin-Williams
}

704 Bedfordshire Road

Louisville, KY 40222

(502) 645-0517

mdfw08@me.com

"The hope of a secure and livable world lies with disciplined nonconformists who are dedicated to justice, peace, and brotherhood." -Martin Luther King, Jr.

\section{Professional Profile}

○ Dedicated to social justice for all and improving the lives of others though effective routines and procedures

○ Providing positive, effective instructional leadership to colleagues and stakeholders

- Creating systems based on data to plan next steps and drive instruction practices

- Experienced in Biology and Science curriculum in middle and high school

$\circ$ Fair, Firm, and Consistent

\section{Education, Honors, and Certifications}

University of Louisville, December 2019

Ed.D in Educational Leadership and Organizational Development

Louisville, Kentucky

Western Kentucky University, Summer 2001

Principal Certification - K-12, Level II

Expiration Date: 6/30/2024

Rank I in Educational Leadership

Bowling Green, Kentucky

Expiration Date: 6/30/2022

University of Louisville, May 1997

Master of Arts in Teaching

Teacher Certification - Biology

Louisville, Kentucky

Expiration Date: 6/30/2022

University of Louisville, Summer 1988

Bachelor of Arts in Biology, Grades 7-12

Louisville, Kentucky 


\section{Leadership}

- Certified in Administrative Leadership (principal) K-12

- Current Principal/Instructional Leader of Carrithers Middle School, Louisville, KY

- Conduct learning walks in all classrooms to observe and provide feedback on observed teaching and learning

- Plans, implements, and monitors instructional practices and strategies in my school building

- Analyze academic and behavior data to plan next steps for school stakeholders

- Chairperson of Carrithers' School-based decision making committee

- Chairperson of Carrithers' Instructional Leadership Team

- Chairperson of Carrithers' Consolidated School Improvement Plan

- Conducts observations and evaluations of certified and classified employees

- Leads and plans professional development activities for faculty and staff

- Leads faculty in book studies to promote positive school climate and culture

- Supervises and plans activities, celebrations, and assemblies for student body

\section{Conference Presentations}

- JCPS Middle School Summer Retreat Facilitator, August 2019

- JCPS Area 4 Retreat Presenter, August 2017

Atherton High School, Louisville, KY

Session Title \#1: Student Autonomy

Session Title \#2: Growth Mindset

- Southern Regional Education Board (SREB) Facilitator, July 2016

Kentucky International Convention Center, Louisville, KY

Session Title \#1: Alignment of teaching tasks and mini tasks

Session Title \#2: Incorporating MDC into the everyday classroom

\section{Employment}

- Principal, Carrithers Middle School, Louisville, KY 2014-present

- Assistant Principal, Carrithers Middle School, Louisville, KY 2011-2014

- Assistant Principal, Johnson Traditional Middle School, Louisville, KY 20062011

- $\quad$ 6 $^{\text {th }}$ Grade Dean, Western Middle School, Louisville, KY 2004-2006

- Biology Teacher, Seneca High School, Louisville, KY 1997-2004

\section{Professional Development}

- Kentucky Continuous Improvement Summit attendee, September 2019 Lexington, KY

- Solution Tree Mike Mattos Response to Intervention Workshop, October 2017

Louisville, KY

- Overcoming the Achievement Gap Trap Workshop, April 2016 Louisville, KY

- JCPS Equity Institute, August 2015, 2016, 2017 Louisville, KY

- $\quad$ SREB Networking Conference, June 2015 Atlanta, GA 


\section{Professional Affiliations}

Association of Middle Level Educators, AMLE

Jefferson County Association of School Administrators, JCASA

Kentucky Association of School Administrators, KASA

"Education is the most powerful weapon which you can use to change the world." -Nelson Mandela 